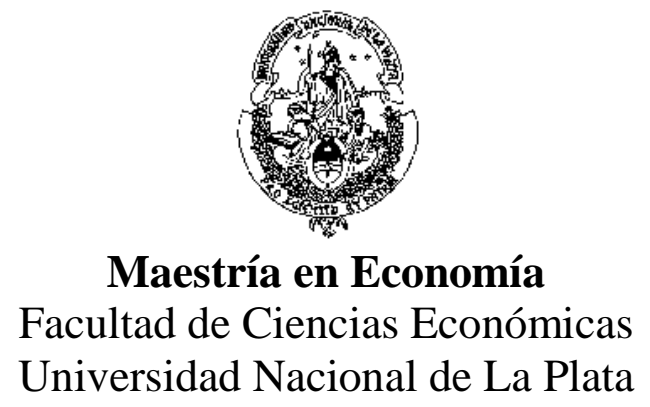

TESIS DE MAESTRIA

\author{
ALUMNO \\ Pablo Gluzmann
}

TITULO

Desigualdad de Ingreso y Bienestar Subjetivo. Un Desafío sobre la Base de la Encuesta Mundial Gallup

\author{
DIRECTOR \\ Leonardo Gasparini \\ FECHA DE DEFENSA
}

$5 / 7 / 2010$ 


\title{
Desigualdad de ingreso y bienestar subjetivo ${ }^{\#}$
}

\section{Un estudio sobre la base de la Encuesta Mundial Gallup}

\author{
Pablo Gluzmann* \\ CEDLAS - CONICET \\ Director: Leonardo Gasparini \\ $\mathbf{C}|\mathbf{E}| \mathbf{D}|\mathbf{L}| \mathbf{A} \mid \mathbf{S}$ \\ Universidad Nacional de La Plata
}

Versión: 26 de Enero de 2010

\begin{abstract}
Resumen
Este trabajo utiliza una nueva fuente de información - la Encuesta Mundial Gallup 2006 - para estimar y caracterizar la desigualdad de los ingresos en América Latina y el Caribe (ALC) en el plano nacional, y comparar las estadísticas de ALC con las de otras regiones del mundo. La encuesta de Gallup tiene la ventaja de ser llevada a cabo en más de 130 países con casi idéntico cuestionario, por lo que constituye un complemento a las encuestas nacionales de hogares para fines de comparación internacional. Además de documentar la desigualdad de ingresos a nivel latinoamericano y mundial, el trabajo estima indicadores de desigualdad en términos de bienestar subjetivo y los compara con aquellos provenientes del ingreso.
\end{abstract}

Palabras clave: desigualdad, ingresos, América Latina, el Caribe, Gallup, bienestar subjetivo, LAC, ALC.

\footnotetext{
\# El presente trabajo es una derivación del documento de Gasparini y Gluzmann (2009), "Estimating Income Poverty and Inequality from the Gallup World Poll, The case of Latin America and the Caribbean”, Documento de trabajo $\mathrm{N}^{\circ} 83$, CEDLAS. Estudio que a su vez proviene de un largo proyecto organizado por el BID: Latin American Research Network en "Quality of Life in Latin America and the Caribbean", realizado por el CEDLAS por Leonardo Gasparini, Mariana Marchionni, Sergio Olivieri y Walter Sosa Escudero. Gallup ha generosamente provisto de los microdatos de la Encuesta Mundial Gallup 2006. Se agradece a Ravi Kanbur, Jere Berhman, Eduardo Lora, Carlos Vélez, Marcelo Neri, Carol Graham, Mauricio Cárdenas, Mariano Rojas, y los participantes del seminario del BID,(Washington D.C.), UNLP (La Plata), NIP (Córdoba) y LACEA (Rio de Janeiro) por sus útiles comentarios. Las opiniones y comentarios en este proyecto son exclusiva responsabilidad del autor.

*Dirección de e-mail: gluzmann@yahoo.com o pgluzmann@depeco.econo.unlp.edu.ar
} 
2. LITERATURA RECIENTE SOBRE DESIGUALDAD GLOBAL ...........................................6

Literatura en base a datos agregados de fuentes secundarias...........................................................6

Literatura en base a microdatos de encuestas de hogares .......................................................... 6

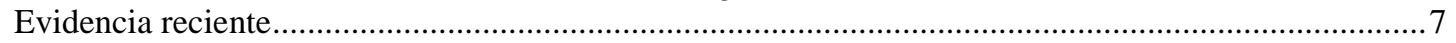

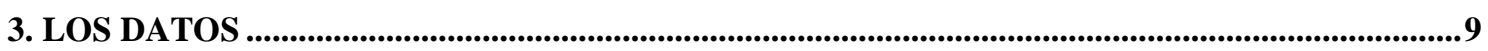

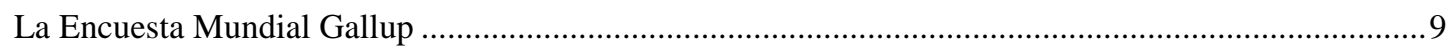

Consistencia de la EMG con la información estadística nacional ....................................................9

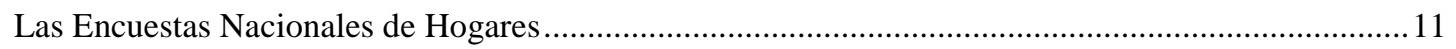

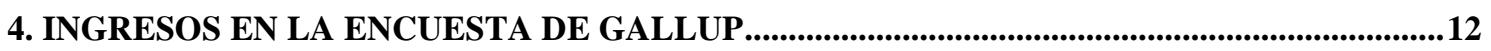

Construcción de variables de ingresos en la EMG .................................................................... 12

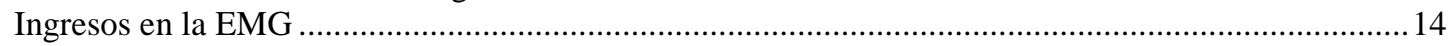

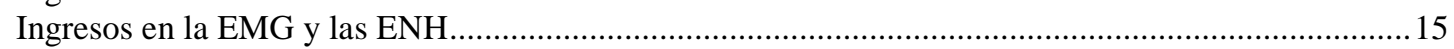

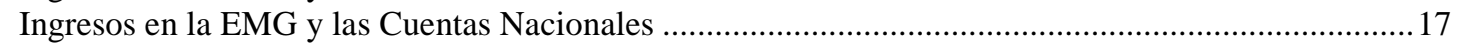

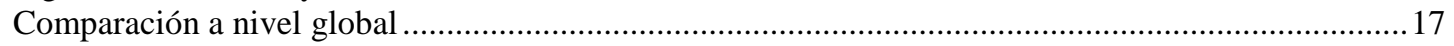

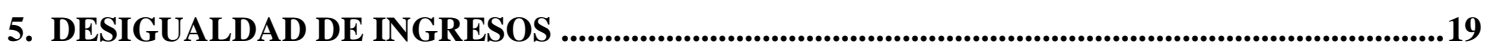

Desigualdad entre naciones de ALC utilizando la EMG y las ENH.................................................19

Contrastando un hecho estilizado: Latinoamérica es la región más desigual del mundo ......................20

Contrastando un segundo hecho estilizado: Latinoamérica es demasiado desigual ............................22

6. DESIGUALDAD DEL BIENESTAR PERSONAL SUBJETIVO ..................................................23

¿Por qué estudiar la desigualdad del bienestar subjetivo? ...........................................................24

Preguntas sobre bienestar subjetivo en la EMG.....................................................................26

Limitaciones sobre la comparabilidad de variables subjetivas ......................................................26

Bienestar subjetivo e ingresos a nivel internacional ..................................................................22

Desigualdad del bienestar subjetivo y de los ingresos a nivel internacional.....................................28

Desigualdad del bienestar subjetivo y desarrollo de los países, ¿una nueva curva de Kuznets? ...........29

Desigualdad y nivel del bienestar subjetivo a nivel internacional ....................................................29

¿Existe un posible efecto aversión a la desigualdad del bienestar subjetivo?.......................................30

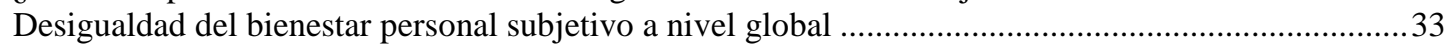

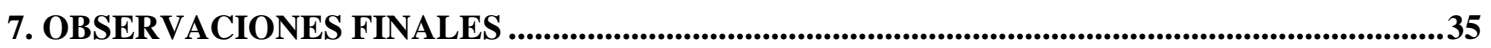

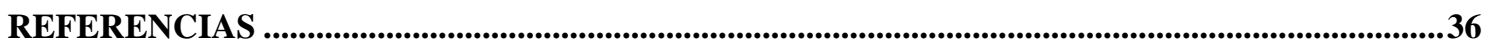

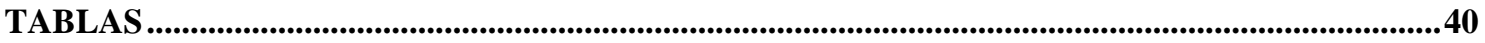

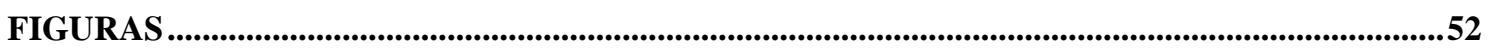




\section{Introducción}

La comparación internacional de la distribución del ingreso ha sido siempre un tema central en la economía. Pareto (1897) produjo una de las primeras contribuciones en este campo mediante la comparación de las distribuciones de ingresos entre estados y ciudades europeas. Kuznets (1955) escribió un artículo fundamental en el que compara la desigualdad entre países con diferentes niveles de desarrollo. Más recientemente, la base de datos internacional de coeficientes de Gini de Deininger y Squire (1996) y los Indicadores del Desarrollo Mundial revitalizaron la literatura empírica de crecimiento mediante la adición de las variables de desigualdad en el análisis.

Milanovic (2009) distingue distintos conceptos de desigualdad internacional y global, adicionales al que estudia Kuznets. La desigualdad internacional no ponderada (llamada también Concepto 1) calcula la desigualdad en PIB per cápita no ponderada de todos los países del mundo. Este concepto está estrechamente relacionado con la literatura de convergencia/divergencia puesto que básicamente evalúa si ha habido o no convergencia entre los ingresos medios de los países. Desigualdad internacional ponderada (Concepto 2) también utiliza PIB per cápita nacional, pero pondera por el tamaño de población de los países, por lo que se acerca al concepto de desigualdad global al tener en cuenta el número de personas que viven en distintos países. Por último, desigualdad global (Concepto 3 ) integra la desigualdad de cada país (estudiada por Kuznets) con el concepto 2 de desigualdad. Este último concepto toma en cuenta la desigualdad entre los ciudadanos del mundo, calculando algún indicador de desigualdad entre ingresos individuales de cada habitante del planeta.

¿Por qué estudiar la desigualdad global? Para responder a esta pregunta, al igual que al analizar la desigualdad dentro de un país o ciudad debemos establecer intereses de carácter normativo. Si se entiende que la desigualdad de ingresos es un indicador de desigualdad de resultados y se cree que la desigualdad de resultados es un "mal" para la sociedad, entonces la desigualdad global es un "mal" para la humanidad y por ende amerita su estudio. Por otra parte si la desigualdad de resultados no es considerada un "mal" siempre que no sea producto de la desigualdad de oportunidades, basta con asumir que la desigualdad de ingresos está de algún modo condicionada por la desigualdad de oportunidades en la medida en que existan factores no elegidos por los individuos (como el lugar de nacimiento, su formación y educación inicial, etc.). Bajo 
estos principios la desigualdad global es un factor sumamente relevante para quien entienda que la desigualdad de oportunidades entre individuos del mundo es un mal para la humanidad, por que la nacionalidad es por excelencia un factor que puede considerarse dado. Sin duda que los individuos al nacer no pueden elegir su nacionalidad, pero además, es difícil o muy costoso que estos puedan cambiar su nacionalidad a lo largo de su vida.

Por último podemos pensar en dos posiciones más individualistas: la primera es el caso de quien no esté interesado en el bienestar de las personas que viven en países extranjeros. Pensemos por ejemplo en el caso de un hacedor de política que solo esté interesado en mejorar el bienestar su nación, y en consecuencia interesado sólo en reducir la desigualdad de su país y no la desigualdad global. El segundo caso sería el de una persona que no esté interesada en reducir ningún tipo de desigualdad (ni de oportunidades, ni de resultado) y por lo tanto no tiene en principio interés en la desigualdad. Para estos dos casos podemos pensar en las distintas externalidades que la desigualdad puede producir, como por ejemplo, la inmigración ilegal, fenómeno que obliga al país receptor a destinar recursos para restringir y controlar la entrada, muchas veces sin demasiado éxito, provocando conflictos sociales dentro del país y empeorando las relaciones con otras naciones.

Ya sea por cualquiera de estos u otros motivos el estudio de la desigualdad internacional y global se ha extendido fuertemente en la literatura reciente. Pueden mencionarse también motivos históricos, teóricos y empíricos, como el incremento de la desigualdad en los países occidentales a partir de los años '80, y de muchos países en desarrollo durante los '90, el desarrollo de modelos teóricos que introducen la desigualdad en el análisis de crecimiento y por supuesto, la mayor disponibilidad y capacidad de procesamiento de datos.

La literatura reciente se puede dividir en dos grandes capítulos, el primero utiliza datos agregados de distribución y cuentas nacionales, mientras que el segundo trabaja con encuestas nacionales de hogares $(\mathrm{ENH})$. Repasaremos esta literatura en la sección siguiente.

Este trabajo utiliza la Encuesta Mundial Gallup (EMG) de 2006, una encuesta llevada a cabo al mismo tiempo en más de 130 naciones alrededor del mundo con casi idéntico cuestionario en todos países, incluyendo preguntas sobre ingreso, tamaño del hogar y bienestar subjetivo. Aunque la encuesta tiene algunas desventajas y 
limitaciones, ofrece una alternativa única para calcular y caracterizar la desigualdad de ingresos en América Latina y el Caribe (ALC), comparar las estadísticas globales de la región con otras regiones del mundo, y estudiar tanto la desigualdad subjetiva como de ingresos a nivel mundial. Se obtienen nuevos resultados sobre desigualdad regional en ALC, y su posición en el ranking mundial de desigualdad. También se reportan interesantes relaciones entre la desigualdad subjetiva, los ingresos y la desigualdad objetiva a nivel mundial.

El resto del documento está organizado de la siguiente forma. En la sección 2 se hace una breve descripción de la literatura reciente sobre desigualdad global. En la sección 3 se describe sucintamente las principales fuentes de información utilizadas: la Encuesta Mundial Gallup (EMG) y las encuestas nacionales de hogares de ALC. La sección 4 está destinada a discutir la medición de los ingresos en la encuesta de Gallup. En la sección 5 se calculan indicadores de desigualdad de ingresos para todos los países de la región sobre la base de datos de la EMG y se comparan los resultados obtenidos a partir de microdatos de las encuestas de hogares. La sección 6 se avoca a estudiar la desigualdad del bienestar subjetivo y su relación con los indicadores de nivel y de desigualdad de ingresos a nivel internacional. Por último la Sección 7 concluye con algunas observaciones finales. 


\section{Literatura reciente sobre desigualdad global}

Como mencionamos anteriormente, la literatura que recientemente se ha ocupado de estimar la desigualdad global, utiliza dos grandes lineamientos metodológicos.

\section{Literatura en base a datos agregados de fuentes secundarias}

Un primer grupo de trabajos sobre desigualdad global se basa en datos agregados de distribución (coeficientes de Gini, y proporción de ingreso por quintiles) obtenidos de fuentes secundarias. Esta información suele ser enriquecida con supuestos que permiten estimar la forma de la distribución general, y se utilizan datos de cuentas nacionales (datos del PIB) para ajustar los ingresos medios. Chotikapanich, Valenzuela and Rao (1997), Schultz (1998), Dikhanov and Ward (2002), Bourguignon y Morrison (2002), Bhalla (2002), Karshenas (2003), Dowrick and Akmal (2005), Sala-i-Martin (2006), y Pinkovskiy y Sala-i-Martin (2009) constituyen los principales ejemplos de esta literatura. Estas contribuciones, aunque sin duda muy pertinentes, están naturalmente plagadas de problemas metodológicos, empezando por el hecho de que los datos de distribuciones secundarias provienen de estudios que utilizan diferentes variables de bienestar (ingreso o consumo, ingreso neto o bruto), tienen diferentes coberturas, diferentes unidades de análisis (individual o familiar) y se basan en un gran número de decisiones metodológicas que ni siquiera están documentadas en la mayoría de los casos (por ejemplo: el tratamiento de ingresos nulos, declaración de datos inexactos, los valores extremos, los precios regionales, renta implícita de la vivienda propia, etc.).

\section{Literatura en base a microdatos de encuestas de hogares}

Un segundo capítulo de la literatura hace comparaciones basadas en microdatos de encuestas de hogares, atendiendo a muchos de los problemas antes mencionados mediante la aplicación de una metodología consistente entre encuestas y países. Esto puede hacerse a nivel regional (véase Gasparini, Gutiérrez y Tornarolli, (2007) para América Latina), o con mucho esfuerzo a nivel mundial. Ravallion, Datt y Van de Walle (1991) y Ravallion y Chen (2007 y 2008) han implementado esta metodología para el calculo de indicadores de pobreza mientras que los trabajos de Milanovic (2002, 2005 y 2009) han realizado la principal contribución en esta metodología aplicada a la medición de la desigualdad. En estos, la desigualdad de los ingresos en todo el mundo 
se calcula a partir de microdatos de encuestas de hogares. De todas formas a pesar procesar las encuestas de forma similar, se reconoce que "... hay problemas que no pueden arreglar. Se sabe que las encuestas difieren entre países, incluyendo cómo las preguntas son formuladas (por ejemplo, el período de referencia), las tasas de respuesta de la encuesta, si las encuestas se utilizan para medir el consumo o ingreso y qué incluye para cada encuesta el agregado de consumo o ingreso ${ }^{1,}$. En un reciente articulo sobre la literatura de desigualdad mundial, Anand y Segal (2008) llegan a conclusiones similares.

\section{Evidencia reciente}

Anand y Segal (2008) adicionalmente resume los principales resultados de los trabajos referidos al tema hasta el año $2006^{2}$, en este trabajo se concluye que a pesar de que todos los autores coinciden en que la desigualdad entre personas del mundo es muy elevada, no existe consenso en términos de evolución: mientras que algunos obtienen incrementos de la desigualdad mundial en los últimos años, otros encuentran que esta se ha reducido. Los trabajos posteriores a 2006 contienen ampliaciones y modificaciones de los anteriores: Milanovic (2009) agrega encuestas de hogares estandarizadas, entre 103 países en 1988 y 123 en 2002, para calcular la desigualdad global extendiendo el análisis hasta este último año (respecto de sus trabajos anteriores), además re-estima los principales indicadores utilizando la PPP revisada del banco mundial con base 2005 y obtiene que la desigualdad global es mayor en términos de nivel que la calculada bajo la versión anterior de la paridad. Pinkovskiy y Sala-i-Martin (2009) asumen una la forma funcional log-normal para extrapolar la distribución del ingreso de cada país en forma paramétrica (en Sala-i-Martin (2006) realizan procedimientos similares pero mediante estimaciones de Kernels). El nivel de PIB per cápita se utiliza para fijar la media de la distribución y la varianza se calcula utilizando mínimos cuadrados sobre proporciones del ingreso por quintiles obtenidos de la base de datos de WIDER. Luego para cada año, se integran las distribuciones de todos los países para la construcción de una estimación de la distribución mundial de ingresos, así como diversas medidas de pobreza y desigualdad. Además incrementan el número de países (de 134 a 191 respecto del anterior trabajo), extienden el período de análisis hasta 2006 y realizan distintos test

\footnotetext{
${ }^{1}$ Ravallion y Chen (2008) página 19.

${ }^{2}$ El trabajo analiza y compara los resultados de Chotikapanich, Valenzuela and Rao (1997), Schultz (1998), Dikhanov and Ward (2002), Bourguignon y Morrison (2002), Bhalla (2002), Dowrick and Akmal (2005), Sala-i-Martin (2006) y Milanovic (2002 y 2005).
} 
robustez de resultados ante cambios en formas funcionales, métodos de interpolación y extrapolación de los datos, y problemas de información en las encuestas.

La tabla 2.1 resume los resultados obtenidos por los últimos trabajos realizados. La tabla muestra que bajo ambas metodologías la desigualdad global puede ser considerada económicamente alta (en todos los casos el coeficiente de Gini supera 0,6) y además es causada en su mayor parte por las desigualdades existentes entre países (la desigualdad entre países es aproximadamente un $70 \%$ de la desigualdad total). Por último puede notarse que estos nuevos trabajos no obtienen resultados que favorezcan el consenso de la literatura en términos de evolución: mientras que los trabajos de Sala-iMartin (2006) y Pinkovskiy y Sala-i-Martin (2009) muestran una reducción en la evolución de la desigualdad global a lo largo del tiempo, los trabajos realizados por Milanovic, muestran una tendencia ambigua dependiendo del período analizado, e incluso hay incremento de la desigualdad considerando tanto el período 1988-2002 como el último tramo (1998-2002).

En la siguiente sección se analizarán en detalle los datos a utilizar en el presente trabajo a fin de proveer de una fuente de datos alternativa y potencialmente complementaria a las descriptas anteriormente. Dado que solo se cuenta con EMG realizada en 2006 no es posible analizar la evolución en el tiempo de estos indicadores pero en la medida en que la encuesta se realice periódicamente esto podría permitir analizar cuáles son los resultados provenientes de esta fuente. 


\section{Los datos}

\section{La Encuesta Mundial Gallup}

La principal fuente de información para este estudio es la Encuesta Mundial Gallup (EMG). En 2006, Gallup recolectó datos a nivel mundial, utilizando un cuestionario idéntico sobre muestras nacionales de adultos de 132 países, 23 de ellos de ALC. El tamaño de las muestras fue de aproximadamente 1.000 hogares en cada país para asegurar la representatividad nacional. Debido a que la encuesta tiene el mismo cuestionario en todos los países, proporciona una oportunidad única para realizar comparaciones entre países ${ }^{3}$. La encuesta Gallup incluye preguntas básicas sobre demografía, educación, empleo, una pregunta sobre ingresos del hogar y distintas preguntas de carácter subjetivo. La encuesta es respondida sólo por un adulto (15 años o más) elegido al azar dentro del hogar.

La tabla 3.1 muestra algunas estadísticas básicas demográficas extraídas de la EMG 2006, utilizando ponderaciones poblacionales. El conjunto de datos incluye las respuestas de 141.739 personas. 21.200 de ellos son habitantes de ALC: 17.144 de América Latina y 4.056 del Caribe. La encuesta tiene cobertura total en América Latina en términos de países, y cuenta con las principales naciones en el Caribe en términos de población: Cuba, República Dominicana, Haití, Jamaica, Puerto Rico y Trinidad y Tobago. Las muestras país son de alrededor de 1.000 observaciones, excepto en Haití, Jamaica, Puerto Rico y Trinidad y Tobago, donde se recogieron alrededor de 500 observaciones.

En siguientes secciones de este documento, se explotará también la cobertura mundial de la encuesta. En principio, este conjunto de datos proporciona una oportunidad única para estudiar una amplia gama de cuestiones con una perspectiva internacional, ya que las muestras son representativas a nivel nacional, y los cuestionarios son idénticos en todos los países.

\section{Consistencia de la EMG con la información estadística nacional}

La Tabla 3.1 indica que la proporción de varones ligeramente es inferior al 50\%, lo que es consistente con datos de censos y encuestas de hogares. Naturalmente, la edad

\footnotetext{
${ }^{3}$ Deaton (2008) es uno de los primeros estudios que utiliza la encuesta Gallup de 2006. Gasparini, Marchionni, Olivieri y Sosa Escudero (2009) estudiaron tres dimensiones de privación (por ingresos, no monetaria y subjetiva) utilizando microdatos de Gallup.
} 
media en la EMG es mayor que en otras fuentes, ya que los encuestados son mayores de 15 años. Aunque la correlación entre la edad media en la encuesta Gallup y las encuestas de hogares es alta (coeficiente de correlación $=0,9$ ), la figura 3.1 muestra diferencias preocupantes en algunos países (e g.. Guatemala y Paraguay). El número medio de hijos menores de 15 años en el hogar reportado en la EMG es algo mayor que en las encuestas nacionales de hogares (ENH): la media en ALC es de 1,5 y 1,34, respectivamente. La correlación entre países del número de niños de Gallup y las encuestas nacionales de hogares (ver figura 3.2) es estadísticamente significativa aunque no demasiado elevada (coeficiente de correlación $=0,56$ ).

Tanto la EMG y como los institutos nacionales de estadística que realizan las ENH en ALC afirman trabajar con muestras representativas a nivel nacional. Sin embargo, en realidad, las muestras pueden diferir en su cobertura geográfica. En particular, la proporción de la población rural puede ser diferente en las dos fuentes, un hecho que sin duda se traduce en diferencias en las estadísticas nacionales. En la tabla 3.2 se implementaron dos definiciones alternativas de población urbana usando datos de la Gallup, estas difieren en clasificar a quienes viven en una pequeña ciudad o pueblo como urbanos (definición 1) o rurales (definición 2). En algunos países (por ejemplo Brasil) la proporción de población urbana en Gallup es similar a los valores reportados en Censos o encuestas cuando se utiliza la definición 1, mientras que otros parecen coincidir con las cifras oficiales cuando se utiliza la definición 2 (por ejemplo Chile, Costa Rica, El Salvador, Perú). En algunos otros países (por ejemplo Bolivia, Colombia, Paraguay) la proporción de población urbana (a partir de encuestas o censos) se encuentra entre las dos alternativas de Gallup. En la mayoría de los casos en que la encuesta de hogares permite reclasificar las observaciones y modificar la definición oficial de zonas urbanas y rurales, se pueden replicar razonablemente las dos figuras alternativas de Gallup de $2006^{4}$.

En resumen, este análisis preliminar sugiere que las estadísticas básicas de la encuesta Gallup son relativamente coherentes con aquellas obtenidas de encuestas de hogares en la mayoría de los países de ALC, pero no en todos, un hecho que plantea algunas dudas sobre la representatividad nacional en esos países. Volveremos a este punto en las siguientes secciones.

\footnotetext{
${ }^{4}$ Excepciones de esto son Jamaica y Venezuela.
} 


\section{Las Encuestas Nacionales de Hogares}

Además de la encuesta de Gallup se utilizan encuestas nacionales de hogares elaboradas por las Oficinas Nacionales de Estadística de los países de ALC próximas al año 2006. La tabla 3.3 muestra las encuestas utilizadas. Se utilizan las bases procesadas en CEDLAS como parte del proyecto SEDLAC (Socioeconomic Database of Latin America and the Caribbean), realizado por CEDLAS y el World Bank's LAC Poverty Group (LCSPP), con la ayuda del Programa MECOVI. En este proyecto los microdatos de las ENH originales se procesan utilizando definiciones homogéneas de variables, siempre sujetas a las limitaciones impuestas por los cuestionarios ${ }^{5}$.

\footnotetext{
${ }^{5}$ Ver www.cedlas.org para más detalles. Gasparini, Gutiérrez y Tornarolli (2007) discuten el uso de los datos para analizar la pobreza y la desigualdad en la región.
} 


\section{Ingresos en la encuesta de Gallup}

A pesar de sus inconvenientes y limitaciones, los ingresos se utilizan ampliamente como indicador de bienestar ${ }^{6}$. En la mayoría de los países la pobreza y la desigualdad son oficialmente medidos sobre la distribución del ingreso. Este es el caso de la mayor parte de los países de ALC, donde rara vez se dispone de datos sobre consumo o gasto en las encuestas de hogares.

\section{Construcción de variables de ingresos en la EMG}

La encuesta de Gallup incluye una sola pregunta sobre ingresos: indaga acerca de cual es el ingreso mensual total del hogar antes de impuestos. La pregunta es clara, pero es demasiado simple y además es reportada por tramos, por lo que es sólo una medida aproximada del ingreso. La pregunta se sitúa casi al final del cuestionario, lo que puede implicar una mayor tasa de no respuesta, y una menor calidad de la información. Por último, la encuesta es realizada a un miembro de la familia seleccionado al azar (mayor de 15 años), el cual no necesariamente es la persona mejor informada sobre ingresos del hogar.

Los tramos de ingreso se expresan en unidades de moneda local (UML), y difieren entre los países, incluso cuando se expresan en dólares estadounidenses ajustados paridad del poder adquisitivo por que el número de tramos es diferente en cada país. En la ronda de 2006 en ALC, el número de tramos va desde 4 en Colombia a 20 en Bolivia. En la mayoría de países (todos en ALC) la pregunta se refiere al ingreso mensual del hogar. Adicionalmente, Gallup utiliza esta información para construir una variable con 28 tramos de ingreso total familiar anual en dólares internacionales ajustados por paridad de poder adquisitivo (PPA) (variable wp4898).

En función de esta información se han elaborado dos variables alternativas de ingresos. La primera, de construcción más sencilla, requiere únicamente de la información de la EMG y será utilizada en este documento tanto para las estimaciones a nivel mundial, como para las comparaciones de ALC con otras regiones del mundo. La variable es construida asignando para cada individuo encuestado, un valor de ingreso total familiar seleccionado aleatoriamente de una distribución uniforme entre el valor mínimo y máximo del tramo reportado para ese individuo en la variable wp4898. El tramo superior no posee un valor máximo puesto que corresponde a los individuos que

\footnotetext{
${ }^{6}$ Ver Deaton (1997 y 2007).
} 
reportan poseer un ingreso total familiar igual o mayor a 125.000 dólares internacionales por año. Para este caso se asumió un valor máximo que duplica al mínimo (es decir de 250,000 dólares internacionales). Para el cálculo del ingreso en términos per cápita simplemente se dividió el ingreso total familiar, por el número de menores de 15 años reportados en la encuesta más 2.

La segunda variable fue construida utilizando tanto la información reportada en tramos de moneda local (UML) de cada país, como información proveniente de las ENH de ALC. Esta variable se utiliza para todas las estimaciones realizadas a nivel país en ALC, a fin de ser comparadas con aquellas obtenidas mediante las ENH. Los pasos realizados para esta variable son los siguientes:

1) Obtención del ingreso total familiar de cada encuestado en dólares internacionales ajustados por PPA:

a. Se determina el número de individuos encuestados en la EMG que reportan ingresos para cada tramo en cada país.

b. Se calcula el ingreso total familiar medio de $n_{i j}$ cuantiles para cada tramo en cada país utilizando las $\mathrm{ENH}$, donde $n_{i j}$ corresponde al número de observaciones en la EMG que reportan ingresos en el tramo $i$ del país $j$.

c. Para cada observación perteneciente al tramo $i$ del país $j$ en la EMG se asigna aleatoriamente el ingreso total familiar medio de uno de los cuantiles estimados en el punto b.

d. Los puntos b y c se realizan para todo tramo $i$ y país $j$.

e. Por último se convierten los valores obtenidos en moneda local a dólares internacionales ajustados por paridad de poder adquisitivo (PPA).

De esta forma se garantiza que para cada observación de la EMG, los ingresos construidos siempre se encuentren dentro del tramo al que el individuo reporta pertenecer, y la información faltante (en qué lugar exacto del tramo se encuentra cada individuo incluyendo a aquellos que reportan estar en el tramo superior) se asigna aleatoriamente siguiendo la distribución observada en las ENH. 
Como hemos mencionado anteriormente esta segunda variable se utiliza para las comparaciones de ingresos en ALC, por lo que resulta útil también computar el ingreso per cápita. La encuesta de Gallup incluye preguntas sobre el número de adultos y niños. Pero desafortunadamente en la base de datos de 2006 solo se incluye la respuesta referida a la cantidad de adultos en tres países de $\mathrm{ALC}^{7}$. Además, el número de niños no se registra en Honduras y Nicaragua, y las respuestas válidas son menos del $70 \%$ en Argentina y México. En función de esto se calculó el número de miembros en cada hogar sumando el número de niños menores de 15 reportados en la encuesta de Gallup a la media de los adultos (mayores de 15 años) calculada a partir de las ENH. Para cada país se toma este promedio, en cuatro grupos según el área de residencia (urbana o rural), y el tipo de hogar (con o sin hijos), y se aplican las medias a los hogares correspondientes en la encuesta de Gallup. Además, se estimó el número de niños en hogares con falta de información en Honduras, Nicaragua, Argentina y México, utilizando los datos de la ronda de 2007 de Gallup.

\section{Ingresos en la EMG}

La Tabla 4.1 muestra la media, mediana y el porcentaje de respuestas válidas del ingreso familiar total mensual, y per cápita para todos los países de ALC. La tasa de no respuesta de ingresos es del 14\%, con valores máximos en Trinidad y Tobago (39\%) y Honduras (33\%). En promedio (ponderado por población), el ingreso per cápita es $8 \%$ mayor en el Caribe. El promedio no ponderado en el Caribe es 59\% mayor: la principal razón de esta diferencia se basa en los bajos ingresos relativos en los países altamente poblados del Caribe (Cuba y Haití). La dispersión de ingresos en el Caribe es muy alta, mientras el promedio del ingreso per cápita mensual declarada a Gallup en Puerto Rico es de 578 dólares EE.UU. en Haití es sólo de 73 dólares. En América Latina la dispersión es menor: los extremos son Bolivia con un ingreso per cápita de 81 dólares y Chile con un ingreso per cápita de 321 dólares $^{8}$.

Una fuente probable de errores de medición en la EMG proviene del hecho de que el demandado no es necesariamente el jefe de hogar o su cónyuge. Lamentablemente, la base de 2006 no permite identificar el rol que cumple la persona en el hogar. Por lo tanto, con el fin de comprobar la solidez de algunos resultados se

\footnotetext{
${ }^{7}$ En 2007, sólo seis países de ALC tienen respuestas válidas a esta pregunta.

${ }^{8}$ En Colombia más del $70 \%$ de la población se encuentra en un solo tramo de ingresos por lo que se suprime este país para el resto del análisis.
} 
calcularon estadísticas de ingreso tomando en consideración las respuestas de los encuestados mayores a un cierto umbral. Los resultados son robustos a este cambio: por ejemplo, el coeficiente de correlación lineal del ingreso per cápita de toda la muestra y una muestra donde se eliminan los encuestados menores de 30 años es de 0,99. Tampoco los valores de pobreza y desigualdad se alteran de manera significativa.

En la tabla 4.2, la población se divide en los que responden a la pregunta de ingresos (columna "Si") y los que no lo hacen (en la columna "No"), se calculan estadísticas de estos grupos por separado. El análisis se limita a los países en los que la no respuesta de ingresos es superior al 15\%. Si la no-respuesta ingresos es al azar, el test " $\mathrm{t}$ " de diferencias de medias en la tercera columna de cada panel debería ser reducido. En la mayoría de los países de la región, de hecho, es el caso para la participación de los hombres y la tasa de urbanización. En contraste, en algunos países (por ejemplo Argentina y Costa Rica) la falta de respuesta parece estar concentrada en los sectores acomodados. La población con acceso a teléfono, computadora e Internet es significativamente mayor entre los que se niegan a responder a la pregunta de ingresos. Eso también es cierto para el conjunto de países (tomando tanto Latinoamérica, el Caribe y ALC). Sin embargo, puede notarse que en muchos casos las diferencias entre grupos no son estadísticamente significativas.

Aunque la evidencia muestra que la no-respuesta de ingresos es no-aleatoria en la EMG, al menos en algunos países, la magnitud y la tendencia no parece ser muy diferente a la observada en las encuestas de hogares (Gasparini, Gutiérrez y Tornarolli, 2007).

\section{Ingresos en la EMG y las ENH}

Las encuestas nacionales de hogares son la principal fuente de información sobre ingreso de los hogares. Estas encuestas suelen incluir un número relativamente elevado de preguntas dirigidas a la captura de todas las fuentes de ingresos. Sin embargo, mientras las encuestas de hogares son sin duda mejores como fuente de información sobre el ingreso nacional comparadas con la EMG, esta última tiene la gran ventaja de poseer un cuestionario similar en todos los países del mundo, y por lo tanto podrían competir con las encuestas nacionales como fuente de información para comparaciones internacionales. En esta sección se compara la distribución de los ingresos nacionales 
procedentes de la encuesta de Gallup con los obtenidos de las ENH realizadas por las oficinas nacionales de estadística en Latinoamérica y el caribe.

Si bien la EMG se realizó en 2006, no todas las encuestas en nuestra base de datos corresponden a ese año (15 de 20). Para hacer comparable ambas fuentes de información se ajustaron los ingresos de cada encuesta por el crecimiento del producto entre el año de la encuesta y el año 2006 (lo que implica asumir implícitamente que no se produjeron cambios distributivos entre el año de la encuesta y 2006).

Se calcularon para cada país, estimaciones no paramétricas de la función de densidad del ingreso per cápita de ambas fuentes de información, los gráficos se muestran en la figura 4.1. La primera figura de cada país compara la distribución proveniente de la EMG con aquella obtenida en base a las ENH, la segunda reescala los ingresos de la EMG igualando la media entre ambas distribuciones. En general, los ingresos en Gallup son menores que en las encuestas de hogares. Cuando se ajustan los ingresos por la diferencia de medias entre distribuciones, estas se acercan razonablemente en buena parte de los países. La figura 4.2 muestra las comparaciones entre Gallup y encuestas de hogares de toda la región. Ambas distribuciones parecen coincidir razonablemente bien en el caso de América Latina, pero no en el caso del Caribe, donde la distribución de Gallup parece más igualitaria.

Tabla 4.3 contiene estimaciones del ingreso medio familiar y per cápita en UML para cada país, junto con los porcentajes de ingreso de cada quintil. La media (mediana) de ingresos en Gallup es del 57\% (63\%) del valor de las encuestas de hogares. Sólo en Jamaica y Venezuela los ingresos en Gallup son más altos que en las encuestas de hogares. En la mayoría de los países la relación entre el quintil más pobre y más rico es algo menor en las encuestas de hogares.

La correlación lineal del ingreso per cápita entre países en Gallup y las encuestas de hogares nacionales es positiva, significativa, pero no demasiado alta $(0,61)$. Aunque esta se vuelve sustancialmente alta $(0,95)$ cuando se eliminan las desviaciones principales Jamaica, Honduras y Venezuela (ver figura 4.3). Idéntico resultado se obtiene si analizamos las medianas, el coeficiente de correlación es 0,58 y 0,93, respectivamente. El ranking en términos de ingreso entre países es similar (tabla 3.4). La correlación de Spearman es 0,94 para los medios y de 0,88 para las medianas cuando se eliminan las principales desviaciones (panel B de la tabla 3.4). 


\section{Ingresos en la EMG y las Cuentas Nacionales}

Hay una serie de razones por las cuales el ingreso medio puede variar entre las cuentas nacionales $(\mathrm{CN})$ y encuestas de hogares ${ }^{9}$. Las encuestas en su mayoría registran ingresos disponibles de fuentes laborales y transferencias, mientras que las $\mathrm{CN}$ suelen proporcionar estadísticas basadas el PIB per cápita o el consumo. Los principales resultados (por ejemplo ranking de países y tasas de crecimiento) en principio deberían ser similares, con independencia de la fuente de información, pero no siempre es así: Gasparini, Gutiérrez y Tornarolli (2007) documentan de diferencias significativas en tasas de crecimiento para ALC.

La figura 4.4 muestra una relación razonable entre el ingreso medio de Gallup y el PIB per cápita en los países de ALC. La correlación lineal es de 0,55 para la muestra completa, y se eleva a 0,83 cuando se eliminan los principales valores extremos (Honduras y Jamaica). Tabla 3.5 muestra el ranking para ALC de acuerdo con ambas variables. La mayoría de los países se encuentran en una posición similar en la escala de ingresos. Argentina y México tienen ingresos promedio en Gallup demasiado bajos en comparación con las cifras de las CN. El coeficiente de correlación de Spearman es positivo y significativo $(0,86)$.

\section{Comparación a nivel global}

La EMG permite comparaciones entre diferentes regiones del mundo. De acuerdo a los estos microdatos, los ingresos en Latinoamérica son mayores que en África subsahariana, y que en el sur de Asia, y menores que en el resto de las regiones (véase la tabla 4.6) ${ }^{10}$. En ALC el ingreso medio por habitante es el $13 \%$ del valor en América del Norte, $21 \%$ en Europa Occidental, y 65\% en Europa Oriental y Asia Central $^{11}$. Estos valores implican algunas discrepancias con las cifras de cuentas nacionales donde las brechas de ingresos entre ALC y el resto de las regiones son más pequeñas $^{12}$. La contradicción principal se plantea en la comparación de Latinoamérica y

\footnotetext{
${ }^{9}$ Ver Deaton (2005).

${ }^{10}$ La Tabla 3.3 registra los ingresos anuales, no mensuales como en los cuadros anteriores. Además, como nuestro conjunto de datos incluye ingresos en UML sólo para los países de ALC, para estas comparaciones se utiliza la variable elaborada en función de la estandarización de ingresos llevada a cabo por Gallup (descripta anteriormente).

${ }^{11}$ La tasa de no respuesta para Norte de África y Medio Oriente es muy alta (89\%), y su ingreso medio parece demasiado alto. El número de miembros del hogar en África subsahariana no está disponible en la base 2006, por lo que no se puede calcular el ingreso per cápita.

${ }^{12}$ El PIB per cápita (PPP) para 2006 en Latinoamérica fue el 22\% del valor en América del Norte, 30\% del de Europa Occidental, y $87 \%$ del de Europa Oriental y Asia central.
} 
Asia: mientras que según la EMG, el ingreso medio es mayor en Asia Oriental y el Pacífico que en Latinoamérica, y es sólo un 12\% mayor en Latinoamérica que en el Sur de Asia, los resultados procedentes de otras fuentes revelan diferencias de ingreso a favor de Latinoamérica ${ }^{13}$.

Es interesante extender estas comparaciones con la distribución del ingreso. La Figura 4.5 compara la función de densidad la distribución del ingreso per cápita en América Latina estimada no paramétricamente (kernel) con las funciones de otras regiones en el mundo. Incluso después de considerar sus inconvenientes y limitaciones, la potencia de la encuesta de Gallup se desprende figuras como la 4.5. Varios autores han tratado de llegar a distribuciones del ingreso comparables entre regiones. Para este fin se deben utilizar datos de fuentes muy diferentes, y hacer un sinnúmero de supuestos. Gallup tiene la ventaja de proporcionar los datos necesarios para estos cálculos en función de la misma pregunta, en más de un centenar de países.

La distribución del ingreso en Latinoamérica parece similar a la del Caribe. La distribución de Latinoamérica se encuentra a la izquierda de la distribución, tanto de Asia Oriental y el Pacífico, Europa Oriental y Asia Central. Las diferencias se hacen más dramáticas en la comparación con Europa Occidental y América del Norte. En la siguiente sección, nos concentraremos en analizar la desigualdad de los ingresos.

\footnotetext{
${ }^{13}$ El PIB per cápita (PPP) para 2006 de Latinoamérica fue 35\% mayor al de Asia Oriental y el Pacífico y más de 4 veces mayor al del Sur de Asia.
} 


\section{Desigualdad de ingresos}

Latinoamérica y el Caribe ha sido identificada como una región con altos niveles de desigualdad. En esta sección se proporcionan cálculos sobre desigualdad a nivel país y regional, con datos de la EMG.

\section{Desigualdad entre naciones de ALC utilizando la EMG y las ENH}

Comenzamos mostrando las estimaciones del indicador más difundido de desigualdad: el coeficiente de Gini para la distribución del ingreso familiar per cápita. En la mayoría de los países la desigualdad de ingresos es menor en los datos de Gallup, que en las encuestas nacionales de hogares (ver Tabla 5.1), este hecho podría ser consecuencia de que Gallup posee un cuestionario de ingresos más débil, lo que hace que se pierdan fuentes de ingresos importantes para los no pobres ${ }^{14}$. Más preocupantes son las diferencias en el ranking de la desigualdad entre los países ALC (Figura 5.1). Algunos países que son tradicionalmente considerados como relativamente igualitarios respecto de la norma en ALC parecen bastante desiguales (ej: Uruguay, Venezuela). Por otra parte, otros países tradicionalmente considerados como muy desiguales no son clasificados de esta forma (ej: Haití). La correlación de Spearman del coeficiente de Gini de la EMG y las ENH es positiva $(0,354)$, pero no estadísticamente significativa al 10\%. La correlación lineal es positiva (0,359), pero débil (ver figura 5.2).

Es interesante comparar los índices de Gini de la EMG, con alguna otra fuente que estime indicadores de las ENH pero que posea un número mayor de países a fin de ver cuán débil es esta relación a nivel internacional. Para esto se tomaron índices de Gini de la base de WIDER (2009). Para incrementar la comparabilidad se consideraron solo coeficientes de Gini sobre personas, calculados en base a ingresos (es decir que se eliminaron aquellos calculados sobre hogares, y los provenientes de consumo, gasto o salarios), de estos se consideró para cada país el valor más próximo al año 2006 pero no anterior al año $2000^{15}$. Este procedimiento deja 59 países con datos de ambas fuentes. La correlación entre coeficientes de Gini de la EMG y de WIDER es de 0,75,

\footnotetext{
${ }^{14}$ Se eliminó Honduras y Nicaragua ya que la desigualdad es demasiado baja debido a la estimación realizada del número de niños (siendo estos los únicos dos países que carecen de información sobre esta variable).

1535 países poseen datos de 2006, 6 países de 2005, 6 de 2004, 2 de 2003, 3 de 2002, 5 de 2001 y 4 del año 2000 .
} 
significativa al $1 \%$, lo que muestra un resultado más prometedor que el obtenido al comparar Ginis de América Latina ${ }^{16}$.

Hay un debate de larga data sobre el desempeño económico de Cuba. Desafortunadamente, el gobierno de ese país ha impedido la utilización de microdatos de encuestas nacionales, necesarios para hacer fiables las comparaciones internacionales. La Figura 5.1 es una de las pocas piezas de evidencia del nivel presumiblemente bajo de desigualdad de los ingresos en Cuba. Aunque es probable que el rango de Cuba en este gráfico refleje la realidad, el resultado debe ser tomado aún con prudencia, habida cuenta de las discusiones anteriormente mencionadas y las preocupaciones sobre la fiabilidad de las encuestas en ese país.

\section{Contrastando un hecho estilizado: Latinoamérica es la región más desigual del mundo}

Desde hace tiempo que América Latina es considerada la región más desigual del mundo. Esta propuesta se ha basado en microdatos de encuestas de hogares que difieren en varios aspectos entre países de diferentes partes del mundo. Aunque sin duda plausible, la declaración seguirá siendo discutible, sin microdatos comparables. La EMG hace una contribución a este problema proporcionando datos sobre ingresos de la misma pregunta en todos los países del mundo.

Hay dos posibilidades a la hora de analizar la desigualdad entre regiones del mundo. La primera es considerar cada región como una unidad y calcular la desigualdad entre todas las personas en la región, convirtiendo sus ingresos a una moneda común. En esa alternativa se ignora totalmente a la división en los países de cada región. La segunda alternativa consiste en calcular la desigualdad en cada región, tomando la media de los niveles de desigualdad en los países que la conforman.

La evaluación de la desigualdad en el primer sentido (la desigualdad global de la región) se presenta en la Figura 5.3. La curva de Lorenz de Latinoamérica está claramente por debajo de las de Europa Occidental, América del Norte y Europa Oriental y Asia Central, pero está por encima de las de Asia Oriental y el Pacífico y el Caribe. El coeficiente de Gini de Latinoamérica es 0,525 (ver tabla 5.2), superior al de Europa Occidental $(0,402)$, América del Norte $(0,438)$ y Europa Oriental y Asia Central

\footnotetext{
${ }^{16}$ La principal fuente de información de WIDER en Latinoamérica y el Caribe es la base de datos SEDLAC elaborada por el CEDLAS y el Banco mundial, como hemos mencionado esta fuente es precisamente la utilizada en este trabajo para las estadísticas de las ENH.
} 
$(0,497)$, pero menor al del Sur de Asia (0,534), el Caribe $(0,591)$, y Asia Oriental y el Pacífico $(0,594)$. La tabla 5.3 muestra que la mayoría de los resultados son robustos a la elección del índice de desigualdad. La excepción es la comparación entre Latinoamérica y el Sur de Asia, un hecho que no sorprende, dado el cruce de las curvas de Lorenz en la figura 5.3.

Algunos de los resultados cambian a la hora de tomar la segunda alternativa para medir la desigualdad regional; es decir considerar promedios simples del coeficiente de Gini de cada país (segunda columna en la tabla 5.2 y figura 5.4). Ahora, Latinoamérica se ubica como la región más desigual del mundo, y el Caribe se ve menos desigual. El promedio de los Ginis en América Latina $(0,499)$ sólo es comparable al del Sur de Asia $(0,489)$, y es muy superior a la desigualdad del Caribe $(0,456)$.

Para entender la diferencia en los resultados, debemos notar que la dispersión en el ingreso medio es menor en Latinoamérica que en otras regiones como Asia Oriental y el Pacífico y el Caribe. El coeficiente de Gini de la distribución de los ingresos medios entre los países es 0,271 en Latinoamérica, 0,401 en el Caribe y 0,338 en Asia Oriental y el Pacífico. Esto implica que los países de América Latina son relativamente similares en términos de desarrollo, comparados con los del Caribe o Asia Oriental. En Gallup, la proporción de ingresos entre el país más pobre y el más rico es inferior a 5 en Latinoamérica (Bolivia y Chile), más de 8 en Asia Oriental y el Pacífico (Camboya y Hong Kong), y más de 10 en el Caribe (Haití y Puerto Rico).

A fin de analizar la desigualdad regional, se realiza una descomposición del índice de Theil regional por países (véase la tabla 5.4 y figura 5.5). La proporción del componente de la desigualdad entre países de Latinoamérica es relativamente pequeña en comparación con otras regiones del mundo. En cambio, en el Caribe la desigualdad entre países es casi la mitad de la desigualdad regional global.

La Tabla 5.6 permita dar un breve vistazo a la desigualdad mundial realizando una descomposición de Theil a nivel global, el coeficiente agregado es de 0,769. Es interesante observar que casi la mitad de las disparidades de ingresos del mundo pueden explicarse por las diferencias entre los países. Este porcentaje es algo menor que el valor estimado por otros autores (ver tabla 2.1), pero aún es muy alto. 


\section{Contrastando un segundo hecho estilizado: Latinoamérica es demasiado desigual}

Kuznets (1955) encontró pruebas de una relación de U invertida entre la desigualdad y el desarrollo en términos de ingreso y propuso una explicación posible a este fenómeno. La Figura 5.6 hace una pequeña contribución a la extensa y rica literatura que ha generado ese artículo, mostrando un diagrama de dispersión sobre los coeficientes de Gini calculados en base a la EMG y el PIB per cápita (en el panel A), y el ingreso per cápita (panel B). La relación entre Gini y PIB parece ser negativa. Si tenemos en cuenta que los países de bajos ingresos de África y el Medio Oriente no están en la muestra, la cifra es compatible con la existencia de una curva de Kuznets. El panel B también muestra una relación negativa entre desigualdad e ingreso per cápita de ambos medidos con datos de Gallup.

Es interesante notar, en particular, en el panel A, que casi todas las observaciones en América Latina están por encima de la curva. Esto es evidencia a favor del "exceso de desigualdad de Latinoamérica" documentado en Londoño y Székely (2000) y Gasparini, Cruces y Tornarolli (2009) entre otros: Los países latinoamericanos tienen altos niveles de desigualdad del ingreso, incluso después de considerar sus niveles de desarrollo económico ${ }^{17}$.

En la sección siguiente se estudiará la desigualdad en términos de bienestar personal subjetivo y su relación con los indicadores provenientes del ingreso.

\footnotetext{
${ }^{17}$ En el panel B de este fenómeno es menos claro, tal vez como resultado de la subestimación relativa de los ingresos de Latinoamérica en la encuesta de Gallup, una posibilidad discutida anteriormente.
} 


\section{Desigualdad del bienestar personal subjetivo}

La Encuesta Mundial Gallup contiene preguntas de carácter subjetivo, lo que permite extender el análisis de desigualdad sobre dimensiones relacionadas con el bienestar personal subjetivo.

El análisis de bienestar subjetivo es muy reciente en la economía pero el número de trabajos que estudian este campo se ha incrementado exponencialmente ${ }^{18}$. El trabajo de Easterlin (1995) es un texto de referencia por su paradoja: "el aumento de los ingresos de todos no aumenta la felicidad de todos". La idea central es que los individuos basan su nivel de bienestar en comparación con el resto de los individuos, lo que ha motivado el estudio de la relación entre ingresos y el bienestar. Clark y Oswald (1996), Ferrer-i-Carbonnell (2005) y Helliwell and Huang (2009) encuentran evidencia de este efecto negativo entre bienestar de un individuo y el ingreso del resto del grupo al que se asume como referencia.

En contraste, Hirschman y Rothschild (1973) consideró la posibilidad de que los ingresos de otras personas puedan ejercer una influencia positiva en el bienestar individual si juegan el papel de señal (la luz al final del túnel). La idea central es que si el ingreso de los otros individuos aumenta, esto proporciona la esperanza (y por lo tanto un mayor nivel de bienestar) de encontrarse en una situación mejor en el futuro. Senik (2004 y 2008) proporciona evidencia sobre el predominio de este último efecto en países con mayor movilidad e incertidumbre (como Estados Unidos, países en desarrollo y recientemente desarrollados) en contraste con el predominio de efectos negativos en los países desarrollados de Europa Occidental. Recientemente, Stevenson y Wolfers (2008a) encuentran una relación claramente positiva entre el nivel de bienestar subjetivo y el producto o ingreso de los países en base a datos de la Encuesta Mundial de Valores y la Encuesta Mundial Gallup, resultado a favor de la predominancia de los ingresos absolutos en la determinación de la felicidad.

Un capítulo interesante de la literatura empírica se ha concentrado en la relación entre distribución del ingreso y bienestar subjetivo. Entre los primeros trabajos Morawetz (1977) estudia el nivel de satisfacción en dos pequeñas comunidades de Israel, con similares características a excepción de su nivel de desigualdad y encuentra

\footnotetext{
${ }^{18}$ Kahneman and Krueger (2006) describe el desarrollo y utilización de medidas de bienestar subjetivo. Senik (2009) resume la literatura que compara desigualdad en el ingreso y bienestar subjetivo.
} 
un efecto positivo y significativo en el nivel de satisfacción de los individuos del pueblo con menor desigualdad, controlado por características demográficas. Schwarze y Härpfer (2007) encontraron que la desigualdad reduce el nivel de satisfacción analizando datos entre regiones de Alemania. Recientemente Bjørnskov, Dreher, Fischer y Schnellenbach (2009) estudiaron la relación entre desigualdad y bienestar subjetivo utilizando preguntas sobre percepciones de la Encuesta Mundial de Valores sobre 69 países e índices de Gini de la base de WIDER, entre sus resultados encuentran solo una débil relación entre desigualdad y nivel de bienestar subjetivo entre países, pero encuentran que quienes perciben habitar en un país inequitativo suelen tener un menor nivel bienestar subjetivo y preferir niveles mayores de redistribución.

El análisis empírico del bienestar subjetivo ha sido muy prolífico en los últimos años no obstante el análisis de la desigualdad en esta materia es aún muy escaso. Stevenson y Wolfers (2008b) realizan una contribución en este campo analizando la desigualdad de la felicidad en los Estados Unidos entre 1972 y 2006. Los autores analizan datos de bienestar subjetivo de la General Social Survey sobre respuestas con tres categorías: "no muy feliz", "algo feliz" y "muy feliz". Estas categorías son puramente ordinales (nada indica por ejemplo, que la distancia en términos de felicidad entre "no muy feliz" y "algo feliz" sea la misma que entre "algo feliz" y "muy feliz"). Este problema obliga a los autores a utilizar la estrategia de estimar una variable latente sobre la base de las respuestas a esta pregunta categórica. Los autores encuentran que si bien no ha habido incrementos en el bienestar subjetivo medio, la desigualdad del bienestar subjetivo ha disminuido sustancialmente desde la década del '70. También encuentran grandes cambios en los niveles de desigualdad entre grupos, como la reducción de la brecha entre blancos y negros, y entre hombres y mujeres, así como un aumento de la brecha entre niveles educativos, lo que sumado a grandes aumentos en la desigualdad de ingresos sugiere un papel importante de los factores no pecuniarios en la configuración de la distribución del bienestar.

\section{¿Por qué estudiar la desigualdad del bienestar subjetivo?}

La desigualdad en términos de ingreso ha sido ampliamente estudiada en la literatura, y dado el creciente interés por las medidas de bienestar subjetivo podemos pensar qué ventajas y desventajas puede tener estudiar la desigualdad de las respuestas en esta dimensión. 
Bajo condiciones de certidumbre e igualdad de habilidades podemos definir la igualdad de oportunidades como ausencia de envida. Para visualizar esto supongamos dos individuos que solo difieren en sus preferencias: supongamos por ejemplo que el primero tiene una mayor predilección hacia el ocio que al consumo de bienes. En este caso el primer individuo trabajará menos horas que el segundo y por lo tanto su ingreso será menor, pero en términos de bienestar "no envidiará" al segundo individuo puesto que él obtendría un bienestar menor si trabajara más horas. Un sinnúmero de ejemplos como este podrían establecerse tanto en modelos estáticos como intertemporales, donde diferencias en los ingresos no impliquen diferencias en términos de igualdad de oportunidades, siempre que los individuos de menores ingresos "no envidien" la vida de aquellos con mayores ingresos.

Bajo incertidumbre esta distinción no es tan clara puesto podrá existir "envidia" en términos de resultados obtenidos, en este sentido puede definirse la igualdad de oportunidades como ausencia de envidia en términos esperados.

Si tenemos en cuenta la posibilidad de diferencias en términos de habilidades innatas, la envidia puede producirse a pesar de haber igualdad de oportunidades. Pero si la distribución de habilidades innatas es similar entre países (o en el tiempo) este factor no debería provocar alteraciones en términos comparativos de indicadores agregados que midan esta dimensión.

Podemos pensar entonces, que medir la desigualdad del bienestar subjetivo aproxima mejor el concepto de desigualdad de oportunidades que medir la desigualdad en términos de ingresos. Al menos una parte de las diferencias de ingreso que no tienen origen en la desigualdad de oportunidades pueden eliminarse si remplazamos esta dimensión por el bienestar subjetivo, porque la parte que "eligen los individuos" no causará diferencias en el bienestar subjetivo (como sí en los ingresos).

Las desventajas más importantes tienen que ver con las dificultades de medir el bienestar subjetivo; las encuestas disponibles establecen preguntas que sólo son aproximaciones a esta dimensión y que poseen grandes limitaciones en términos de comparabilidad por las posibles diferencias en la interpretación de las preguntas. En contraste, para medir el ingreso se ha desarrollado una amplia gama de preguntas que permiten su cuantificación con un alto grado de precisión lo que motiva el uso esta 
dimensión como aproximación objetiva a la medición del bienestar ${ }^{19}$. Revisaremos algunas de las limitaciones respecto de la medición del bienestar subjetivo en las siguientes subsecciones.

\section{Preguntas sobre bienestar subjetivo en la EMG}

En la EMG la variable wp16 de la encuesta responde a la siguiente pregunta: "Por favor, imagine una escalera con escalones numerados de cero en la parte inferior a diez en la parte superior. Supongamos que decimos que la parte superior de la escalera representa la mejor vida posible para usted y la parte inferior de la escalera representa la peor vida posible para usted. Si el escalón más alto es 10 y el primer escalón es 0 , En qué escalón de la escalera se siente usted personalmente en la actualidad?". Esta variable puede ser considerada una aproximación del bienestar del individuo entre lo peor y lo mejor posible en que se puede encontrar. La formulación de esta pregunta es muy conveniente puesto que incorpora la idea de 11 niveles en principio equidistantes (peldaños en una escalera) lo que nos permite, en principio, computar indicadores directamente sobre esta variable ${ }^{20}$.

Si la literatura sobre desigualdad del bienestar subjetivo es escasa, su análisis a nivel internacional o global es nulo. La EMG permite una oportunidad única para realizar este tipo de análisis y comparar sus resultados con los obtenidos en términos de ingreso.

\section{Limitaciones sobre la comparabilidad de variables subjetivas}

Antes de realizar este análisis debemos tener en cuenta que la comparabilidad de las respuestas entre individuos es limitada. El principal problema que surge al comparar respuestas es que los mínimos y máximos no son comparables entre personas. La mejor y la peor vida posible que imagina cada individuo puede ser diferente, y por lo tanto cualquier respuesta no es estrictamente comparable entre individuos. Por ejemplo, es probable que la peor y mejor vida posible de una persona pobre difiera de las que

\footnotetext{
${ }^{19}$ En la práctica debemos tener en cuenta que las ENH (que habitualmente miden ingreso o consumo) tienen además, un mayor grado de desarrollo y mayor representatividad, de hecho en el presente documento se señalan algunos de los inconvenientes e inconsistencias en los datos de Gallup que pueden encontrarse también, en otras encuestas dirigidas a medir el bienestar subjetivo.

${ }^{20}$ En sí, cualquier pregunta sobre bienestar o felicidad es de carácter ordinal, pero hay una cuestión de grado: al establecer 11 peldaños de una escalera, la pregunta de la EMG brinda alguna aproximación de la distancia entre éstos, lo cual es más conveniente para analizar desigualdad que otras preguntas puramente categóricas. Podría evaluarse de todas formas la estimación de una variable latente en futuras investigaciones.
} 
imagina una persona rica. De todas formas la literatura compara y computa indicadores agregados sobre este tipo de indicadores.

Existe sin embargo una cierta asimetría en la interpretación de los resultados: si se encuentra por ejemplo que ricos y pobres reportan estar en el mismo nivel, nada garantiza que tengan niveles similares de bienestar subjetivo, pero si encontramos que los ricos en promedio reportan niveles mayores que los pobres, este sí es un resultado interesante ya que resulta difícil imaginar que la peor y mejor vida posible de una persona pobre esté por encima (en términos ordinales) de las que imagina una persona rica. En general, los resultados obtenidos van en este último sentido, y es por eso que podemos interpretarlos como una aproximación al bienestar subjetivo (en el ejemplo, la evidencia en este sentido puede interpretarse como que en general los pobres tienden a ser menos felices que los $\left.\operatorname{ricos}^{21}\right)$.

Para las comparaciones internacionales estas incompatibilidades pueden profundizarse: si las personas tienen en cuenta el bienestar de su entorno a la hora de determinar mínimos y máximos, estos pueden estar más distanciados aún, si comparamos gente de diferentes países. Por ejemplo, si los habitantes de un país rico suponen como la peor vida posible, la vida de quienes consideran que están peor en su país, este mínimo podría ser igual o mejor que la mejor vida posible en un país donde los individuos sean muy pobres. Por eso debemos ser extremadamente cautos a la hora de interpretar los resultados.

En resumen, cualquier diferencia en las respuestas de los individuos será producto de la distinta interpretación de esta pregunta o las diferencias en el bienestar que estos poseen (lo que lamentablemente es imposible de separar), pero a favor de la compatibilidad de las respuestas debemos tener en cuenta que la EMG realiza exactamente la misma pregunta a los individuos de todos los países eliminando otras posibles fuentes de incompatibilidad entre respuestas.

Por último cabe mencionar que las observaciones realizadas son pertinentes tanto para el cómputo de indicadores de nivel (por ejemplo medias) como para indicadores de dispersión. Por ejemplo, para computar la media de un país o región necesitamos que las respuestas estén en "la misma unidad de medida" lo cual es necesario también para computar el Gini de esta variable en el país o región.

\footnotetext{
${ }^{21}$ Ver por ejemplo Easterlin (1995).
} 


\section{Bienestar subjetivo e ingresos a nivel internacional}

Como se mencionó anteriormente, Stevenson y Wolfers (2008a) realiza un análisis exhaustivo de esta relación entre países utilizando entre otras fuentes la EMG, y brindan evidencia a favor del no cumplimento de la paradoja de Easterlin. Realizando un simple gráfico que relacione las observaciones de cada país para estas variables puede visualizarse claramente esta relación. La figura 6.1 muestra la relación entre la media del bienestar subjetivo de los individuos y el logaritmo del ingreso medio de cada país calculado con datos de la EMG. La figura 6.2 muestra la misma relación pero comparando con el PBI per cápita de los países. Como hemos mencionado anteriormente no se disponen de datos de ingreso per cápita en la EMG 2006 para los países de África y el Medio Oriente, pero sí se posee información de la variable representativa del bienestar subjetivo por lo tanto la figura 6.2 incluye a estos países ${ }^{22}$. Vemos que en ambos casos existe una relación positiva: en para la figura 6.1 la correlación es positiva ( 0,68 sin ponderar y 0,71 ponderando por población) y significativa con un nivel de confianza del 1\%, para la figura 6.2 los valores son aún mayores 0,80 y 0,77 respectivamente.

\section{Desigualdad del bienestar subjetivo y de los ingresos a nivel internacional}

En una segunda instancia podemos explorar que relación existe entre desigualdad de ingresos y del bienestar subjetivo: la figura 6.3 muestra la relación entre coeficientes de Gini computados en base al ingreso per cápita y computados en base al bienestar subjetivo para todos los países del mundo, la correlación es positiva $(0,35$ sin ponderar y .57 ponderando por población) y significativa al $1 \%$. Si bien la correlación es menor que al analizar medias, este resultado nos indica que en principio países con menor desigualdad de ingresos son también países donde la desigualdad de las respuestas acerca de su bienestar en simples escalones ordinales es también menor.

Las figuras 6.1, 6.2 y 6.3 muestran en color rojo a los países de Latinoamérica y en color verde a aquellos del Caribe. La tabla 6.1 resume las correlaciones de las variables que intervienen en estas figuras para todos países del mundo (que ya hemos comentado), y adicionalmente contiene los coeficientes de tomar sólo a Latinoamérica, al Caribe y a ALC. Los valores son también positivos en todos los casos aunque a veces

\footnotetext{
${ }^{22}$ La figura 6.2 incluye en total 41 países más que la figura 6.1, de los cuales 26 países corresponden al África subsahariana, 11 al Norte de África y Medio Oriente, 2 a Europa Oriental y Asia Central, 1 al Sur de Asia y 1 a Asia Oriental y el Pacífico.
} 
no son significativos. A pesar de que el menor número de observaciones involucradas explica buena parte de la no significatividad, llaman la atención algunos valores relativamente bajos como la correlación ponderada y sin ponderar entre desigualdad del bienestar subjetivo y de los ingresos en ALC.

\section{Desigualdad del bienestar subjetivo y desarrollo de los países, ¿una nueva curva de}

\section{Kuznets?}

Como hemos mencionado Kuznets (1955) encontró una relación de U invertida entre desigualdad y desarrollo en términos de ingreso. Este importante resultado empírico ha motivado su estudio por parte de un gran número de trabajos. La EMG nos permite por primera vez evaluar qué ocurre si analizamos las relaciones entre desigualdad y desarrollo en términos subjetivos y objetivos. Las figuras 6.4 y 6.5 relacionan el índice de Gini del bienestar subjetivo con el logaritmo del ingreso medio y del producto per cápita, respectivamente. Por idénticos motivos que en las figuras $6.1 \mathrm{y}$ 6.2, la figura 6.4 no incluye a un gran número de países de bajos ingresos mientras que la figura 6.5 si los incluye. Una rápida mirada a estas figuras nos hace notar la existencia de una $U$ invertida también en este caso, en la figura 6.5 la relación es aún más notoria. La tabla 6.2 muestra los coeficientes de las regresiones entre estas variables, en todos los casos el coeficiente del ingreso o producto es positivo y el del término cuadrático es negativo (y son ambos estadísticamente significativos al 1\%).

El trabajo de Kuznets ha motivado una extensa y aún inconclusa discusión en términos de cuál es la causalidad entre desarrollo y desigualdad, así como sobre la existencia o no de esta curva para un determinado país en términos dinámicos. Por lo que no se enumerarán las posibles causas de esta relación, pero de todas formas es interesante ver que también podemos encontrar una notoria y similar relación entre la desigualdad en términos de bienestar subjetivo y el nivel de desarrollo en términos económicos de los países. Adicionalmente podemos notar que los países latinoamericanos no parecen en este caso tener necesariamente un exceso de desigualdad del bienestar subjetivo, resultado que sí era evidente al analizar desigualdad de los ingresos.

\section{Desigualdad y nivel del bienestar subjetivo a nivel internacional}

Analizaremos ahora la relación entre el bienestar subjetivo medio y el coeficiente de Gini de esta dimensión, la figura 6.6 muestra esta relación. Una rápida 
mirada al gráfico nos muestra una relación marcadamente negativa, el coeficiente de correlación alcanza $-0,79$ y $-0,78$ ponderado y sin ponderar por la población de los países (y son ambos significativos al 1\%). Esto nos indica que países en donde los individuos tienden a situarse en mejores niveles en términos de bienestar o felicidad, son también países que poseen menos dispersión en este sentido. El interesante interrogante que muestra este gráfico es por qué no vemos aquí una $U$ invertida como en el caso las figuras 6.4 y 6.5. También este efecto puede observarse al analizar desigualdad de ingresos, la figura 6.7 relaciona la desigualdad en ingresos con el bienestar medio subjetivo. Vemos aquí también, una relación negativa aunque menos pronunciada, con correlaciones de $-0,54$ y $-0,46$, ponderando y sin ponderar, ambas significativas al $1 \%$, pero como se explicó anteriormente esta figura carece de la mayor parte de los países con menores ingresos, por lo que no es posible aquí establecer si existe una relación de $\mathrm{U}$ invertida o una relación siempre negativa ${ }^{23}$.

\section{¿Existe un posible efecto aversión a la desigualdad del bienestar subjetivo?}

Una explicación posible (y por supuesto que muy preliminar) de observar una relación marcadamente negativa entre desigualdad y bienestar subjetivo (y no una $\mathrm{U}$ invertida) puede ser la siguiente: si la desigualdad en el bienestar es considerada un “mal” por los individuos ya sea por motivos egoístas o altruistas ${ }^{24}$, podrá provocar un menor nivel de satisfacción a todos los individuos ceteris paribus su nivel de ingreso. Este efecto, que podríamos denominar efecto aversión a la desigualdad tal vez permita explicar las diferencias entre ordenar a los países por ingreso y ordenarlos por nivel de bienestar subjetivo.

Si el bienestar promedio en los países se ve afectado por el efecto aversión a la desigualdad, los países con menores ingresos y baja desigualdad tendrán un incremento (ceteris paribus) en su nivel medio de satisfacción. Por otra parte los países con ingresos medios y alta desigualdad tendrán (ceteris paribus) un nivel medio de satisfacción menor, y por último los países de ingresos altos y baja desigualdad tendrán (también ceteris paribus) un mayor nivel de satisfacción. Estos efectos pueden explicar

\footnotetext{
${ }^{23}$ Adicionalmente se computó la correlación entre estos indicadores utilizando los datos de WIDER, la correlación es de de 0,51 , significativo al $1 \%$, resultado en línea con los obtenidos utilizando solo la EMG.

${ }^{24}$ Ver Senik (2009) para una revisión de la literatura sobre los posibles motivos a favor y en contra de la aversión a la desigualdad.
} 
el pasaje de una $U$ invertida a una curva con pendiente marcadamente negativa cuando pasamos de medir ingreso (o producto) per cápita, a medir nivel medio de satisfacción.

Con el objeto de indagar un poco más cuán posible es este efecto podemos crear alguna variable que permita aproximar la relación entre nivel de ingreso y de bienestar subjetivo. Podemos por ejemplo, calcular el ratio entre el bienestar subjetivo y el logaritmo del producto, y luego restar a cada observación el valor promedio entre todos los países. De este modo países con valores positivos para esta variable tendrán un nivel de bienestar subjetivo relativo su ingreso superiores al promedio y países con valores negativos tendrán un nivel de bienestar subjetivo relativo su ingreso menores que el promedio de los países en el mundo. La figura 6.8 muestra la relación entre el coeficiente de Gini sobre el bienestar subjetivo y esta variable. A simple vista puede verse que los países con mayor desigualdad tienen un nivel de bienestar subjetivo menor, relativo a su nivel de ingreso. Por otra parte países con baja desigualdad poseen niveles de bienestar subjetivo mayor respeto de su nivel de ingreso. La correlación confirma este resultado, esta es negativa $(-0,67)$ y significativa al $1 \%$.

Otra alternativa es indagar si existe un patrón identificable en los posibles cambios en los rankings de países en términos de ingreso y de bienestar subjetivo. La figura 6.9 muestra la relación entre el coeficiente de Gini sobre el bienestar subjetivo y la diferencia de cada país en términos de ranking de bienestar subjetivo y de ranking de ingresos. Vemos que los países que tienen mayor desigualdad tienden a estar peor rankeados en términos de bienestar subjetivo que en términos de ingreso, y los países con bajos niveles de desigualdad del bienestar tienden a rankearse mejor en términos de bienestar subjetivo que de ingresos. Esto muestra nuevamente evidencia a favor del efecto aversión a la desigualdad, el coeficiente de correlación entre estas variables es nuevamente negativo $(-0,33)$ y significativo al $1 \%$.

Podemos también replicar este análisis para la relación entre desigualdad de ingresos y nivel medio del bienestar subjetivo. Las figuras 6.10 y 6.11 son equivalentes a las figuras 6.8. y 6.9 pero utilizando la desigualdad de los ingresos. Las relaciones aquí son mucho menos concluyentes, la correlación para la primera variable construida es de $-0,12$ y la correlación para la variable construida en base rankings es positiva $(0,22)$ y significativa al $5 \%$.

Una posible fuente de generación de resultados tan dispares podría ser la diferencia en los países involucrados. Por los motivos antes mencionados en el último 
ejercicio no se incluye a muchos países de bajos ingresos situados en la cola izquierda de la U invertida en la curva de Kuznets. La falta de estos países es un claro problema de omisión no aleatorio de observaciones y puede afectar los rankings de países. Para dilucidar este interrogante se replicó el análisis de las figuras 6.8 y 6.9 con la misma muestra de países involucrados en las figuras 6.10 y 6.11. Los resultados sorprendentemente se mantienen, la correlación para la primera y segunda variable son de $-0,73$ y $-0,34$ respectivamente, ambas significativas al $1 \%$.

Dados los inconvenientes encontrados en Gallup para medir ingresos (en las secciones anteriores) podemos utilizar datos de desigualdad de la base de WIDER, a fin de descartar que problemas de medición de los ingresos en la EMG expliquen los patrones encontrados. Nuevamente, los anteriores resultados se mantienen: la correlación entre desigualdad de ingresos usando estos datos y las variables de ratio y ranking recalculadas para esta sub-muestra de países son de -0.03 y 0.51 respectivamente (siendo la última significativa al 1\%), mientras que al analizar la desigualdad del bienestar subjetivo con esta muestra de 59 países, las correlaciones son de $-0,75$ y -0.20 , siendo el primero significativo al $1 \%$.

Por último, podemos pensar la posibilidad de que potenciales problemas sobre la forma de medir bienestar subjetivo, afecten a los indicadores de desigualad de forma asimétrica a los distintos países. Para evaluar este problema se computaron para cada país índices de Gini utilizando solo las observaciones que poseen un nivel de bienestar subjetivo inferior a la media del país, y se replicó el análisis anterior. El objeto de este ejercicio es testear si la existencia de un límite superior provoca algún sesgo negativo sobre la medición de la desigualdad en países con altos niveles de bienestar subjetivo. Los resultados nuevamente se mantienen: la correlación entre estos ginis y el nivel de bienestar subjetivo es de $-0,61$, significativa al $1 \%$, la correlación respecto de las variables de ratios y rankings es de $-0,65$ y $-0,37$ respectivamente, ambas significativas al $1 \%$.

Estos resultados muestran una interesante paradoja: se evidencia un efecto aversión a la desigualdad del bienestar subjetivo pero no respecto a la desigualdad de ingresos. En otras palabras, los habitantes de países con mayores niveles de desigualdad del bienestar subjetivo claramente poseen un menor nivel de bienestar en promedio, pero si analizamos esta relación en términos de ingreso la esta tendencia desaparece o incluso se revierte. 
Recordemos que al menos en principio, la dispersión de variables tendientes a captar el bienestar en términos subjetivos excluye respecto a la desigualdad del ingreso las fuentes de dispersión que "no provocan envidia". En función de esto, podemos elaborar la siguiente hipótesis: si los individuos perciben como un "mal" la desigualdad de oportunidades (en contraposición a la desigualdad de resultados) y además las preguntas subjetivas captan mejor esta dimensión que el ingreso, entonces será más probable encontrar efectos de aversión a la desigualdad utilizando la primer variable que la segunda.

La evaluación de esta hipótesis requiere un análisis mucho más profundo de este problema que excede el alcance de este trabajo, pero los resultados obtenidos sugieren al menos la posibilidad de ocurrencia de este fenómeno.

\section{Desigualdad del bienestar personal subjetivo a nivel global}

El siguiente paso es el análisis a nivel global, la tabla 6.3 y la figura 6.12 muestran el coeficiente de Gini sobre ingresos y sobre el bienestar subjetivo, computados a nivel regional y como promedio de los coeficientes de cada país. Podemos notar aquí algunas similitudes y diferencias entre estas medidas.

En primer lugar vemos que Europa Occidental y el Norte de América son las regiones con menor desigualdad tanto de ingresos como en términos de bienestar subjetivo. Además Latinoamérica no parece ser en términos subjetivos la región más desigual pero al igual que en términos de ingreso mejora su posición en el ranking al considerar la desigualdad global de la región. Algo similar ocurre con el Sur de Asia y también con Asia Oriental y el Pacífico que mejoran y empeoran respectivamente, su posición en el ranking tanto en términos de ingreso como en términos de bienestar subjetivo. Por último, vemos que El Caribe no cambia su posición como sí ocurre en términos de ingreso, y figura como la región más desigual en términos subjetivos, seguida del África subsahariana.

Al agrupar los países en términos de ingreso los resultados corroboran la existencia de una relación de tipo Kuznets entre la desigualdad subjetiva y el nivel de ingreso (ver tabla 6.3 y figura 6.12).

La tabla 6.4 y figura 6.13 muestran la descomposición del índice de Theil a nivel regional. El componente de desigualdad entre países es sustancialmente menor que aquella obtenida en función de los ingresos, pero es en este aspecto donde la 
incompatibilidad entre estas variables se hace mayor, porque como hemos mencionado anteriormente es imposible identificar los efectos de escala entre países, además el carácter acotado de la variable subjetiva (11 niveles) deja poco lugar a diferencias de nivel en términos absolutos. De todas formas podemos notar que al igual que en la tabla 5.4, El Caribe y Asia Oriental y el Pacífico son las regiones con una mayor proporción de desigualdad entre países (sólo superada ahora por el Norte de África y Medio Oriente).

Por último y solo a efectos ilustrativos la tabla 6.5 muestra la descomposición del índice de Theil de la desigualdad subjetiva a nivel mundial, dado las aclaraciones expuestas anteriormente la interpretación de estos resultados es muy limitada, pero podría ser de utilidad en el futuro en la medida en que nuevas versiones de la encuesta se realicen, a fin de poder evaluar la evolución en el tiempo de estos indicadores. 


\section{Observaciones finales}

La Encuesta Mundial Gallup constituye un poderoso instrumento para la comparación internacional de las variables socio-económicas. Este trabajo explota este conjunto de datos para estudiar la desigualdad de ingresos en Latinoamérica y el Caribe, y comparar esta región con el resto del mundo. Además se analiza por primera vez la desigualdad en términos de bienestar subjetivo a nivel internacional, y se explora la relación entre esta dimensión y los indicadores provenientes del ingreso.

Entre los principales resultados del trabajo se encuentra que América Latina, la región tradicionalmente concebida como de mayor desigualdad y con exceso de desigualdad (en relación a su nivel de ingreso) deja de poseer estos atributos si comparamos la desigualdad a nivel global de las regiones. También se obtienen correlaciones positivas entre desigualdad de ingresos y del bienestar subjetivo, se obtiene una curva del tipo de Kuznets al comparar la desigualdad del bienestar subjetivo con el producto, pero una relación marcadamente negativa si se la compara con el nivel medio de bienestar subjetivo. Esto podría fundamentarse en la utilidad que provoca sobre los individuos habitar un país más igualitario en términos de bienestar. De todas formas todos estos interesantes resultados deben ser tomados con extrema cautela, puesto que también el trabajo evidencia ciertos problemas y limitaciones en la encuesta y las medidas utilizadas.

No proponemos el uso de la encuesta de Gallup, como sustituto de las encuestas de hogares en el análisis de distribución del ingreso, las encuestas nacionales son considerablemente más grandes y más ricas. De hecho, en el documento se señalan algunos de los inconvenientes e inconsistencias en los datos de Gallup, que limitan su uso. Sin embargo, al mismo tiempo, se destaca el enorme potencial de la Encuesta Mundial Gallup (u otras encuestas similares) si sus inconvenientes se superan en las siguientes rondas de la encuesta puesto que permite una oportunidad única para realizar comparaciones internacionales de estadísticas sociales y aspectos subjetivos. 


\section{Referencias}

Anand, S. y Segal P. (2008), "What do we know about global income inequality?", Journal of Economic Literature, vol. 46(1).

Bhalla, S. (2002), "Imagine there's no country: poverty, inequality and growth in the era of globalization", Institute for International Economics, Washington DC.

Bjørnskov, C., Dreher, A., Fischer, J. y Schnellenbach, J. (2009) "On the relation between income inequality and happiness: Do fairness perceptions matter?", MPRA Paper No 19494.

Bourguignon, F. y Morrisson, C. (2002), "Inequality among world citizens: 1820-1992”, American Economic Review, vol. 92(4), pp. 727-744.

Clark, A. y Oswald, A. (1996), "Satisfaction and Comparison Income", Journal of Public Economics, vol. 61, pp. 359-381.

CEDLAS (2007), "A Guide to SEDLAC”, documento disponible en SEDLAC: www.depeco.econo.unlp.edu.ar/cedlas/sedlac

Chotikapanich, D., Valenzuela, R. y. Prasada Rao D. (1997), "Global and Regional Inequality in the Distribution of Income: Estimation with Limited and Incomplete Data", Empirical Economics, Vol 22, pp. 533-46.

Deaton, A. (1997), "The analysis of household surveys. Microeconomic analysis for development policy", The World Bank, Washington D.C.

Deaton, A. (2005), "Measuring poverty in a growing world (or measuring growth in a poor world)", The Review of Economics and Statistics, vol. 87(1).

Deaton, A. (2008), "Income, Health, and Well-Being Around the World", Journal of Economic Perspectives, vol. 22(2).

Deininger, K. y Squire, L. (1996), “A New Data Set Measuring Income Inequality”, World Bank Economic Review, vol. 10(3).

Diener, E. y Oishi, S. (2000), "Money and happiness: Income and subjective well-being across nations", en "Culture and subjective well-being", Capítulo 8, MIT Press. 
Dikhanov, Y. y Ward, M. (2002), "Evolution of the Global Distribution of Income, 1970-99", World Bank, presentado en CEPAL $4^{\circ}$ meeting of the Expert Group on Poverty Statistics.

Dowrick, S. y Akmal, M. (2005), "Contradictory Trends in Global Income Inequality: A Tale of Two Biases", Review of Income and Wealth, vol. 51(2), pp. 201229.

Easterlin, R. (1995), "Will Raising the Income of all Increase the Happiness of All?", Journal of Economic Behavior and Organization, vol. 27(1), pp. 35-47.

Gasparini, L., Cruces, G., Marchioni, M. y Tornarolli, L. (2009), “A turning point? Recent developments on inequality in Latin America and the Caribbean”, Documento de trabajo $N^{\circ} 81$ del CEDLAS y PNUD.

Gasparini, L. y Gluzmann, P. (2009), "Estimating Income Poverty and Inequality from the Gallup World Poll, The case of Latin America and the Caribbean", Documento de trabajo $\mathrm{N}^{\circ} 83$ del CEDLAS.

Gasparini, L., Gutiérrez, F. y Tornarolli, L. (2007), “Growth and income poverty in Latin America and the Caribbean: evidence from household surveys", Review of Income and Wealth, vol. 53(2).

Gasparini, L., Marchionni, M., Olivieri, S. and Sosa Escudero, W. (2009), "Multidimensional poverty in Latin America and the Caribbean", Mimeo, CEDLAS.

Ferrer-i-Carbonell, A. (2005), "Income and Well-being: An Empirical Analysis of the Comparison Income Effect", Journal of Public Economics, vol. 89, pp. 997-1019.

Helliwell, J. y Huang, H. (2009), "How's the Job? Well-Being and Social Capital in the Workplace", Industrial and Labor Relations Review, forthcoming.

Hirschman, A. y Rothschild M. (1973), “The Changing Tolerance for Income Inequality in the Course of Economic Development", Quarterly Journal of Economics, vol. 87 , pp. 544-566.

Kahneman, D., y Krueger, A.,(2006), "Developments in the Measurement of Subjective Well-Being", Journal of Economic Perspectives, vol. 20(1), pp. 3-24.

Karshenas, M. (2003), "Global poverty: National Accounts based versus survey based estimates", Development and Change, vol. 34(4). 
Kuznets, S. (1955), "Economic growth and income inequality", American Economic Review, vol. 45, pp. 1-28.

Londoño, J. y Székely, M. (2000), "Persistent poverty and excess inequality: Latin America 1970-1995”, Journal of Applied Economics, vol. 3(1), pp. 93-134.

Milanovic, B. (2002), “True World Income Distribution, 1988 and 1993: First Calculation Based on Household Surveys Alone”, Economic Journal, vol. 112(476), pp. $51-92$.

Milanovic, B. (2005), "Worlds Apart: Measuring International and Global Inequality", Princeton University Press.

Milanovic, B. (2009), "Global inequality recalculated: The effect of new 2005 PPP estimates on global inequality”, MPRA Paper N ${ }^{\circ}$ 16538, Librería de la Universidad de Munich, Alemania.

Morawetz D. (1977), "Income Distribution and Self-Rated Happiness: Some Empirical Evidence", The Economic Journal, vol. 87, pp. 511-522.

Pareto, V. (1897), “Cours d’èconomie politique”, Pichon, Paris.

Pinkovskiy, M. y Sala-i-Martin, X. (2009), "Parametric estimations of the world distribution of income", NBER Working Paper Nº 15433.

Ravallion, M. y Chen, S. (2007), “China’s (Uneven) Progress Against Poverty.” Journal of Development Economics, vol 82(1), pp. 1-42.

Ravallion, M. and Chen, S. (2008), “The Developing World Is Poorer Than We Thought, But No Less Successful in the Fight against Poverty". Policy Research Working Paper 4703. The World Bank.

Ravallion, M., Datt, G. and van de Walle, D. (1991), "Quantifying Absolute Poverty in the Developing World", Review of Income and Wealth vol. 37.

Sala-i-Martin, X. (2006), “The world distribution of income: falling poverty and ...convergence, period”, The Quarterly Journal of Economics vol. 121(2).

Schultz, T. (1998), "Inequality in the Distribution of Personal Income in the World: How it is Changing and Why", Journal of Population Economics, vol. 11(3), pp. 307-344. 
Schwarze J. and M. Härpfer (2007), “Are People Inequality Averse, and do they Prefer Redistribution by the State? Evidence from German Longitudinal Data on Life Satisfaction", Journal of Socio-Economics, vol. 36(2), pp. 233-249.

Senik, C. (2004), "When Information Dominates Comparison. Learning from Russian Subjective Panel Data”, Journal of Public Economics, vol. 88(9-10), pp. 20992133.

Senik, C. (2008), “Ambition and Jealousy. Income Interactions in the "Old Europe" versus the "New Europe" and the United States", Economica, vol. 75, pp. 495513.

Senik C. (2009), "Income Distribution and Subjective Happines, a Survey" OECD Social, Employment and Migration Working Papers N 96.

Stevenson, B. y Wolfers, J. (2008a), "Economic Growth and Subjective WellBeing: Reassessing the Easterlin Paradox”, NBER Working Paper $N^{\circ} 14820$,

Stevenson, B. y Wolfers, J. (2008b), "Happiness inequality in the United States", NBER Working Paper No 14220, 


\section{Tablas}

Tabla 2.1

\begin{tabular}{|c|c|c|c|c|c|c|c|c|c|}
\hline Artículo & Indicadores & 1988 & 1993 & 1998 & 2000 & 2002 & 2006 & Número de países & Fuentes de información \\
\hline \multirow{4}{*}{ Sala-I-Martin (2006) } & "Gini & 0.649 & 0.640 & $\begin{array}{l}0.638 \\
\end{array}$ & 0.637 & & & \multirow{4}{*}{138} & \multirow{6}{*}{$\begin{array}{c}\text { Basado en datos agregados } \\
\text { de distribución y Cuentas } \\
\text { Nacionales }\end{array}$} \\
\hline & Theil & 0.808 & 0.787 & 0.785 & 0.783 & & & & \\
\hline & within & $32.2 \%$ & $34.2 \%$ & $34.6 \%$ & $34.9 \%$ & & & & \\
\hline & between & $67.8 \%$ & $65.8 \%$ & $65.5 \%$ & $65.2 \%$ & & & & \\
\hline \multirow{2}{*}{$\begin{array}{l}\text { Pinkovskiy \& Sala-i- } \\
\text { Martin (2009) }\end{array}$} & Gini & $\begin{array}{l}0.648 \\
\end{array}$ & 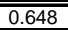 & 0.637 & (20.633 & 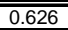 & 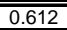 & \multirow{2}{*}{191} & \\
\hline & Theil & 0.797 & 0.802 & 0.785 & 0.774 & 0.751 & 0.706 & & \\
\hline \multirow{4}{*}{ Milanovic (2005) } & Gini & 0.619 & 0.652 & 0.642 & & & & \multirow{4}{*}{$\begin{array}{l}\text { Entre } 102 \text { y } 122 \\
\text { países ( } 86 \text { comunes } \\
\text { entre años) }\end{array}$} & \multirow{8}{*}{$\begin{array}{l}\text { Basado en microdatos de } \\
\text { encuestas de hogares }\end{array}$} \\
\hline & Theil & 0.715 & 0.818 & 0.792 & & & & & \\
\hline & within & $27.9 \%$ & $27.9 \%$ & $29.4 \%$ & & & & & \\
\hline & between & $72.1 \%$ & $72.1 \%$ & $70.6 \%$ & & & & & \\
\hline \multirow{4}{*}{ Milanovic (2009) } & $\begin{array}{l}\text { Gini (using } 1993 \mathrm{PPP}) \\
\end{array}$ & $\begin{array}{l}0.623 \\
\end{array}$ & 0.655 & $\begin{array}{l}0.644 \\
\end{array}$ & & (20.657 & & \multirow{4}{*}{$\begin{array}{l}\text { Entre } 103 \text { y } 124 \\
\text { países }\end{array}$} & \\
\hline & Gini (using 2005 PPP) & 0.684 & 0.699 & 0.694 & & 0.708 & & & \\
\hline & Theil (using 1993 PPP) & 0.715 & 0.812 & 0.791 & & 0.834 & & & \\
\hline & Theil (using 2005 PPP) & 0.875 & 0.937 & 0.942 & & 1.001 & & & \\
\hline
\end{tabular}

Tabla 3.1

Estadísticas demográficas básicas

Encuesta Mundial Gallup 2006

\begin{tabular}{|c|c|c|c|c|}
\hline & Observaciones & $\begin{array}{l}\text { Porcentaje } \\
\text { de Hombres }\end{array}$ & $\begin{array}{c}\text { Edad media del } \\
\text { encuestado }\end{array}$ & $\begin{array}{c}\text { Niños en el } \\
\text { Hogar }\end{array}$ \\
\hline Latinoamérica & 17,144 & $48.2 \%$ & 37.1 & 1.5 \\
\hline Argentina & 1,000 & $48.0 \%$ & 41.0 & 2.0 \\
\hline Bolivia & 1,000 & $49.8 \%$ & 35.6 & 1.9 \\
\hline Brasil & 1,029 & $48.3 \%$ & 36.7 & 1.3 \\
\hline Chile & 1,007 & $48.7 \%$ & 39.8 & 1.3 \\
\hline Colombia & 1,000 & $47.9 \%$ & 37.2 & 1.4 \\
\hline Costa Rica & 1,002 & $49.5 \%$ & 36.9 & 1.4 \\
\hline Ecuador & 1,067 & $48.9 \%$ & 37.5 & 1.7 \\
\hline El Salvador & 1,000 & $48.6 \%$ & 35.7 & 1.6 \\
\hline Guatemala & 1,021 & $47.1 \%$ & 36.0 & 1.8 \\
\hline Honduras & 1,000 & $48.6 \%$ & 34.1 & \\
\hline México & 1,007 & $47.2 \%$ & 36.1 & 2.0 \\
\hline Nicaragua & 1,001 & $48.5 \%$ & 34.7 & \\
\hline Panamá & 1,005 & $50.2 \%$ & 37.2 & 1.5 \\
\hline Paraguay & 1,001 & $47.3 \%$ & 37.5 & 2.0 \\
\hline Perú & 1,000 & $49.6 \%$ & 37.7 & 1.7 \\
\hline Uruguay & 1,004 & $47.4 \%$ & 43.3 & 1.0 \\
\hline Venezuela & 1,000 & $49.0 \%$ & 36.5 & 1.5 \\
\hline El Caribe & 4,056 & $48.4 \%$ & 38.4 & 1.2 \\
\hline Cuba & 1,000 & $48.1 \%$ & 41.3 & 0.9 \\
\hline República Dominicana & 1,000 & $49.1 \%$ & 36.9 & 1.7 \\
\hline Haití & 505 & $48.6 \%$ & 34.2 & 1.3 \\
\hline Jamaica & 543 & $48.6 \%$ & 38.1 & 1.0 \\
\hline Puerto Rico & 500 & $47.2 \%$ & 42.5 & 0.7 \\
\hline Trinidad y Tobago & 508 & $49.7 \%$ & 38.4 & 0.7 \\
\hline LAC & 21,200 & $48.2 \%$ & 37.2 & 1.5 \\
\hline \multicolumn{5}{|l|}{ Regiones Geográficas } \\
\hline Asia Oriental y el Pacífico & 19,630 & $48.8 \%$ & 42.1 & 1.0 \\
\hline Europa Orientral y Asia Central & 32,757 & $48.1 \%$ & 42.0 & 0.9 \\
\hline Norte de África y Medio Oriente & 15,837 & $53.3 \%$ & 33.9 & 1.5 \\
\hline Sur de Asia & 7,380 & $52.0 \%$ & 35.6 & 2.0 \\
\hline África Subsaharaniana & 26,506 & $49.0 \%$ & 34.3 & \\
\hline Europa Occidental & 16,073 & $48.0 \%$ & 47.0 & 0.6 \\
\hline Norte de América & 2,356 & $47.5 \%$ & 46.6 & 0.7 \\
\hline \multicolumn{5}{|l|}{ Regiones por Ingeso } \\
\hline Ingresos Altos: OECD & 23,559 & 0.481 & 46.7 & 0.6 \\
\hline Ingresos Altos: no OECD & 9,934 & 0.490 & 36.8 & 1.6 \\
\hline Ingresos Bajos & 37,429 & 0.511 & 35.1 & 2.0 \\
\hline Ingresos Medios-Bajos & 41,219 & 0.492 & 40.9 & 1.0 \\
\hline Ingresos Medios-Altos & 24,994 & 0.480 & 39.3 & 1.1 \\
\hline
\end{tabular}

Fuente: elaboración propia basada en microdatos de la EMG 2006 
Tabla 3.2

Porcentaje de observaciones urbanas

Encuesta Mundial Gallup 2006

\begin{tabular}{lcccc}
\hline \hline & \multicolumn{2}{c}{ Gallup } & \multirow{2}{*}{ Encuestas } & Censos \\
\cline { 2 - 3 } Latinoamérica & Def. 1 & Def. 2 & & \\
Argentina & 99.9 & 85.9 & solo urbana & 88.5 \\
Bolivia & 95.8 & 54.3 & 62.5 & 63.4 \\
Brasil & 81.8 & 72.8 & 82.8 & 82.2 \\
Chile & 99.0 & 84.3 & 86.6 & 86.3 \\
Colombia & 99.9 & 50.7 & 73.5 & 76.0 \\
Costa Rica & 84.1 & 55.5 & 59.0 & 60.0 \\
Ecuador & 97.6 & 60.0 & 66.3 & 63.9 \\
El Salvador & 72.0 & 53.7 & 59.7 & 62.4 \\
Guatemala & 94.8 & 36.1 & 45.5 & 40.3 \\
Honduras & 56.8 & 42.1 & 45.6 & 54.5 \\
México & 83.6 & 67.3 & 76.6 & 74.8 \\
Nicaragua & 81.1 & 51.8 & 55.8 & 56.9 \\
Panamá & 93.3 & 55.6 & 63.1 & 56.9 \\
Paraguay & 69.9 & 37.7 & 56.9 & 57.3 \\
Perú & 98.7 & 64.3 & 65.1 & 73.5 \\
Uruguay & 99.5 & 89.3 & 92.4 & 92.3 \\
Venezuela & 97.5 & 68.3 & & 87.4 \\
\hline El Caribe & & & & \\
Cuba & 100 & 100 & & 75.7 \\
República Dominican & 75.7 & 62.5 & 64.6 & 66.5 \\
Haití & 70.7 & 50.4 & 40.6 & 37.0 \\
Jamaica & 94.8 & 37.8 & 44.1 & 57.1 \\
Puerto Rico & 54.2 & 40.6 & & 74.9 \\
Trinidad y Tobago & 93.1 & 11.6 & & \\
\hline
\end{tabular}

Fuente: elaboración propia basada en microdatos de la EMG 2006 e información censal Nota: Se implementaron dos definiciones de urbano en la EMG clasificando alternativamente a quienes reportan vivir en un pequeño pueblo como urbano (definición 1) o rural (definición 2) 
Tabla 3.3

Encuestas Nacionales de Hogares de ALC usadas en este trabajo

\begin{tabular}{|c|c|c|c|c|}
\hline País & Nombre de la Encuesta & Sigla & Año & Observaciones \\
\hline \multicolumn{5}{|c|}{ Latinoamérica } \\
\hline \multicolumn{5}{|l|}{ Argentina } \\
\hline & Encuesta Permanente de Hogares-Continua & $\mathrm{EPH}-\mathrm{C}$ & 2006 & 99,726 \\
\hline \multicolumn{5}{|l|}{ Bolivia } \\
\hline & Encuesta Continua de Hogares- MECOVI & $\mathrm{ECH}$ & 2005 & 16,895 \\
\hline \multicolumn{5}{|c|}{ - } \\
\hline & Pesquisa Nacional por Amostra de Domicilios & PNAD & 2006 & 410,241 \\
\hline \multicolumn{5}{|c|}{${ }^{-1}$} \\
\hline & Encuesta de Caracterización Socioeconómica Nacional & CASEN & 2006 & 268,873 \\
\hline \multicolumn{5}{|l|}{ Colombia } \\
\hline & Encuesta Continua de Hogares & $\mathrm{ECH}$ & 2006 & 120,583 \\
\hline \multicolumn{5}{|l|}{ Costa Rica } \\
\hline & Encuesta de Hogares de Propósitos Múltiples & EHPM & 2006 & 45,139 \\
\hline \multicolumn{5}{|l|}{ Ecuador } \\
\hline & Encuesta de Empleo, Desempleo y Subempleo & ENEMDU & 2006 & 77,964 \\
\hline \multicolumn{5}{|c|}{ EI Salvador } \\
\hline Guatemala & Encuesta Nacional sobre Condiciones de Vida & ENCOVI & 2006 & 68,739 \\
\hline Honduras & Encuesta Permanente de Hogares de Propósitos Múltiples & EPHPM & 2006 & 99,645 \\
\hline mexico & Encuesta Nacional de Ingresos y Gastos de los Hogares & ENIGH & 2006 & 83,624 \\
\hline \multicolumn{5}{|c|}{ 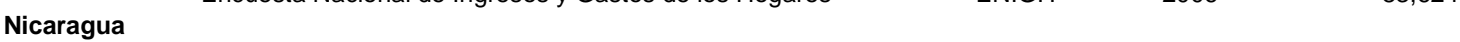 } \\
\hline \multicolumn{5}{|c|}{ Encuesta Nacional de Hogares sobre Medición de Nivel de Vida } \\
\hline \multirow{2}{*}{\multicolumn{5}{|c|}{ Encuesta de Hogares }} \\
\hline & & & & \\
\hline \multirow{2}{*}{\multicolumn{5}{|c|}{ the }} \\
\hline & & & & \\
\hline \multirow{2}{*}{ Uruguay } & & & & \\
\hline & Encuesta Continua de Hogares & $\mathrm{ECH}$ & 2006 & 256,866 \\
\hline Venezuela & Encuesta de Hogares Por Muestreo & EHM & 2005 & 165,079 \\
\hline \multicolumn{5}{|c|}{$\begin{array}{l}\text { El Caribe } \\
\text { R. Dominicana }\end{array}$} \\
\hline \multirow{2}{*}{ Haití } & Encuesta Nacional de Fuerza de Trabajo & ENFT & 2006 & 28,655 \\
\hline & Enquête sur les Conditions de Vie en Haïti & $\mathrm{ECVH}$ & 2001 & 33,007 \\
\hline & Jamaica Survey of Living Conditions & JSLC & 2002 & 18,943 \\
\hline
\end{tabular}

Fuente: CEDLAS 
Tabla 4.1

Ingresos mensuales en la EMG

América Latina y el Caribe, 2006

Estimaciones propias en US\$ PPP en base a la pregunta original

\begin{tabular}{|c|c|c|c|c|c|c|}
\hline & \multicolumn{3}{|c|}{ Ingreso total familiar } & \multicolumn{3}{|c|}{ Ingreso per cápita familiar } \\
\hline & Media & Mediana & respuestas (\%) & Media & Mediana & respuestas (\%) \\
\hline Latinoamérica & 703 & 487 & $86.5 \%$ & 174 & 109 & $85.4 \%$ \\
\hline Argentina & 904 & 720 & $80.4 \%$ & 208 & 171 & $80.4 \%$ \\
\hline Bolivia & 365 & 239 & $89.9 \%$ & 81 & 49 & $88.9 \%$ \\
\hline Brasil & 754 & 524 & $96.0 \%$ & 209 & 130 & $96.0 \%$ \\
\hline Chile & 1,333 & 733 & $87.1 \%$ & 321 & 176 & $85.0 \%$ \\
\hline Costa Rica & 972 & 779 & $79.7 \%$ & 229 & 170 & $79.5 \%$ \\
\hline Ecuador & 519 & 386 & $98.1 \%$ & 112 & 75 & $98.0 \%$ \\
\hline El Salvador & 550 & 416 & $83.4 \%$ & 123 & 84 & $83.1 \%$ \\
\hline Guatemala & 406 & 319 & $86.1 \%$ & 86 & 62 & $85.4 \%$ \\
\hline Honduras & 1,029 & 976 & $66.9 \%$ & 213 & 200 & $66.9 \%$ \\
\hline México & 548 & 427 & $78.4 \%$ & 117 & 86 & $75.2 \%$ \\
\hline Nicaragua & 647 & 537 & $80.8 \%$ & 113 & 95 & $79.2 \%$ \\
\hline Panamá & 588 & 397 & $97.4 \%$ & 138 & 82 & $96.6 \%$ \\
\hline Paraguay & 657 & 423 & $95.8 \%$ & 135 & 71 & $90.1 \%$ \\
\hline Perú & 478 & 360 & $87.4 \%$ & 101 & 69 & $87.1 \%$ \\
\hline Uruguay & 918 & 661 & $93.3 \%$ & 275 & 178 & $93.0 \%$ \\
\hline Venezuela & 738 & 468 & $81.8 \%$ & 166 & 91 & $81.4 \%$ \\
\hline El Caribe & 706 & 400 & $82.9 \%$ & 187 & 97 & $82.2 \%$ \\
\hline Cuba & 463 & 442 & $92.8 \%$ & 124 & 114 & $92.8 \%$ \\
\hline República Dominicana & 693 & 401 & $84.8 \%$ & 162 & 86 & $83.1 \%$ \\
\hline Haití & 301 & 212 & $93.1 \%$ & 73 & 47 & $92.9 \%$ \\
\hline Jamaica & 1,278 & 828 & $64.1 \%$ & 359 & 205 & $64.1 \%$ \\
\hline Puerto Rico & 2,020 & 1,204 & $91.4 \%$ & 578 & 346 & $91.2 \%$ \\
\hline Trinidad y Tobago & 962 & 735 & $61.4 \%$ & 273 & 190 & $59.4 \%$ \\
\hline LAC & 703 & 477 & $85.8 \%$ & 175 & 108 & $84.8 \%$ \\
\hline
\end{tabular}

Fuente: Elaboración propia basada en microdatos de la EMG 2006.

\section{Tabla 4.2}

Variables seleccionadas por categoría de no respuesta de ingresos

\begin{tabular}{|c|c|c|c|c|c|c|c|c|c|c|c|c|c|c|c|c|c|c|c|c|c|}
\hline & \multirow{2}{*}{\multicolumn{3}{|c|}{$\%$ de Hombres }} & \multirow{2}{*}{\multicolumn{3}{|c|}{$\%$ Urbano }} & \multicolumn{15}{|c|}{ \% de acceso a servicios de: } \\
\hline & & & & & & & & Agua & & & lectricida & & & Teléfono & & & mputad & & & Internet & \\
\hline & Si & No & t-test & Si & No & t-test & $\mathrm{Si}$ & No & t-test & $\mathrm{Si}$ & No & t-test & $\mathrm{Si}$ & No & t-test & & No & t-test & $\mathrm{Si}$ & No & $\overline{\text { t-test }}$ \\
\hline Latinoamérica & $43.9 \%$ & $43.1 \%$ & 0.70 & $90.2 \%$ & $87.4 \%$ & 3.65 & $90.2 \%$ & $90.6 \%$ & -0.57 & $95.5 \%$ & $93.2 \%$ & 4.03 & $53.2 \%$ & $60.4 \%$ & -6.39 & $19.8 \%$ & $26.7 \%$ & -6.82 & $8.2 \%$ & $12.1 \%$ & -5.34 \\
\hline Argentina & $38.3 \%$ & $31.1 \%$ & 1.92 & $99.9 \%$ & $100 \%$ & -1.00 & $95.1 \%$ & $95.4 \%$ & -0.14 & $99.1 \%$ & $99.0 \%$ & 0.20 & $55.3 \%$ & $77.4 \%$ & -6.35 & $25.7 \%$ & $37.1 \%$ & -2.99 & $12.1 \%$ & $21.2 \%$ & -2.89 \\
\hline Costa Rica & $49.2 \%$ & $49.8 \%$ & -0.14 & $83.3 \%$ & $91.0 \%$ & -3.20 & $95.7 \%$ & $99.0 \%$ & -3.28 & $99.6 \%$ & $99.5 \%$ & 0.22 & $72.1 \%$ & $83.3 \%$ & -3.65 & $23.8 \%$ & $42.9 \%$ & -5.03 & $8.8 \%$ & $16.3 \%$ & -2.69 \\
\hline El salvador & $49.8 \%$ & $48.6 \%$ & 0.25 & $73.3 \%$ & $69.9 \%$ & 0.83 & $81.7 \%$ & $88.4 \%$ & -2.23 & $93.4 \%$ & $92.5 \%$ & 0.42 & $59.7 \%$ & $71.7 \%$ & -2.92 & $13.2 \%$ & $11.6 \%$ & 0.55 & $3.9 \%$ & $2.8 \%$ & 0.74 \\
\hline Honduras & $49.2 \%$ & $50.2 \%$ & -0.29 & $58.6 \%$ & $58.9 \%$ & -0.10 & $88.2 \%$ & $73.6 \%$ & 5.31 & $74.4 \%$ & $68.6 \%$ & 1.90 & $24.7 \%$ & $28.0 \%$ & -1.10 & $9.7 \%$ & $9.4 \%$ & 0.18 & $2.3 \%$ & $1.8 \%$ & 0.45 \\
\hline México & $45.6 \%$ & $42.2 \%$ & 0.90 & $87.2 \%$ & $82.5 \%$ & 1.59 & $94.0 \%$ & $96.3 \%$ & -1.48 & $98.7 \%$ & $99.5 \%$ & -1.33 & $54.3 \%$ & $49.8 \%$ & 1.17 & $18.0 \%$ & $20.9 \%$ & -0.92 & $8.1 \%$ & $10.1 \%$ & -0.89 \\
\hline Venezuela & $39.0 \%$ & $39.6 \%$ & -0.14 & $97.2 \%$ & $99.4 \%$ & -2.62 & $96.9 \%$ & $97.3 \%$ & -0.23 & $98.4 \%$ & $98.4 \%$ & 0.06 & $65.0 \%$ & $56.6 \%$ & 2.09 & $29.9 \%$ & $30.3 \%$ & -0.11 & $11.1 \%$ & $11.6 \%$ & -0.18 \\
\hline El Caribe & $47.2 \%$ & $44.6 \%$ & 1.24 & $82.8 \%$ & $88.0 \%$ & -3.61 & $83.3 \%$ & $90.0 \%$ & -5.07 & $94.6 \%$ & $97.5 \%$ & -4.01 & $46.4 \%$ & $54.0 \%$ & -3.64 & $19.0 \%$ & $27.8 \%$ & -4.77 & $11.0 \%$ & $18.5 \%$ & -4.71 \\
\hline Jamaica & $50.9 \%$ & $45.1 \%$ & 1.28 & $94.3 \%$ & $93.8 \%$ & 0.19 & $99.1 \%$ & $97.4 \%$ & 1.38 & $98.9 \%$ & $100 \%$ & -2.01 & $42.7 \%$ & $55.4 \%$ & -2.86 & $38.2 \%$ & $40.5 \%$ & -0.52 & $37.6 \%$ & $37.9 \%$ & -0.07 \\
\hline Trinidad \& & $51.9 \%$ & $46.9 \%$ & 1.10 & $91.7 \%$ & $95.8 \%$ & -1.94 & $88.5 \%$ & $94.3 \%$ & -2.36 & $97.1 \%$ & $99.5 \%$ & -2.19 & $68.9 \%$ & $69.6 \%$ & -0.16 & $22.6 \%$ & $25.8 \%$ & -0.80 & $13.7 \%$ & $10.8 \%$ & 0.97 \\
\hline LAC & $44.5 \%$ & $43.4 \%$ & 1.05 & $88.8 \%$ & $87.5 \%$ & 1.93 & $88.9 \%$ & $90.4 \%$ & -2.54 & $95.3 \%$ & $94.2 \%$ & 2.37 & $51.9 \%$ & $58.9 \%$ & -6.99 & 19.7 & $27.0 \%$ & -8.25 & $8.7 \%$ & $13.6 \%$ & -7.28 \\
\hline
\end{tabular}

Fuente: Elaboración propia basada en microdatos de la EMG 2006.

Nota: La columna "Si" reporta medias de cada variable para quienes respondieron la pregunta de ingreso. La columna "No" muestra las medias de cada variable para quienes no reportaron ingresos. El test t, muestra el valor $t$ del test de medias entre quienes respondieron y no respondieron ingresos

Los países seleccionados fueron aquellos con que poseen un porcentaje de no respuesta de ingresos mayor al $15 \%$ 
Tabla 4.3

Ingreso per cápita en moneda local

Media, mediana y porcentajes del ingreso por quintil

\begin{tabular}{|c|c|c|c|c|c|c|c|c|}
\hline & & & & & $\%$ del & reso p & quintil & \\
\hline & & Media & Mediana & 1 & 2 & 3 & 4 & 5 \\
\hline Latinoamérica & & & & & & & & \\
\hline Argentina & EMG & 227 & 188 & 4.9 & 9.8 & 16.2 & 22.5 & 46.6 \\
\hline & ENH & 527 & 357 & 3.4 & 8.2 & 13.6 & 22.0 & 52.8 \\
\hline Bolivia & EMG & 242 & 147 & 2.5 & 7.3 & 12.1 & 20.2 & 57.9 \\
\hline Duivia & ENH & 539 & 286 & 1.8 & 6.2 & 10.9 & 19.6 & 61.6 \\
\hline Rracil $>$ & EMG & 251 & 156 & 3.0 & 7.4 & 12.4 & 21.1 & 56.1 \\
\hline Brasil & ENH & 534 & 295 & 2.6 & 6.6 & 11.2 & 18.7 & 60.9 \\
\hline Chile & EMG & 95,426 & 52,184 & 3.0 & 6.6 & 10.9 & 18.9 & 60.5 \\
\hline & ENH & 180,810 & 105,851 & 4.2 & 7.8 & 11.8 & 18.7 & 57.5 \\
\hline Costa Rica & EMG & 44,586 & 33,010 & 2.6 & 8.6 & 14.8 & 23.7 & 50.4 \\
\hline & ENH & 103,015 & 65,462 & 3.9 & 8.4 & 12.8 & 20.1 & 54.8 \\
\hline Fcuador & EMG & 60 & 40 & 4.2 & 9.1 & 13.5 & 21.0 & 52.2 \\
\hline Ecuador & ENH & 138 & 82 & 3.6 & 7.6 & 11.9 & 19.1 & 57.8 \\
\hline El Salvador & EMG & 63 & 43 & 3.5 & 8.3 & 13.7 & 21.0 & 53.5 \\
\hline & ENH & 121 & 83 & 4.6 & 9.2 & 13.8 & 20.7 & 51.7 \\
\hline Guatemala & EMG & 395 & 287 & 3.9 & 9.3 & 14.8 & 21.9 & 50.1 \\
\hline Muateritala & ENH & 974 & 579 & 3.5 & 7.3 & 12.0 & 19.2 & 58.1 \\
\hline Honduras & EMG & 1,505 & 1,413 & 1.3 & 11.1 & 18.6 & 27.1 & 41.9 \\
\hline moriunias & ENH & 1,862 & 1,100 & 2.3 & 6.7 & 12.0 & 20.0 & 59.0 \\
\hline México & EMG & 840 & 615 & 3.2 & 9.0 & 15.0 & 23.5 & 49.4 \\
\hline Tivexico s s & ENH & 2,418 & 1,520 & 3.7 & 8.2 & 12.7 & 19.7 & 55.6 \\
\hline Nicaraqua & EMG & 540 & 455 & 4.8 & 10.7 & 16.5 & 24.9 & 43.1 \\
\hline & ENH & 1,220 & 743 & 3.8 & 7.7 & 12.2 & 19.2 & 57.0 \\
\hline Panamá & EMG & 89 & 53 & 1.7 & 6.3 & 11.9 & 21.4 & 58.6 \\
\hline rallana & ENH & 182 & 105 & 2.5 & 6.8 & 11.7 & 20.1 & 58.9 \\
\hline Paraquav & EMG & 213,709 & 111,538 & 2.0 & 5.5 & 10.7 & 20.9 & 60.9 \\
\hline ralaguay & ENH & 539,205 & 315,036 & 3.0 & 7.1 & 11.8 & 19.1 & 59.0 \\
\hline Perú & EMG & 139 & 96 & 2.8 & 7.8 & 13.8 & 22.0 & 53.6 \\
\hline & ENH & 366 & 237 & 4.0 & 8.0 & 13.0 & 20.7 & 54.3 \\
\hline Uruquay & EMG & 2,879 & 1,860 & 3.3 & 7.4 & 13.0 & 21.6 & 54.7 \\
\hline Uiviguay & ENH & 6,474 & 4,406 & 4.6 & 8.8 & 13.7 & 21.4 & 51.6 \\
\hline Venezuela & EMG & 298,695 & 163,116 & 2.0 & 7.0 & 11.2 & 19.5 & 60.2 \\
\hline & ENH & 280,529 & 194,157 & 2.8 & 8.6 & 13.9 & 21.8 & 52.9 \\
\hline El Caribe & & & & & & & & \\
\hline Ren Dominicana & EMG & 2,156 & 1,143 & 2.3 & 6.1 & 10.6 & 18.8 & 62.1 \\
\hline nep, comminara & ENH & 5,903 & 3,505 & 4.0 & 7.7 & 12.0 & 19.4 & 56.9 \\
\hline Haití & EMG & 1,077 & 692 & 2.7 & 7.8 & 13.2 & 20.3 & 56.0 \\
\hline & ENH & 1,326 & 684 & 2.4 & 6.2 & 10.4 & 17.6 & 63.4 \\
\hline Jamaica & EMG & 16,007 & 9,123 & 2.8 & 6.3 & 11.9 & 19.7 & 59.4 \\
\hline & ENH & 10,302 & 5,198 & 0.1 & 3.2 & 10.1 & 20.1 & 66.5 \\
\hline
\end{tabular}

Fuente: Elaboración propia basada en microdatos de la EMG 2006 y ENH. 
Tabla 4.4

Ranking de países de ALC

Ordenando por Media y Mediana del ingreso per cápita familiar (en Dólares a PPP)

\begin{tabular}{|c|c|c|c|c|}
\hline & \multicolumn{2}{|c|}{ Ranking por medias } & \multicolumn{2}{|c|}{ Ranking por medianas } \\
\hline & EMG & ENH & EMG & ENH \\
\hline 1 & Jamaica & Uruguay & Jamaica & Uruguay \\
\hline 2 & Chile & Chile & Honduras & Chile \\
\hline 3 & Uruguay & Costa Rica & Uruguay & Costa Rica \\
\hline 4 & Costa Rica & Argentina & Chile & Argentina \\
\hline 5 & Honduras & Brasil & Argentina & R. Dominicana \\
\hline 6 & Brasil & R. Dominicana & Costa Rica & Brasil \\
\hline 7 & Argentina & Paraguay & Brasil & México \\
\hline 8 & Venezuela & México & Nicaragua & Paraguay \\
\hline 9 & R. Dominicana & Panamá & Venezuela & Peru \\
\hline 10 & Panamá & Peru & México & Panamá \\
\hline 11 & Paraguay & Honduras & R. Dominicana & El Salvador \\
\hline 12 & El Salvador & Ecuador & El Salvador & Honduras \\
\hline 13 & México & Nicaragua & Panamá & Nicaragua \\
\hline 14 & Nicaragua & El Salvador & Ecuador & Ecuador \\
\hline 15 & Ecuador & Jamaica & Paraguay & Guatemala \\
\hline 16 & Peru & Guatemala & Peru & Jamaica \\
\hline 17 & Guatemala & Bolivia & Guatemala & Venezuela \\
\hline 18 & Bolivia & Venezuela & Bolivia & Bolivia \\
\hline 19 & Haití & Haití & Haití & Haití \\
\hline
\end{tabular}

B. Sin los principales outliers

\begin{tabular}{rlllll}
\hline \hline & \multicolumn{2}{c}{ Ranking por medias } & & \multicolumn{2}{c}{ Ranking por medianas } \\
\cline { 2 - 3 } \cline { 5 - 5 } & \multicolumn{2}{c}{ EMG } & ENH & & \multicolumn{2}{c}{ EMG } & ENH \\
\hline 1 & Chile & Uruguay & & Uruguay & Uruguay \\
2 & Uruguay & Chile & & Chile & Chile \\
3 & Costa Rica & Costa Rica & & Argentina & Costa Rica \\
4 & Brasil & Argentina & & Costa Rica & Argentina \\
5 & Argentina & Brasil & & Brasil & R. Dominicana \\
6 & R. Dominicana & R. Dominicana & & Nicaragua & Brasil \\
7 & Panamá & Paraguay & & México & México \\
8 & Paraguay & México & & R. Dominicana & Paraguay \\
9 & El Salvador & Panamá & & El Salvador & Peru \\
10 & México & Peru & & Panamá & Panamá \\
11 & Nicaragua & Ecuador & & Ecuador & El Salvador \\
12 & Ecuador & Nicaragua & & Paraguay & Nicaragua \\
13 & Peru & El Salvador & & Peru & Ecuador \\
14 & Guatemala & Guatemala & & Guatemala & Guatemala \\
15 & Bolivia & Bolivia & Bolivia & Bolivia \\
16 & Haití & Haití & Haití & Haití \\
\hline
\end{tabular}

Fuente: Elaboración propia basada en microdatos de la EMG 2006 y ENH. 
Tabla 4.5

Ranking de países de ALC

Ordenando por PBI per cápita e ingreso per cápita familiar (en Dólares a PPP)

\begin{tabular}{rll}
\hline \hline & \multicolumn{1}{c}{ PBI (CN) } & Ingreso (EMG) \\
\hline 1 & Trinidad \& Tobago & Chile \\
2 & Argentina & Uruguay \\
3 & Chile & Trinidad \& Tobago \\
4 & Costa Rica & Costa Rica \\
5 & México & Brasil \\
6 & Uruguay & Argentina \\
7 & Brasil & Venezuela \\
8 & Panamá & R. Dominicana \\
9 & R. Dominicana & Panamá \\
10 & Venezuela & Paraguay \\
11 & Perú & El Salvador \\
12 & Paraguay & México \\
13 & El Salvador & Nicaragua \\
14 & Ecuador & Ecuador \\
15 & Guatemala & Perú \\
16 & Nicaragua & Guatemala \\
17 & Bolivia & Bolivia \\
18 & Haiti & Haiti \\
\hline
\end{tabular}

Fuente: Elaboración propia basada en microdatos de la EMG 2006 y datos de Cuentas Nacionales de WEO.

Tabla 4.6

Ingresos anuales en la EMG 2006 y PBI

Ingreso en dólares PPP de la variable categórica estandarizada por Gallup

\begin{tabular}{|c|c|c|c|c|c|c|c|}
\hline & \multirow{2}{*}{\multicolumn{3}{|c|}{ Ingreso total familiar }} & \multirow{2}{*}{\multicolumn{3}{|c|}{ Ingreso per cápita familiar }} & \multirow{3}{*}{$\begin{array}{c}\text { PBI per cápita en } \\
2006 \text { (PPP) } \\
\end{array}$} \\
\hline & & & & & & & \\
\hline & Media & Mediana & respuestas (\%) & Media & Mediana & respuestas (\%) & \\
\hline Latinoamérica & 8,573 & 5,018 & 0.87 & 2,870 & 1,621 & 0.87 & 9,873 \\
\hline El Caribe & 8,136 & 4,615 & 0.83 & 2,999 & 1,558 & 0.83 & 7,998 \\
\hline LAC & 8,542 & 4,979 & 0.87 & 2,879 & 1,617 & 0.86 & 9,740 \\
\hline \multicolumn{8}{|l|}{ Regiones Geográficas } \\
\hline Asia Oriental y el Pacífico & 12,039 & 6,209 & 0.85 & 4,632 & 2,190 & 0.84 & 7,297 \\
\hline Europa Orientral y Asia Central & 11,509 & 7,586 & 0.83 & 4,461 & 2,827 & 0.79 & 11,134 \\
\hline Norte de África y Medio Oriente & 35,728 & 30,770 & 0.11 & 13,623 & 12,008 & 0.11 & 8,242 \\
\hline Sur de Asia & 8,061 & 3,361 & 0.83 & 2,557 & 1,385 & 0.79 & 2,184 \\
\hline África Subsaharaniana & 5,773 & 2,464 & 0.88 & & & & \\
\hline Europa Occidental & 32,392 & 28,009 & 0.75 & 13,466 & 10,631 & 0.75 & 32,143 \\
\hline Norte de América & 55,820 & 42,526 & 0.91 & 21,932 & 15,744 & 0.91 & 43,371 \\
\hline \multicolumn{8}{|l|}{ Regiones por Ingeso } \\
\hline Ingresos Altos: OECD & 41,796 & 30,818 & 0.79 & 16,824 & 11,907 & 0.79 & 35,536 \\
\hline Ingresos Altos: no OECD & 31,683 & 21,229 & 0.55 & 12,444 & 8,127 & 0.55 & 28,350 \\
\hline Ingresos Bajos & 7,575 & 3,336 & 0.86 & 2,666 & 1,430 & 0.32 & 1,920 \\
\hline Ingresos Medios-Bajos & 9,223 & 5,751 & 0.70 & 3,523 & 1,957 & 0.64 & 4,802 \\
\hline Ingresos Medios-Altos & 11,178 & 7,110 & 0.75 & 3,957 & 2,333 & 0.68 & 11,728 \\
\hline
\end{tabular}

Fuente: Elaboración propia basada en microdatos de la EMG 2006 y datos de Cuentas Nacionales de WEO. 
Tabla 5.1

Desigualdad en ALC

Coeficientes de Gini, 2006

\begin{tabular}{lccc}
\hline \hline & EMG & ENH & diferencia \\
\hline Latinoamérica & & & \\
Argentina & 0.415 & 0.483 & -0.068 \\
Bolivia & 0.540 & 0.601 & -0.061 \\
Brasil & 0.522 & 0.564 & -0.042 \\
Chile & 0.556 & 0.546 & 0.010 \\
Costa Rica & 0.474 & 0.492 & -0.018 \\
Ecuador & 0.469 & 0.535 & -0.066 \\
El Salvador & 0.490 & 0.494 & -0.004 \\
Guatemala & 0.455 & 0.524 & -0.069 \\
México & 0.459 & 0.510 & -0.051 \\
Panamá & 0.558 & 0.548 & 0.010 \\
Paraguay & 0.578 & 0.539 & 0.039 \\
Perú & 0.502 & 0.498 & 0.004 \\
Uruguay & 0.506 & 0.450 & 0.056 \\
Venezuela & 0.564 & 0.476 & 0.088 \\
\hline El Caribe & & & \\
Cuba & 0.357 & n.a & \\
R. Dominicana & 0.584 & 0.519 & 0.065 \\
Haití & 0.525 & 0.592 & -0.068 \\
Jamaica & 0.555 & 0.479 & 0.076 \\
Puerto Rico & 0.532 & n.a & \\
Trinidad y Tobago & 0.474 & n.a & \\
\hline Fuente: Elaboración propia basada en microdatos de la EMG 2006 y ENH.
\end{tabular}

Tabla 5.2

Desigualdad en el Mundo

Coeficientes de Gini para las regiones del mundo, desigualdad global y promedio entre países de la desigualdad nacional

\begin{tabular}{lcc}
\hline \hline & Global & $\begin{array}{c}\text { Promedio } \\
\text { entre países }\end{array}$ \\
\hline Latinoamérica & 0.525 & 0.499 \\
El Caribe & 0.591 & 0.456 \\
LAC & 0.530 & 0.486 \\
\hline Regiones Geográficas & & \\
Asia Oriental y el Pacífico & 0.594 & 0.471 \\
Europa Orientral y Asia Central & 0.497 & 0.418 \\
Sur de Asia & 0.534 & 0.489 \\
Europa Occidental & 0.402 & 0.340 \\
Norte de América & 0.438 & 0.392 \\
\hline Regiones por Ingeso & & \\
Ingresos Altos: OECD & 0.448 & 0.358 \\
Ingresos Altos: no OECD & 0.484 & 0.417 \\
Ingresos Bajos & 0.536 & 0.511 \\
Ingresos Medios-Bajos & 0.558 & 0.464 \\
Ingresos Medios-Altos & 0.521 & 0.431 \\
\hline Fut
\end{tabular}

Fuente: Elaboración propia basada en microdatos de la EMG 2006. 
Tabla 5.3

Desigualdad en el mundo

Indicadores de desigualdad global por regiones

\begin{tabular}{lccccccccc}
\hline & Gini & CV & Theil & Decil 10/Decil 1 & ATK e=0.5 & ATK e=1 & ATK e=2 & GE(0) & GE(2) \\
\hline Latinoamérica & 0.525 & 1.316 & 0.510 & 34.2 & 0.225 & 0.390 & 0.614 & 29.316 & 0.866 \\
El Caribe & 0.591 & 1.792 & 0.713 & 85.5 & 0.299 & 0.469 & 0.708 & 196.938 & 1.606 \\
LAC & 0.530 & 1.360 & 0.526 & 36.7 & 0.231 & 0.396 & 0.622 & 41.572 & 0.924 \\
\hline Regiones Geográficas & & & & & & & & & \\
Asia Oriental y el Pacífico & 0.594 & 1.685 & 0.699 & 61.5 & 0.292 & 0.494 & 0.819 & 0.726 & 1.420 \\
Europa Orientral y Asia Central & 0.497 & 1.120 & 0.435 & 38.6 & 0.205 & 0.381 & 0.702 & 22.298 & 0.628 \\
Sur de Asia & 0.534 & 1.551 & 0.553 & 22.4 & 0.233 & 0.391 & 0.572 & 17.107 & 1.203 \\
Europa Ocidental & 0.402 & 0.886 & 0.285 & 14.9 & 0.133 & 0.250 & 0.449 & 0.288 & 0.393 \\
Norte de América & 0.438 & 0.885 & 0.322 & 18.1 & 0.157 & 0.301 & 0.525 & 0.358 & 0.391 \\
\hline Regiones por Ingeso & & & & & & & & \\
Ingresos Altos: OECD & 0.448 & 0.946 & 0.341 & 18.8 & 0.161 & 0.301 & 0.511 & 0.358 & 0.448 \\
Ingresos Altos: no OECD & 0.484 & 1.135 & 0.424 & 27.7 & 0.192 & 0.337 & 0.556 & 44.133 & 0.644 \\
Ingresos Bajos & 0.536 & 1.523 & 0.551 & 24.8 & 0.234 & 0.396 & 0.588 & 16.336 & 1.160 \\
Ingresos Medios-Bajos & 0.558 & 1.700 & 0.630 & 49.6 & 0.261 & 0.448 & 0.790 & 9.422 & 1.445 \\
Ingresos Medios-Altos & 0.521 & 1.235 & 0.487 & 32.6 & 0.220 & 0.391 & 0.625 & 6.482 & 0.763 \\
\hline
\end{tabular}

Fuente: Elaboración propia basada en microdatos de la EMG 2006.

$\mathrm{CV}=$ Coeficiente de variación. ATK $(e)$ indica al índice de Atkinson con una función CES con parámetro $e$. $\mathrm{GE}(e)$ indica el índice de entropía generalizado con parámetro $e$. $\mathrm{GE}(1)=$ Theil.

Tabla 5.4

Desigualdad por regiones

Descomposición por país del índice de Theil

\begin{tabular}{lcccc}
\hline \hline & Theil & $\begin{array}{c}\text { Dentro de } \\
\text { los países }\end{array}$ & Entre países & $\begin{array}{c}\text { \% entre } \\
\text { países }\end{array}$ \\
\hline Latinoamérica & 0.510 & 0.468 & 0.042 & $8.2 \%$ \\
El Caribe & 0.713 & 0.378 & 0.335 & $47.0 \%$ \\
LAC & 0.526 & 0.461 & 0.064 & $12.2 \%$ \\
\hline Regiones Geográficas & & & & \\
Asia Oriental y el Pacífico & 0.699 & 0.473 & 0.226 & $32.4 \%$ \\
Europa Orientral y Asia Central & 0.435 & 0.321 & 0.114 & $26.3 \%$ \\
Middle East \& North Africa & 0.165 & 0.155 & 0.010 & $5.9 \%$ \\
Sur de Asia & 0.553 & 0.549 & 0.004 & $0.6 \%$ \\
Europa Occidental & 0.285 & 0.223 & 0.061 & $21.5 \%$ \\
Norte de América & 0.322 & 0.322 & 0.000 & $0.0 \%$ \\
\hline Regiones por Ingeso & & & & \\
Ingresos Altos: OECD & 0.341 & 0.289 & 0.052 & $15.3 \%$ \\
Ingresos Altos: no OECD & 0.424 & 0.357 & 0.068 & $15.9 \%$ \\
Ingresos Bajos & 0.551 & 0.532 & 0.019 & $3.5 \%$ \\
Ingresos Medios-Bajos & 0.630 & 0.520 & 0.110 & $17.5 \%$ \\
Ingresos Medios-Altos & 0.487 & 0.396 & 0.092 & $18.8 \%$ \\
\hline
\end{tabular}

Fuente: Elaboración propia basada en microdatos de la EMG 2006.

Tabla 5.5

Desigualdad en el Mundo

Theil descomposiciones a nivel mundial

\begin{tabular}{lcccc}
\hline \hline & Theil & $\begin{array}{c}\text { Dentro del } \\
\text { grupo }\end{array}$ & $\begin{array}{c}\text { Entre } \\
\text { grupos }\end{array}$ & $\begin{array}{c}\% \text { entre } \\
\text { grupos }\end{array}$ \\
\hline Por regiones geográficas & & 0.485 & 0.285 & $37.0 \%$ \\
Por regiones de ingreso & 0.769 & 0.449 & 0.315 & $41.2 \%$ \\
Por países & & 0.390 & 0.380 & $49.4 \%$ \\
\hline
\end{tabular}

Fuente: Elaboración propia basada en microdatos de la EMG 2006. 
Tabla 6.1

Desigualdad internacional del bienestar subjetivo

Coeficientes de correlación

\begin{tabular}{|c|c|c|c|c|c|c|}
\hline & \multicolumn{3}{|c|}{ Correlación simple } & \multicolumn{3}{|c|}{ Correlación ponderando por población } \\
\hline & Figura 6.1 & Figura 6.2 & Figura 6.3 & Figura 6.1 & Figura 6.2 & Figura 6.3 \\
\hline \multirow{2}{*}{ Todo el mundo } & $0.701^{\star \star \star}$ & $0.816^{\star \star \star}$ & $0.354^{\star \star \star}$ & $0.675^{\star \star \star}$ & $0.75^{\star \star \star}$ & $0.566^{\star \star \star}$ \\
\hline & 0.000 & 0.000 & 0.001 & 0.000 & 0.000 & 0.000 \\
\hline \multirow{2}{*}{ Latinoamérica } & 0.444 & $0.634^{\star \star}$ & 0.237 & $0.467^{\star}$ & $0.564^{\star \star}$ & 0.380 \\
\hline & 0.112 & 0.015 & 0.415 & 0.092 & 0.036 & 0.180 \\
\hline \multirow{2}{*}{ El Caribe } & $0.931^{\star \star *}$ & $0.916^{* *}$ & 0.354 & $0.913^{* *}$ & $0.948^{\star \star \star}$ & 0.598 \\
\hline & 0.007 & 0.010 & 0.491 & 0.011 & 0.004 & 0.210 \\
\hline \multirow{2}{*}{ LAC } & $0.564^{\star \star}$ & $0.73^{\star \star \star}$ & 0.070 & $0.537^{\star *}$ & $0.692^{\star \star \star}$ & 0.169 \\
\hline & 0.010 & 0.000 & 0.771 & 0.015 & 0.001 & 0.476 \\
\hline
\end{tabular}

Fuente: Elaboración propia basada en microdatos de la EMG 2006.

Tabla 6.2

Desigualdad internacional del bienestar subjetivo

Regresiones entre Desigualdad del bienestar subjetivo y el ingreso

Variable dependiente:

Coef. de Gini del bienestar subjetivo

\begin{tabular}{r|cc|cc}
\cline { 2 - 5 } & \multicolumn{2}{|c|}{ Sin ponderar } & Ponderando por población \\
\hline Log del ipcf & 0.174 & & 0.269 & \\
Log del ipcf al & $(1.92)^{\star}$ & & $(2.76)^{\star * *}$ & \\
cuadrado & -0.012 & & -0.017 & \\
Log del PBIpc & $(2.29)^{\star *}$ & & $(3.09)^{\star * *}$ & 0.167 \\
Log del PBIpc al & & 0.140 & & $(4.60)^{\star * *}$ \\
cuadrado & & $(3.76)^{\star \star *}$ & & -0.011 \\
Constant & -0.399 & -0.009 & & $(5.14)^{\star * *}$ \\
& $(1.04)$ & $(4.35)^{\star * *}$ & & -0.436 \\
Observations & 88 & -0.284 & -0.838 & $(2.76)^{\star * *}$ \\
R-squared & 0.40 & 0.39 & $(1.98)^{\star}$ & 127 \\
\hline
\end{tabular}

Estadísticos t-student, entre paréntesis

* significativo al 10\%; ** significativo al 5\%; *** significativo al 1\% 
Tabla 6.3

Desigualdad del bienestar subjetivo en el Mundo

Coeficientes de Gini para las regiones del mundo, desigualdad global y promedio entre países de la desigualdad nacional

\begin{tabular}{lcccc}
\hline \hline & Gini del ingreso & \multicolumn{2}{c}{$\begin{array}{c}\text { Gini del bienestar } \\
\text { subjetivo }\end{array}$} \\
& Global & $\begin{array}{c}\text { Promedio } \\
\text { entre países }\end{array}$ & Global & $\begin{array}{c}\text { Promedio } \\
\text { entre países }\end{array}$ \\
\hline Latinoamérica & 0.525 & 0.499 & 0.210 & 0.206 \\
El Caribe & 0.591 & 0.456 & 0.278 & 0.242 \\
LAC & 0.530 & 0.486 & 0.216 & 0.217 \\
\hline Regiones Geográficas & & & & \\
Asia Oriental y el Pacífico & 0.594 & 0.471 & 0.224 & 0.167 \\
Europa Orientral y Asia Central & 0.497 & 0.418 & 0.233 & 0.217 \\
Norte de África y Medio Oriente & & & 0.242 & 0.204 \\
Sur de Asia & 0.534 & 0.489 & 0.209 & 0.203 \\
África Subsaharaniana & & & 0.245 & 0.240 \\
Europa Occidental & 0.402 & 0.340 & 0.137 & 0.132 \\
Norte de América & 0.438 & 0.392 & 0.144 & 0.129 \\
\hline $\begin{array}{l}\text { Regiones por Ingeso } \\
\text { Ingresos Altos: OECD }\end{array}$ & 0.448 & 0.358 & 0.147 & 0.136 \\
Ingresos Altos: no OECD & 0.484 & 0.417 & 0.164 & 0.169 \\
Ingresos Bajos & 0.536 & 0.511 & 0.218 & 0.221 \\
Ingresos Medios-Bajos & 0.558 & 0.464 & 0.234 & 0.227 \\
Ingresos Medios-Altos & 0.521 & 0.431 & 0.228 & 0.212 \\
\hline
\end{tabular}

Fuente: Elaboración propia basada en microdatos de la EMG 2006.

Tabla 6.4

Desigualdad del bienestar subjetivo en el Mundo

Descomposición del índice de Theil por regiones

\begin{tabular}{lcccc}
\hline \hline & Theil & $\begin{array}{c}\text { Dentro de } \\
\text { los países }\end{array}$ & Entre países & $\begin{array}{c}\% \text { entre } \\
\text { países }\end{array}$ \\
\hline Latinoamérica & 0.084 & 0.079 & 0.005 & $5.51 \%$ \\
El Caribe & 0.144 & 0.128 & 0.016 & $10.83 \%$ \\
LAC & 0.089 & 0.082 & 0.007 & $7.44 \%$ \\
\hline Regiones Geográficas & & & & \\
Asia Oriental y el Pacífico & 0.101 & 0.093 & 0.008 & $7.89 \%$ \\
Europa Orientral y Asia Central & 0.103 & 0.099 & 0.004 & $3.50 \%$ \\
Norte de África y Medio Oriente & 0.112 & 0.099 & 0.013 & $11.52 \%$ \\
Sur de Asia & 0.076 & 0.072 & 0.004 & $5.23 \%$ \\
África Subsaharaniana & 0.107 & 0.100 & 0.007 & $6.65 \%$ \\
Europa Occidental & 0.041 & 0.039 & 0.002 & $4.34 \%$ \\
Norte de América & 0.043 & 0.043 & 0.000 & $0.21 \%$ \\
\hline Regiones por Ingeso & & & & \\
Ingresos Altos: OECD & 0.045 & 0.043 & 0.002 & $4.66 \%$ \\
Ingresos Altos: no OECD & 0.052 & 0.048 & 0.004 & $7.88 \%$ \\
Ingresos Bajos & 0.085 & 0.076 & 0.009 & $10.62 \%$ \\
Ingresos Medios-Bajos & 0.111 & 0.107 & 0.003 & $3.00 \%$ \\
Ingresos Medios-Altos & 0.096 & 0.086 & 0.010 & $10.59 \%$ \\
\hline
\end{tabular}

Fuente: Elaboración propia basada en microdatos de la EMG 2006. 
Tabla 6.5

Desigualdad del bienestar subjetivo en el Mundo

Theil descomposiciones a nivel mundial

\begin{tabular}{lcccc}
\hline \hline & Theil & $\begin{array}{c}\text { Dentro del } \\
\text { grupo }\end{array}$ & $\begin{array}{c}\text { Entre } \\
\text { grupos }\end{array}$ & $\begin{array}{c}\text { \% entre } \\
\text { grupos }\end{array}$ \\
\hline Por regiones geográficas & \multirow{2}{*}{0.096} & 0.086 & 0.010 & $10.7 \%$ \\
Por regiones de ingreso & 0.086 & 0.010 & $10.4 \%$ \\
Por países & & 0.080 & 0.016 & $16.5 \%$ \\
\hline
\end{tabular}

Fuente: Elaboración propia basada en microdatos de la EMG 2006. 


\section{Figuras}

\section{Figura 3.1}

Edad promedio

EMG 2006 y ENH

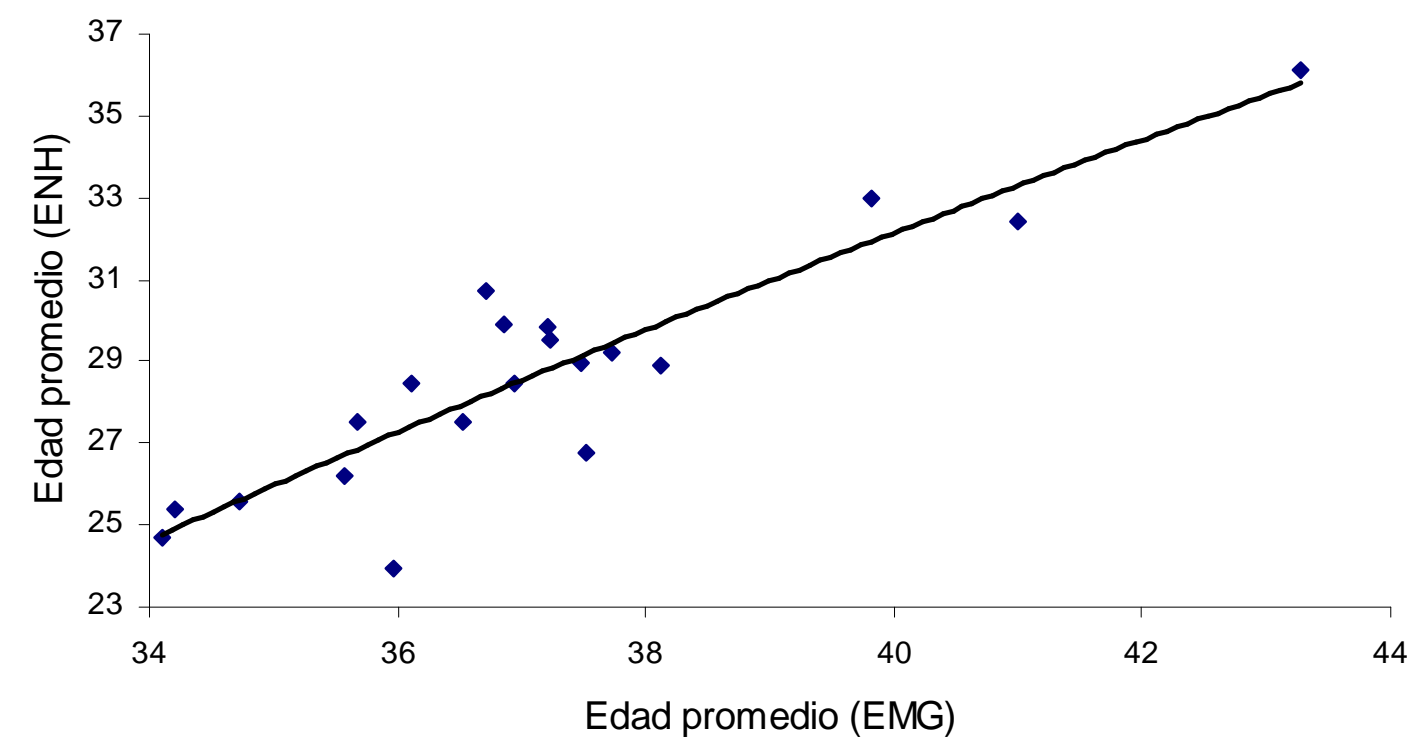

Fuente: elaboración propia basada en microdatos de la EMG 2006 y ENH de ALC Nota: La EMG se realiza solo a personas mayores de 15 Años.

\section{Figura 3.2}

Número de niños en el hogar EMG 2006 y ENH

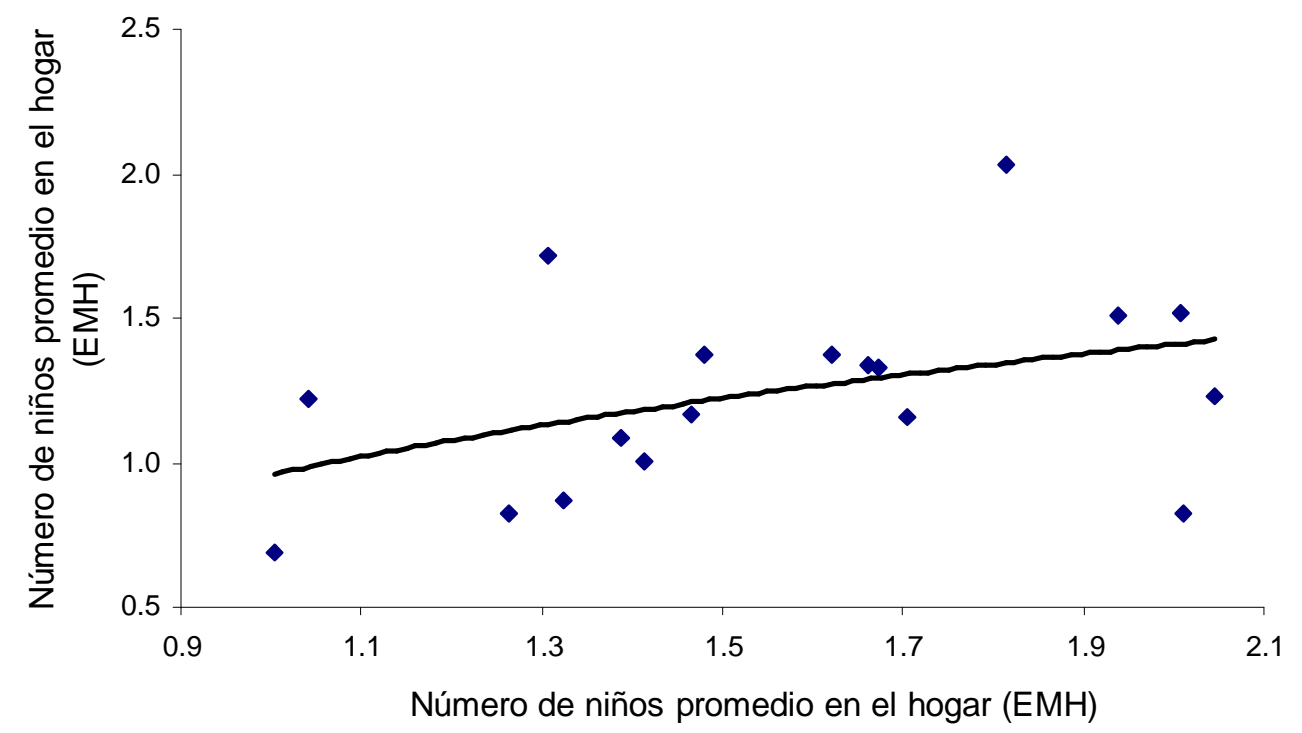

Fuente: elaboración propia basada en microdatos de la EMG 2006 y ENH de ALC 


\section{Figura 4.1}

Función de densidad del logaritmo del ingreso per cápita familiar en los países de ALC EMG y ENH
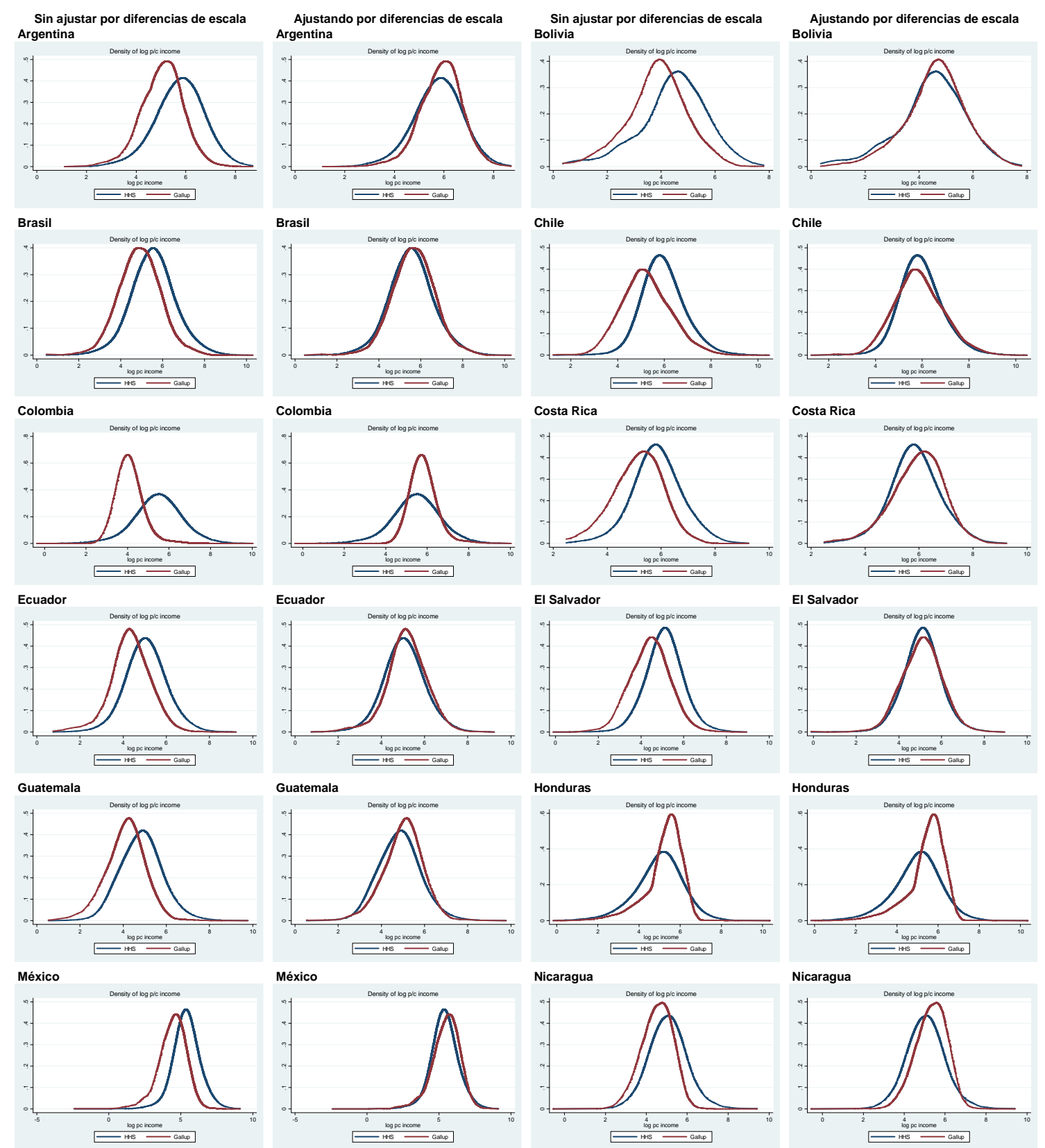
Figura 4.1 (continuación)
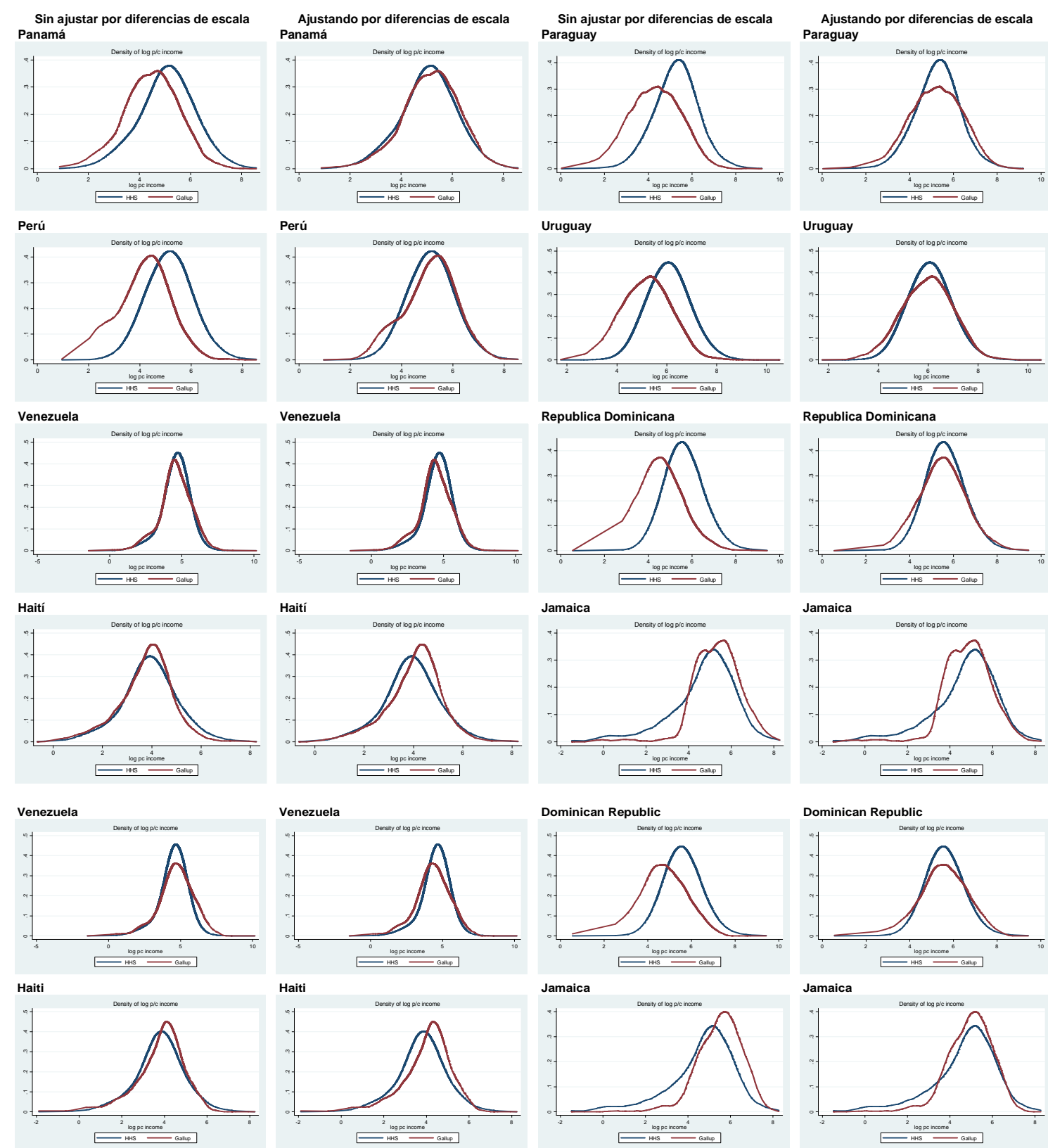

Fuente: elaboración propia basada en microdatos de la EMG 2006 y ENH de ALC

Note: El panel de la izquierda en cada región muestra los datos originales, mientras que en el panel de la derecha se reescalan todos los ingresos de la EMG para coincida la media de ambas distribuciones. 


\section{Figura 4.2}

Función de densidad del log del IPCF para Latinoamérica, El Caribe y ALC EMG y ENH

Estimación no paramétrica (Kernel)

Sin ajustar por diferencias de escala

\section{Latinoamérica}

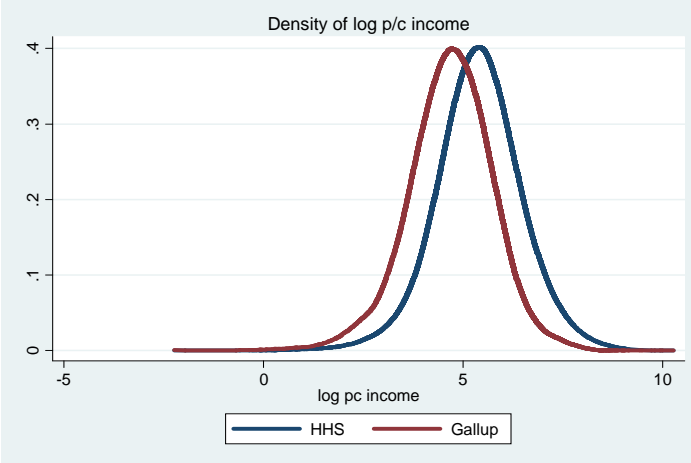

\section{El Caribe}

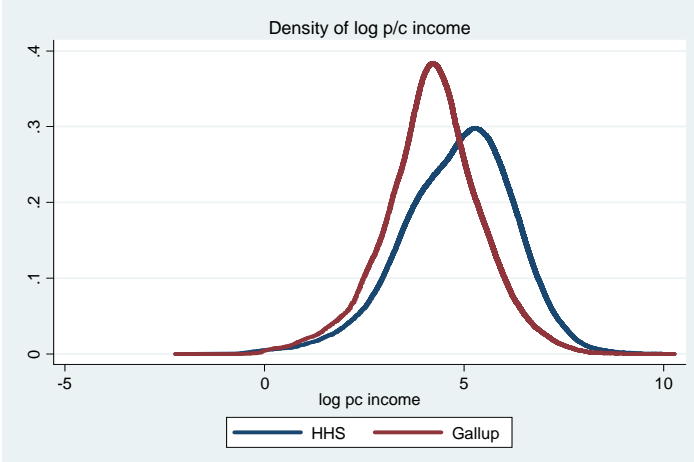

\section{LAC}

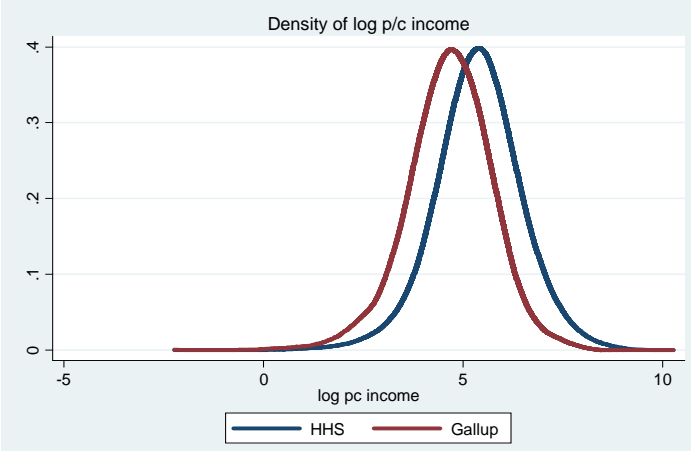

Ajustando por diferencias de escala Latinoamérica

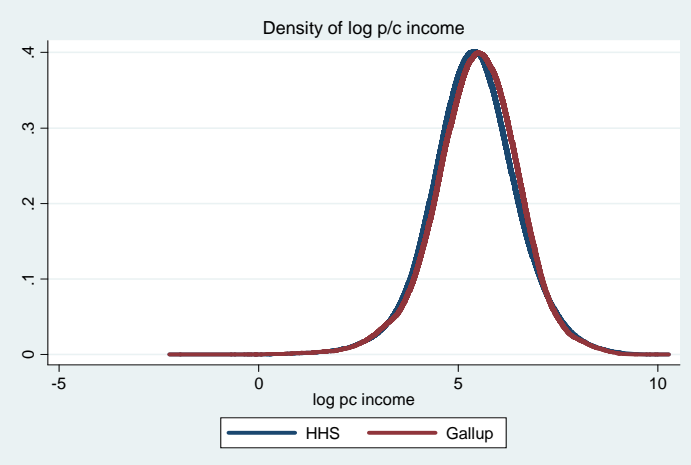

\section{El Caribe}

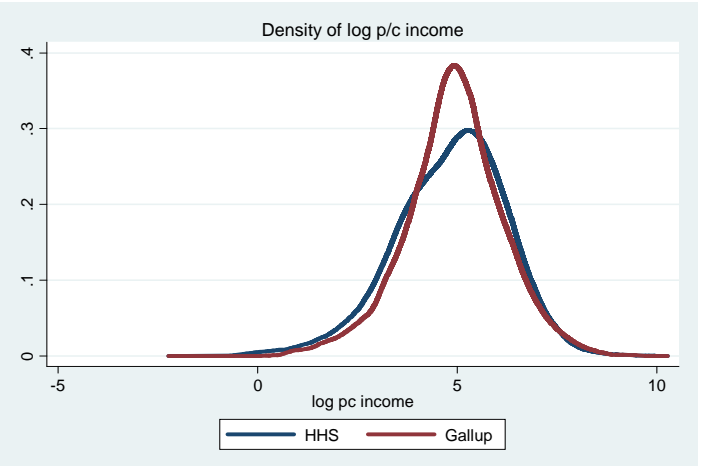

LAC

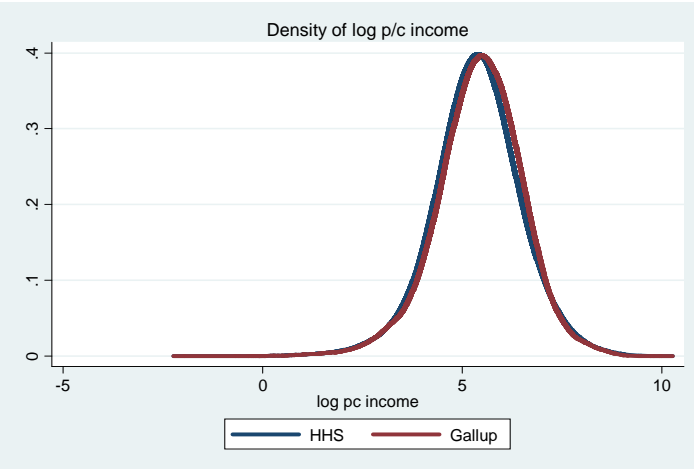

Fuente: elaboración propia basada en microdatos de la EMG 2006 y ENH de ALC

Note: El panel de la izquierda en cada región muestra los datos originales, mientras que en el panel de la derecha se reescalan todos los ingresos de la EMG para coincida la media de ambas distribuciones. 


\section{Figura 4.3}

Relación entre medias y medianas del ingreso per cápita familiar (en dólares PPP) EMG y ENH
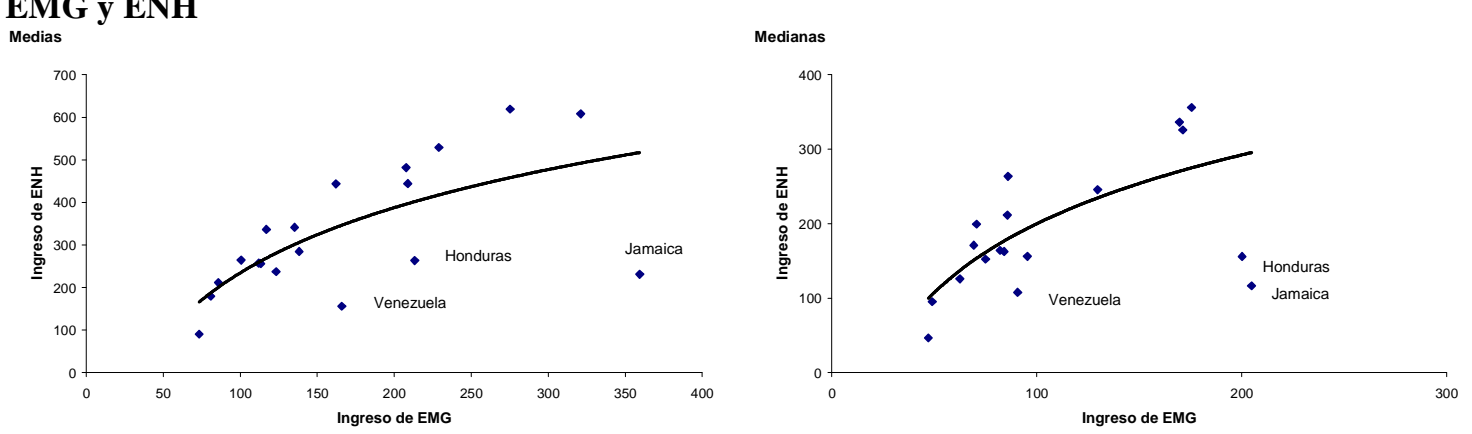

Fuente: elaboración propia basada en microdatos de la EMG 2006 y ENH de ALC

\section{Figura 4.4}

PBI per cápita a PPP (WEO) y Ingreso per cápita familiar de la EMG

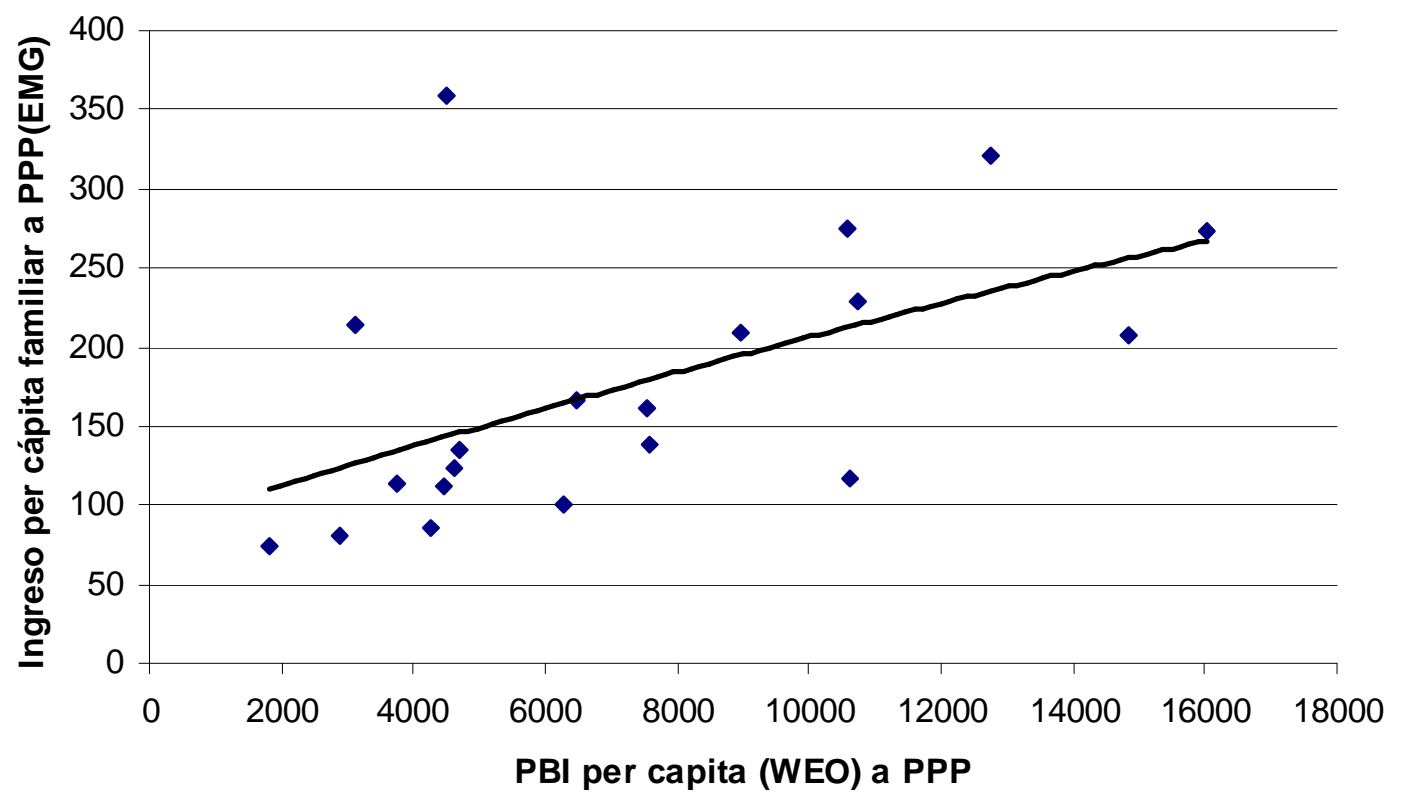

Fuente: elaboración propia basada en microdatos de la EMG 2006 y WEO 


\section{Figura 4.5}

Función de densidad del logaritmo del ingreso per cápita familiar EMG y ENH

Estimación no paramétrica (Kernel)

El Caribe

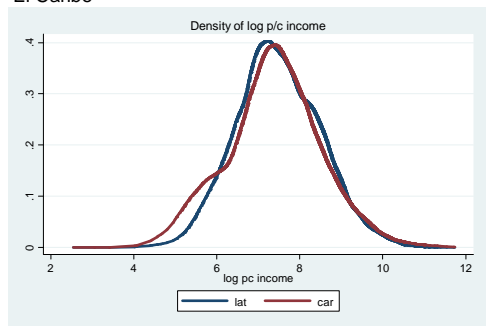

Sur de Asia

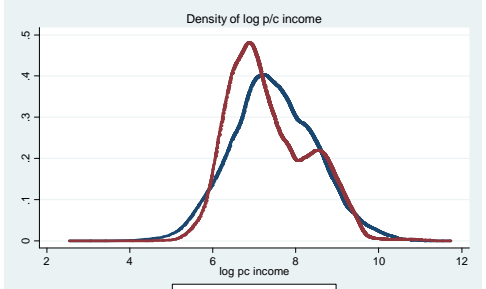

Llat pcincome
Asia Oriental y el Pacífico

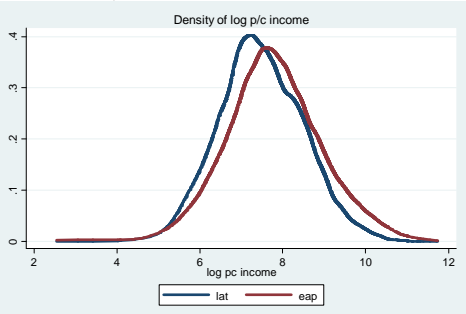

Europa Occidental

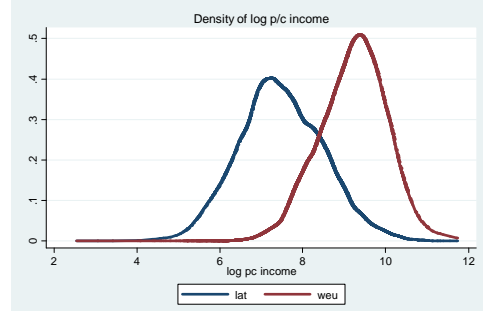

Europa Orientral y Asia Central

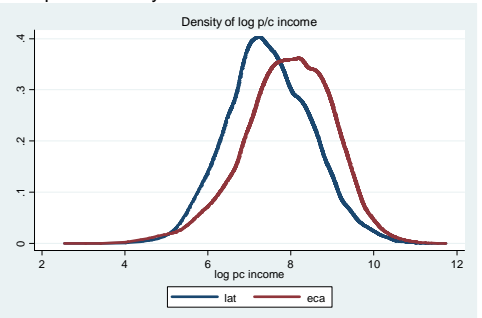

Norte de América

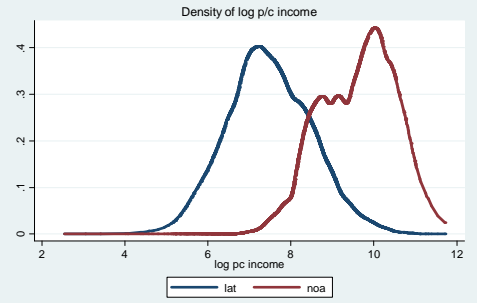

Fuente: elaboración propia basada en microdatos de la EMG 2006. 


\section{Figure 5.1}

Ranking de la desigualdad en ALC

Coeficientes de gini

\section{Encuesta mundial Gallup}

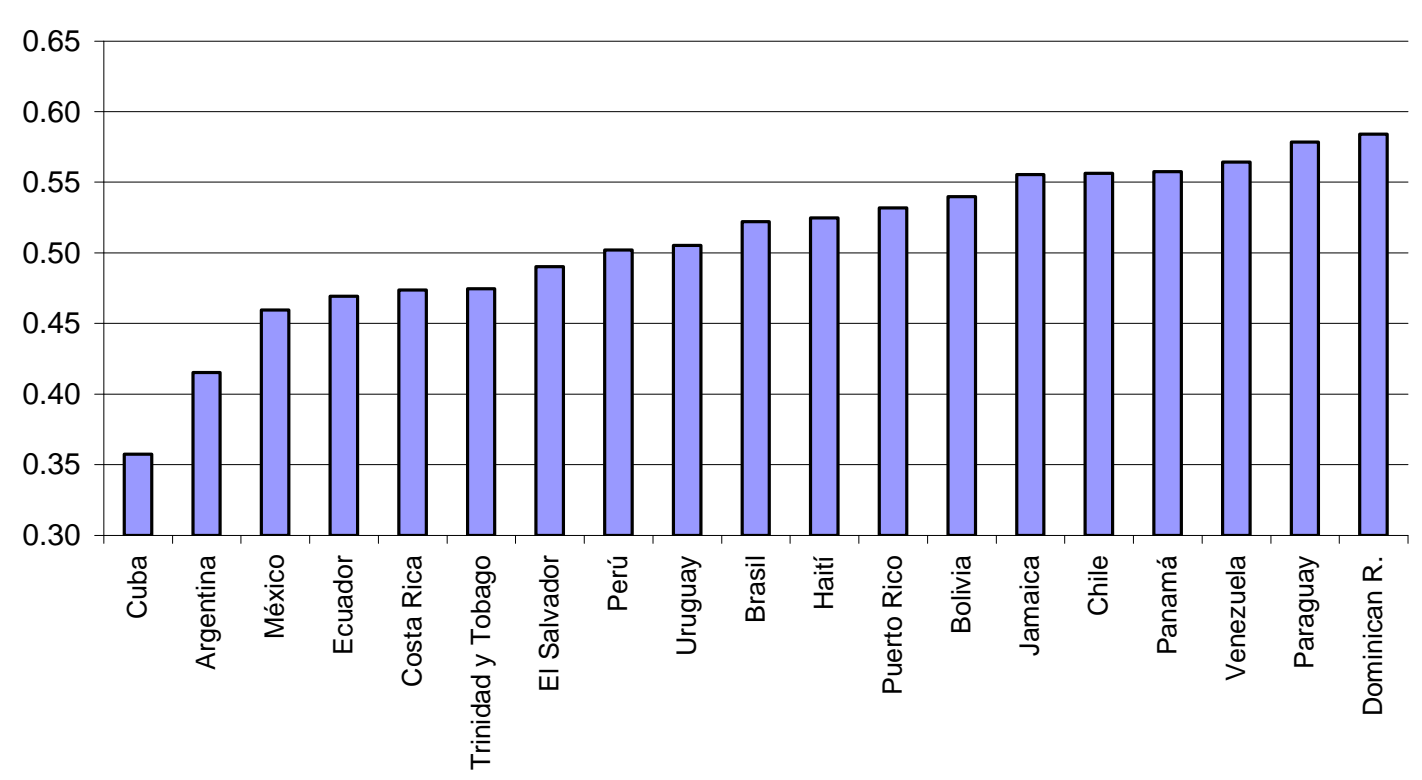

\section{Encuestas Nacionales de Hogares}

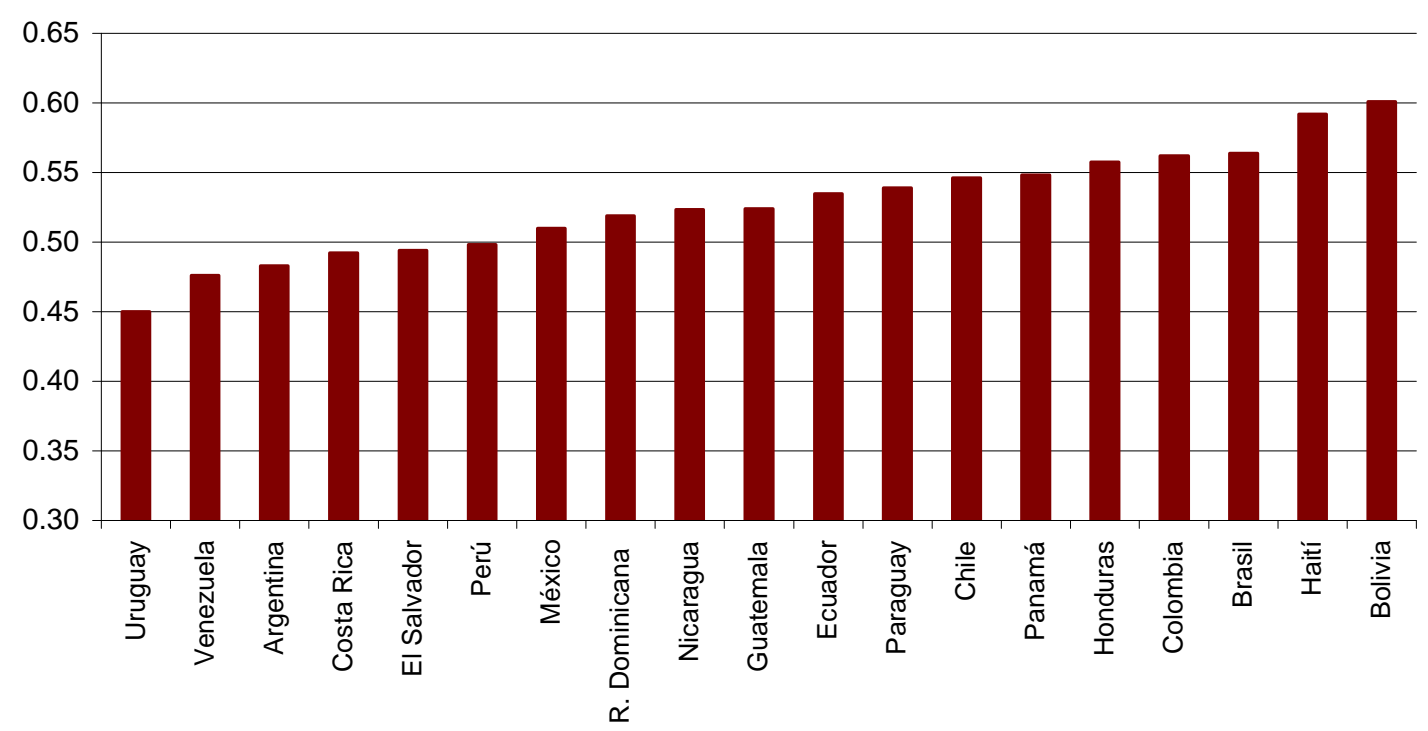

Fuente: elaboración propia basada en microdatos de la EMG 2006 y ENH de ALC. 


\section{Figure 5.2}

El coeficiente de Gini en la EMG y las ENH

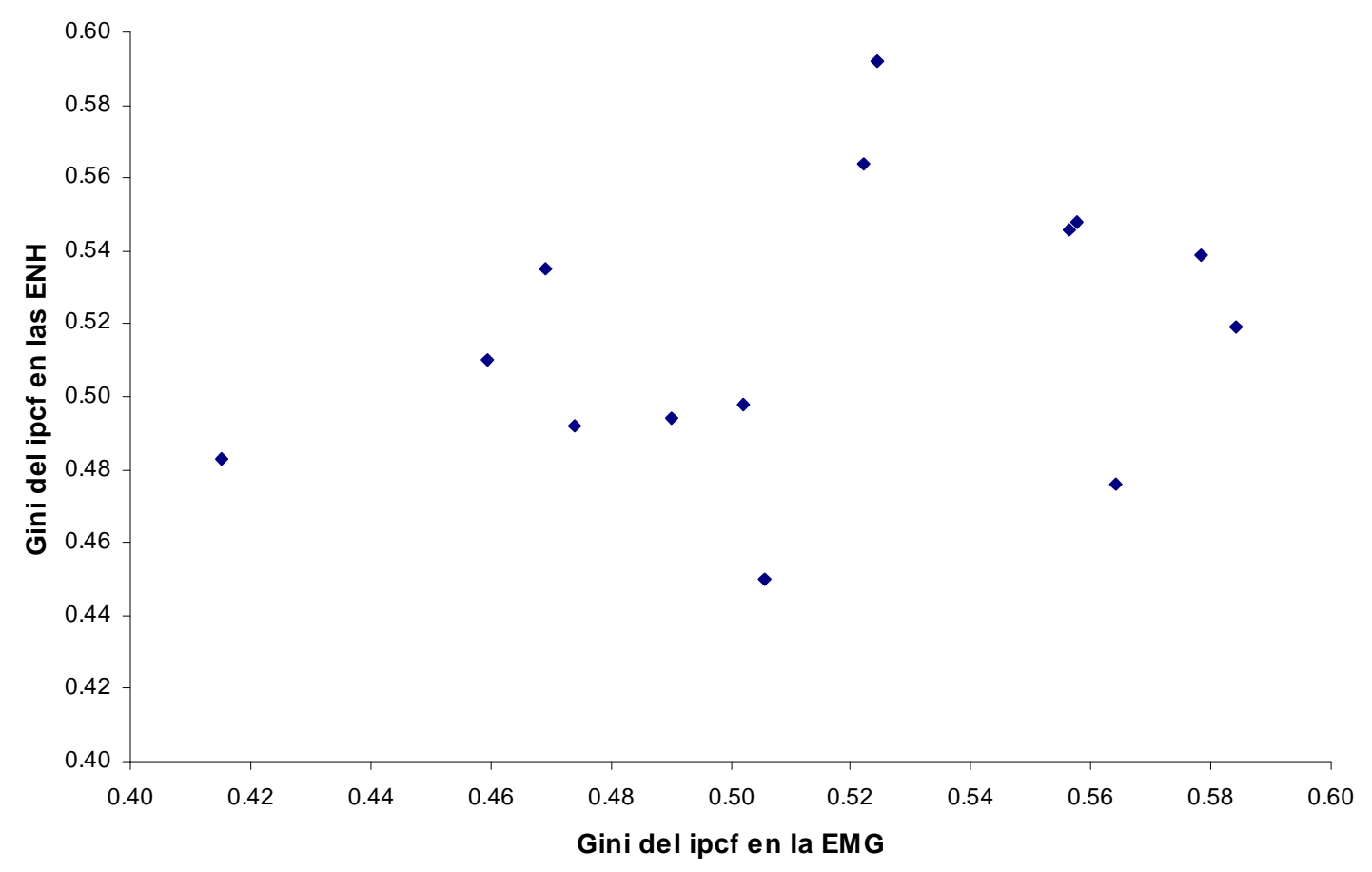

Fuente: elaboración propia basada en microdatos de la EMG 2006 y ENH de ALC.

\section{Figure 5.3}

Curva de Lorenz

Comparación entre Latinoamérica y otras regiones del mundo
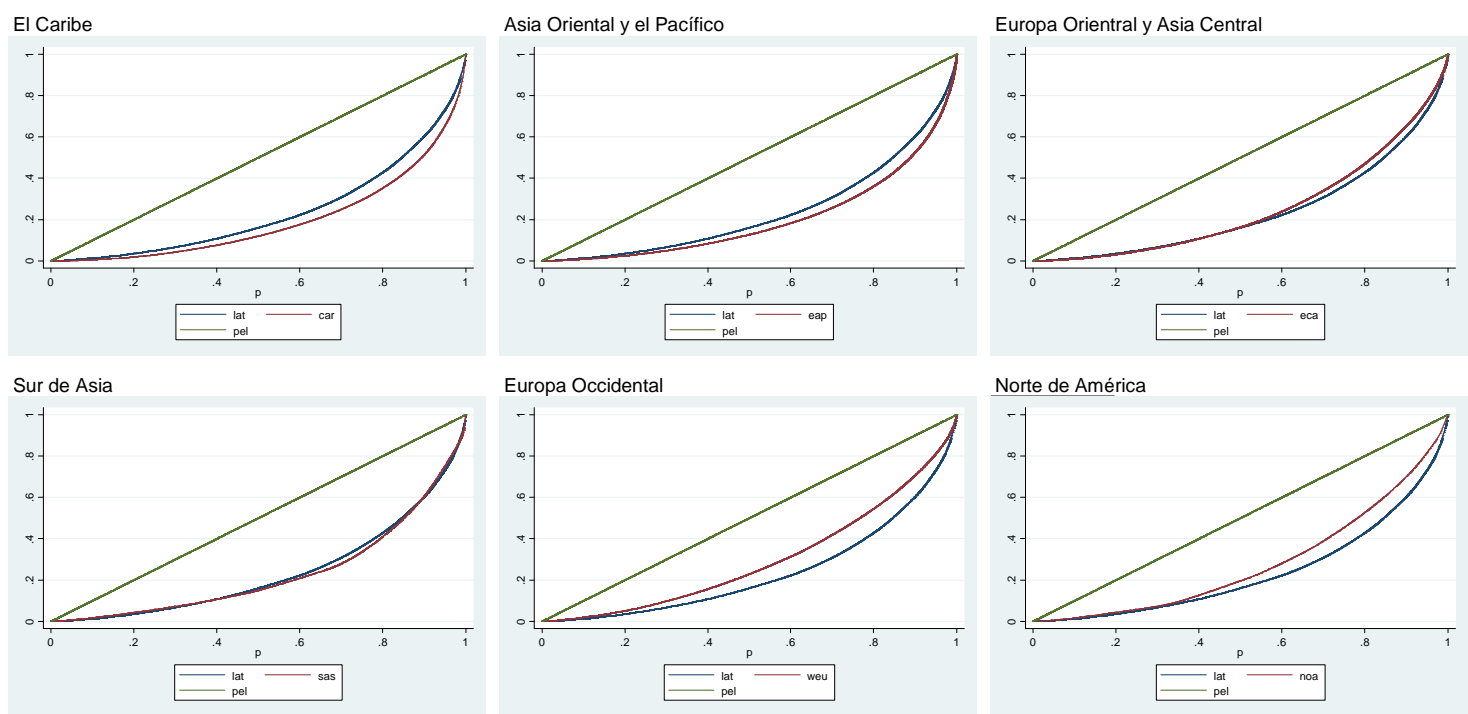

Fuente: elaboración propia basada en microdatos de la EMG 2006.

Nota: $p e l=$ Línea de perfecta igualdad 


\section{Figura 5.4}

\section{Coeficiente de Gini}

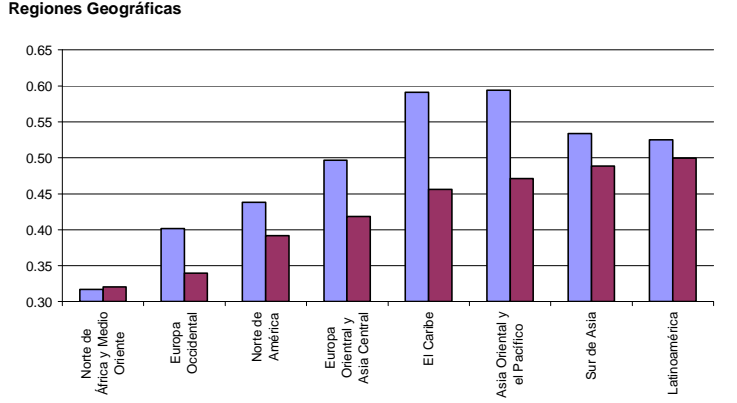

$\square$ Global $\square$ Promedio entre países

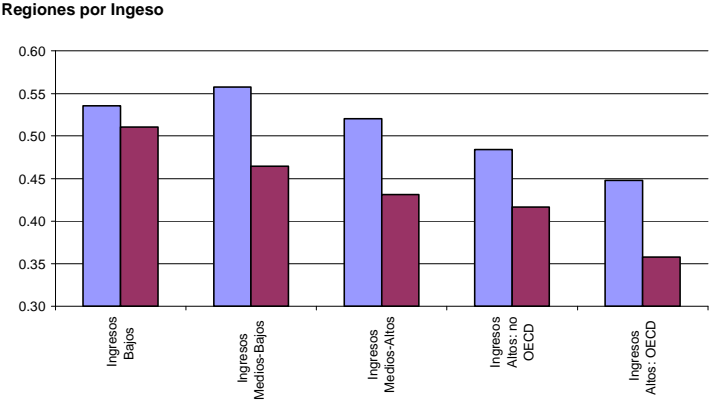

$\square$ Global $\square$ Promedio entre países

Fuente: elaboración propia basada en microdatos de la EMG 2006.

\section{Figura 5.5}

Descomposición del índice de Theil por regiones geográficas e ingreso

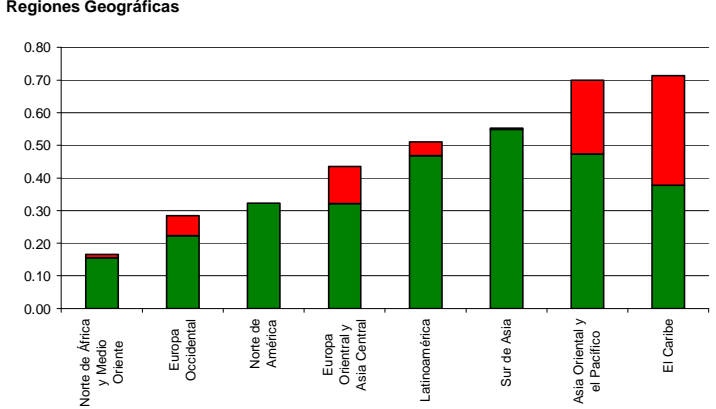

$\square$ Dentro de los países $\square$ Entre países

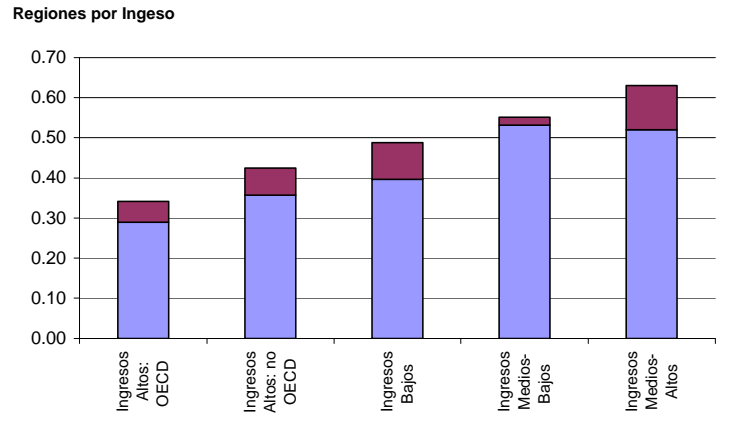

$\square$ Dentro de los países $\square$ Entre países

Fuente: elaboración propia basada en microdatos de la EMG 2006. 


\section{Figura 5.6}

Curva de Kuznets

Gini y Producto

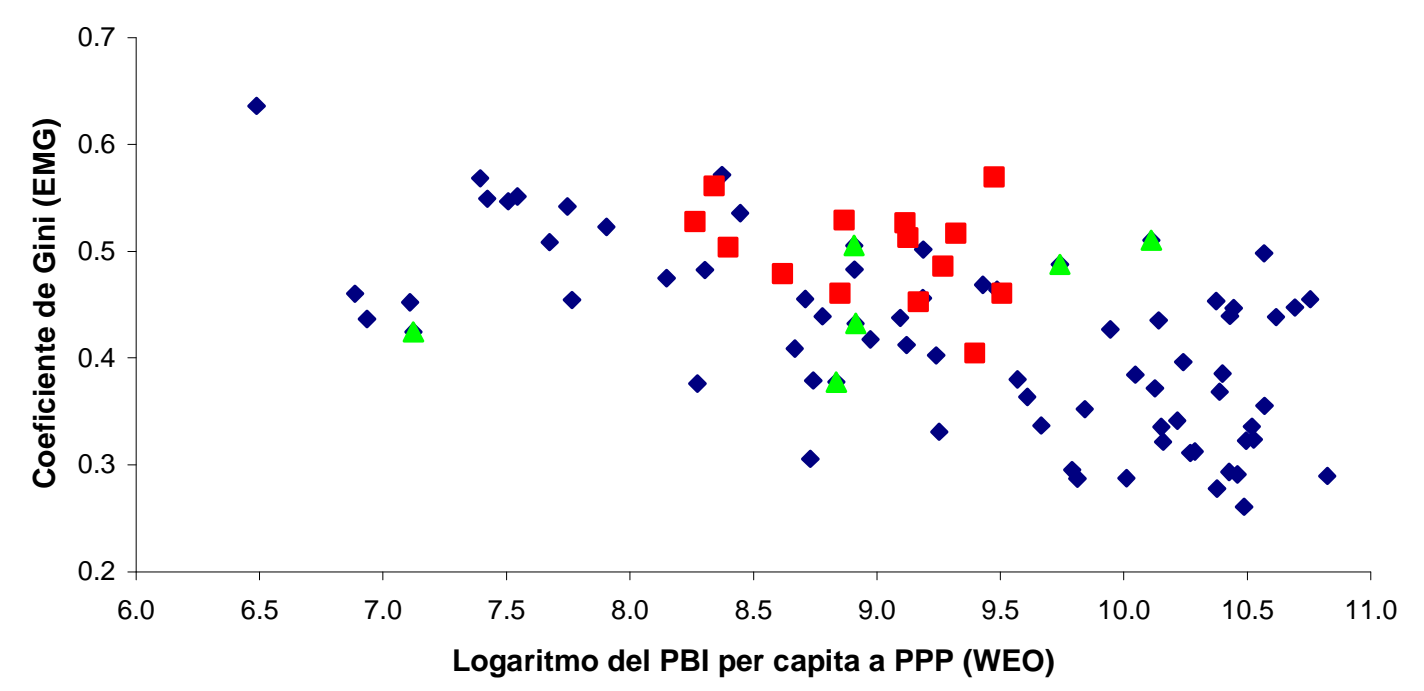

- Resto del mundo $\square$ Latinoamérica $\triangle$ El Caribe

Gini e Ingreso

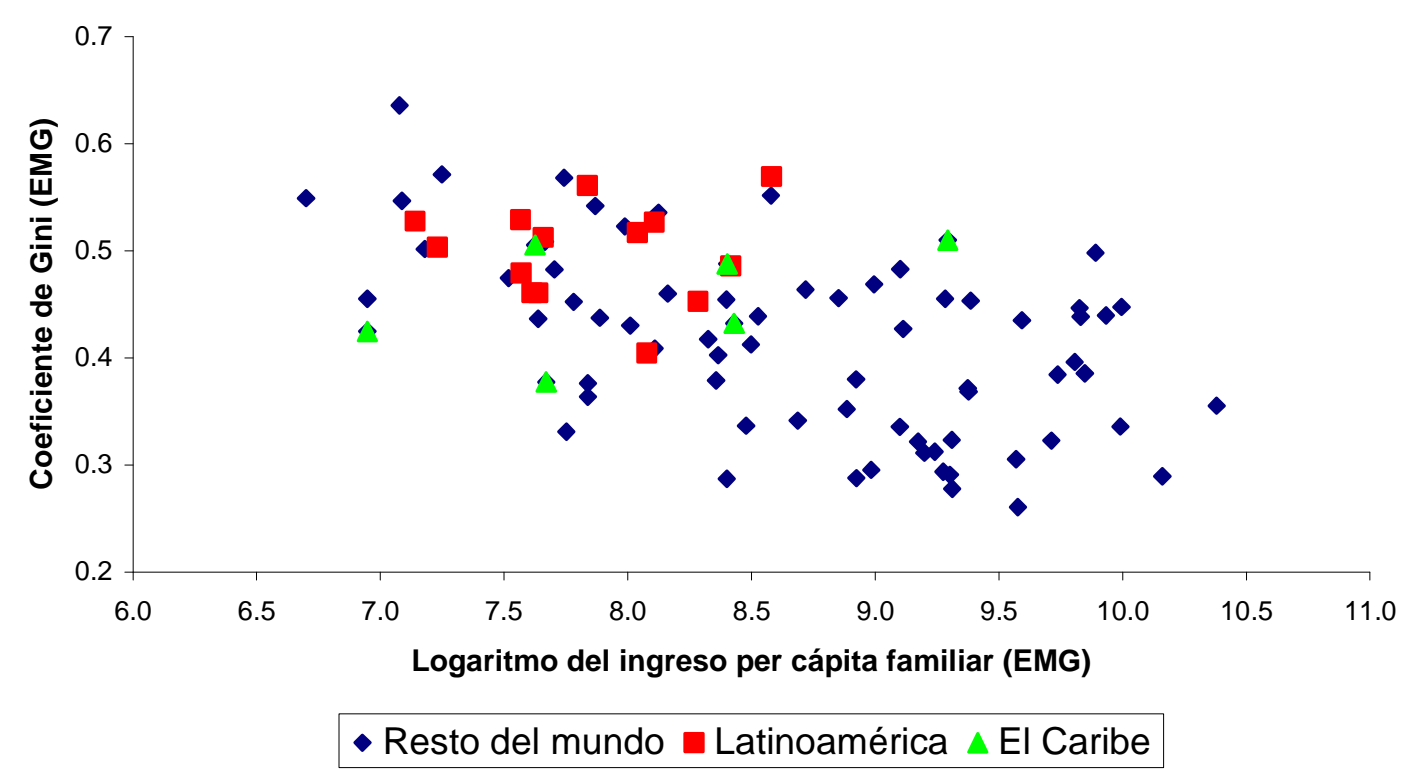

Fuente: elaboración propia basada en microdatos de la EMG 2006 y WEO. 


\section{Figura 6.1}

Bienestar subjetivo e ingresos medios

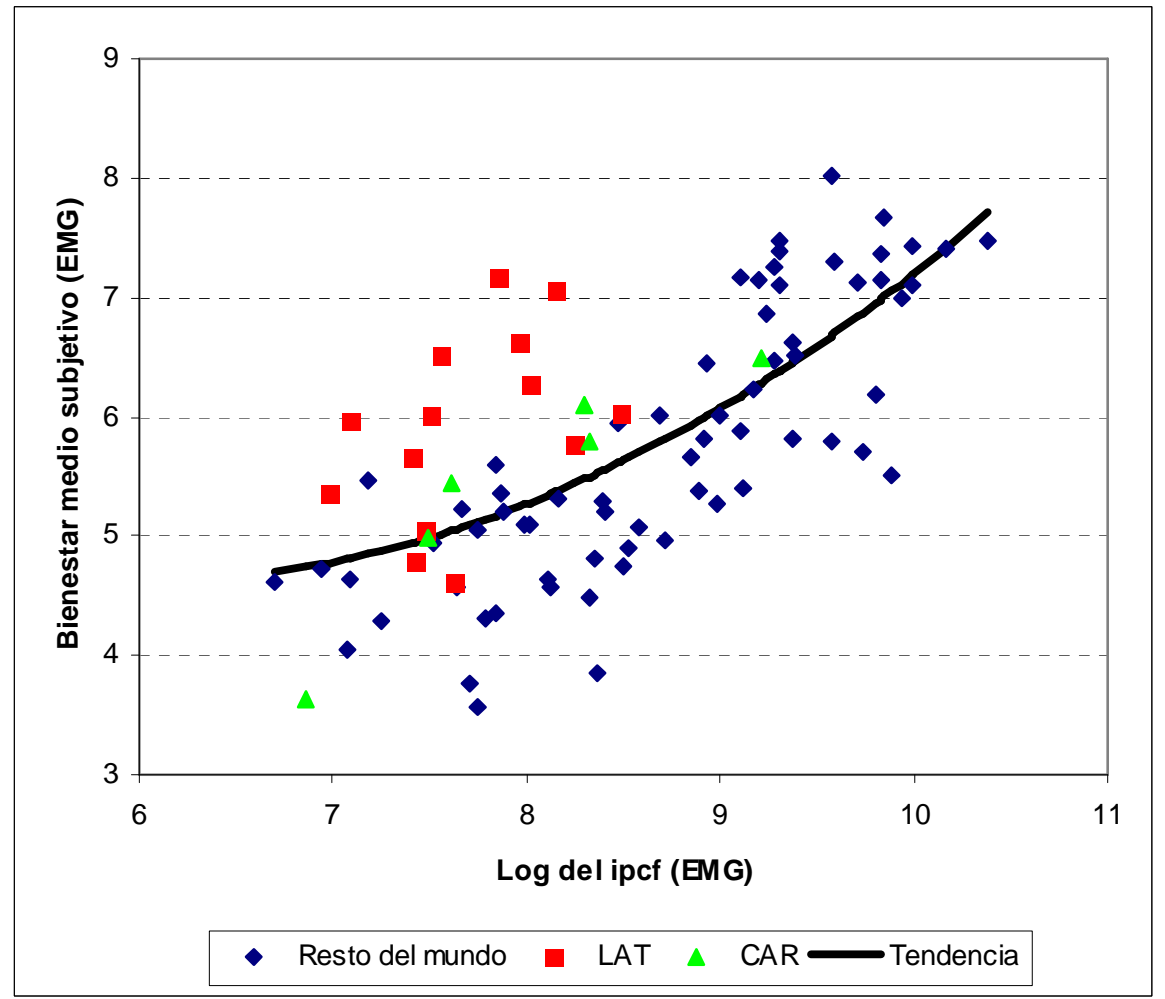

Fuente: elaboración propia basada en microdatos de la EMG 2006.

\section{Figura 6.2}

Bienestar subjetivo medio y producto

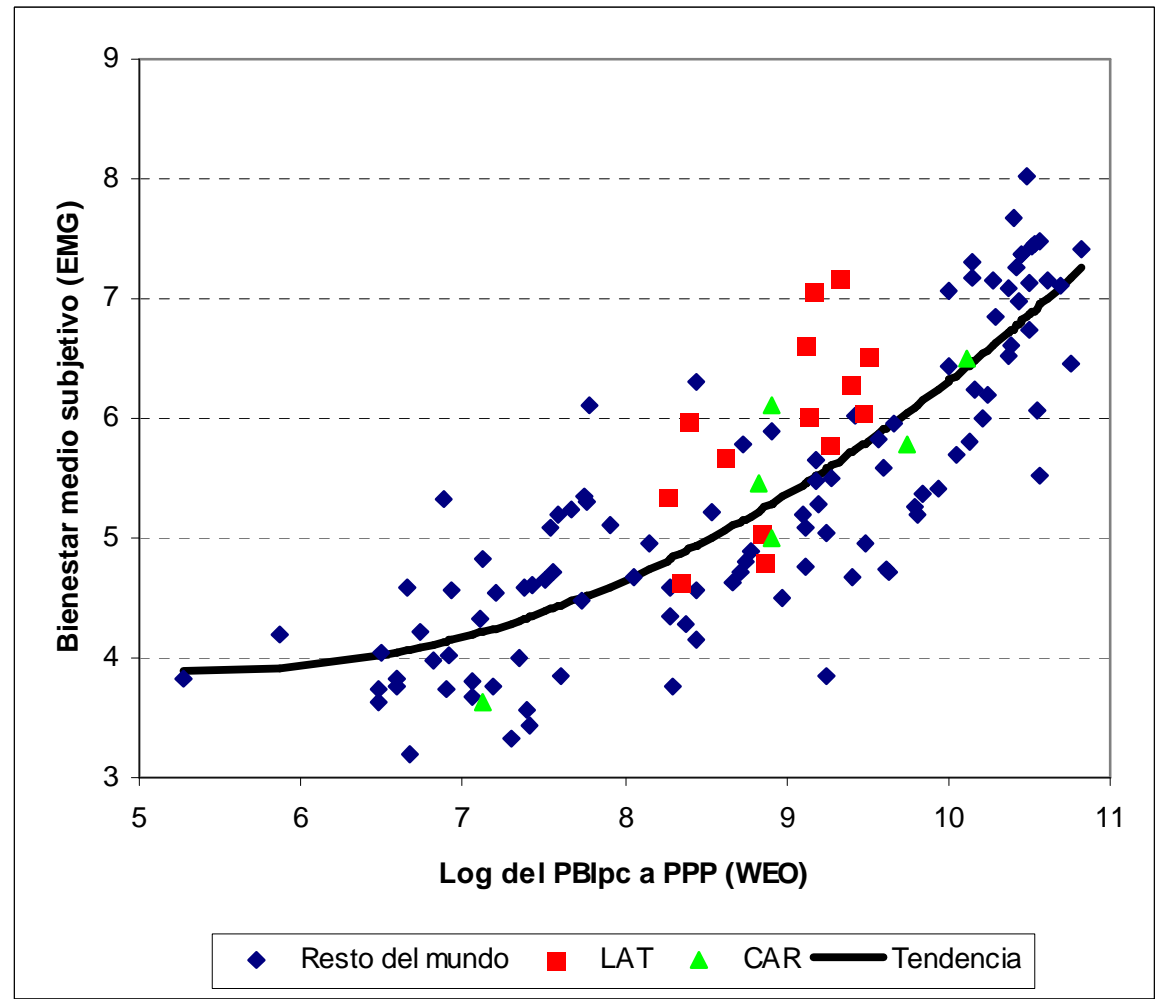

Fuente: elaboración propia basada en microdatos de la EMG 2006 y WEO. 


\section{Figura 6.3}

Desigualdad del bienestar subjetivo y del ingreso

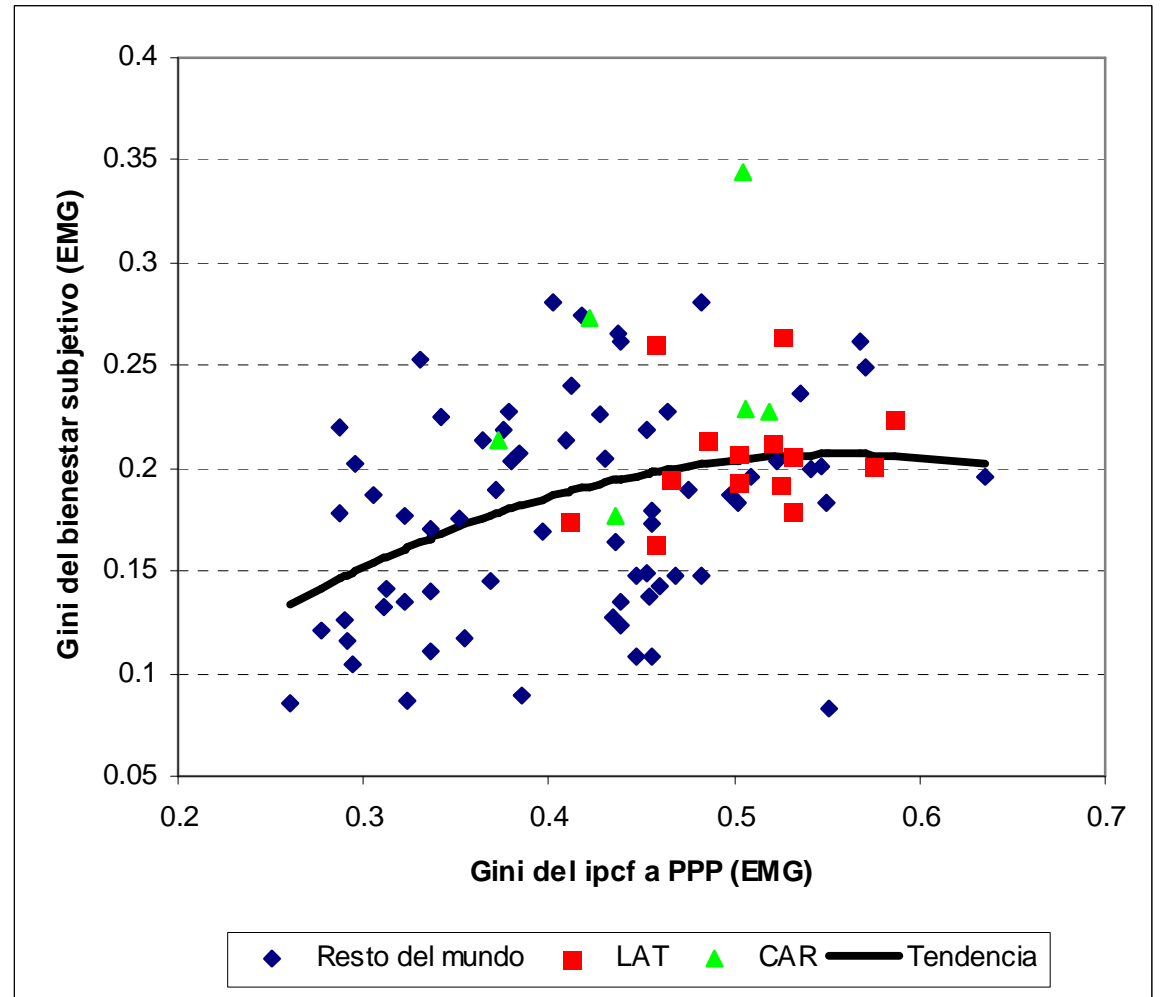

Fuente: elaboración propia basada en microdatos de la EMG 2006.

\section{Figura 6.4}

Curva de Kuznets del bienestar subjetivo

Desigualdad del bienestar subjetivo medio e ingresos medios

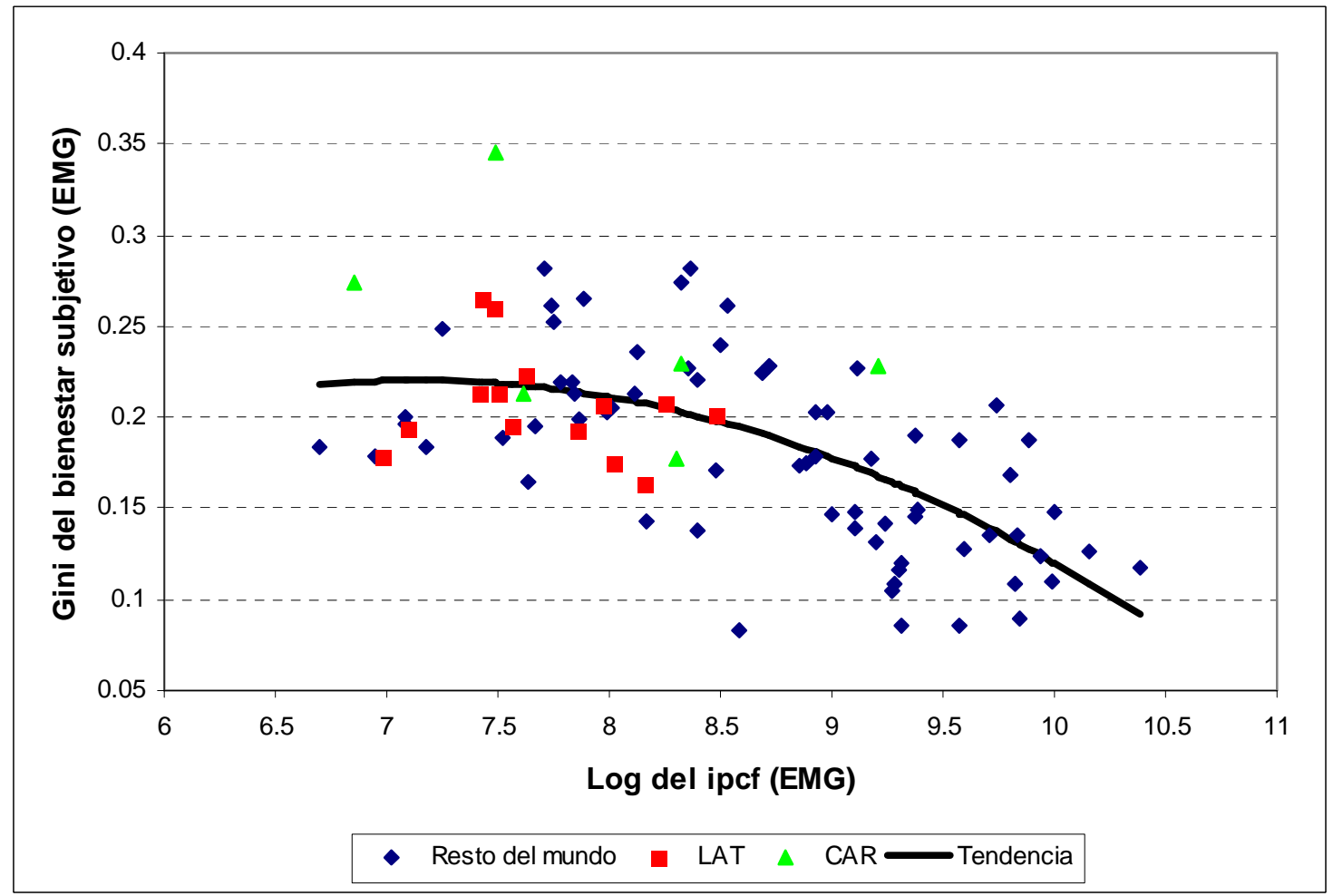

Fuente: elaboración propia basada en microdatos de la EMG 2006. 


\section{Figura 6.5}

Curva de Kuznets del bienestar subjetivo

Desigualdad del bienestar subjetivo medio y producto

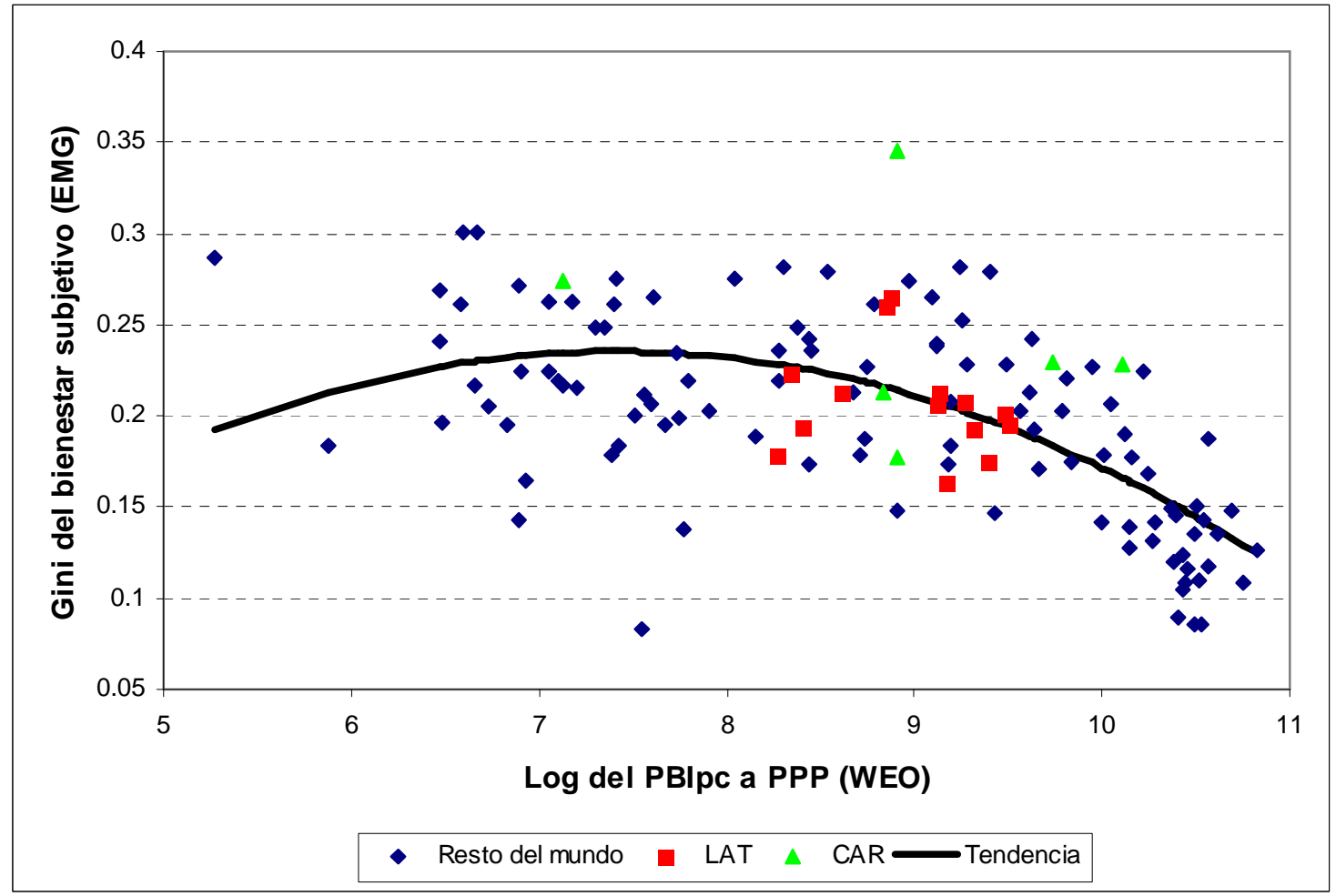

Fuente: elaboración propia basada en microdatos de la EMG 2006 y WEO.

\section{Figura 6.6}

Desigualdad y nivel del bienestar subjetivo medio

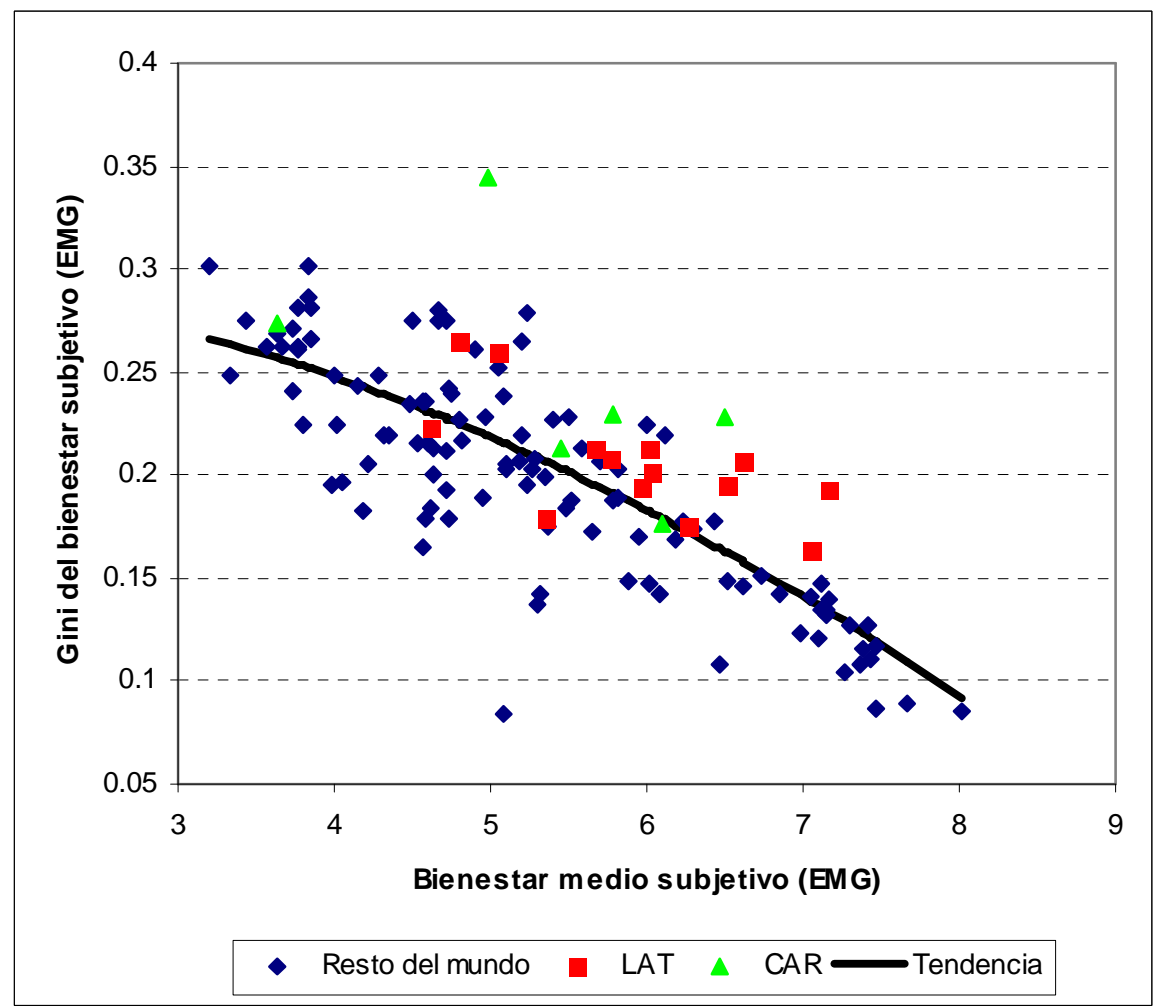

Fuente: elaboración propia basada en microdatos de la EMG 2006. 


\section{Figura 6.7}

Desigualdad de ingresos y bienestar subjetivo medio

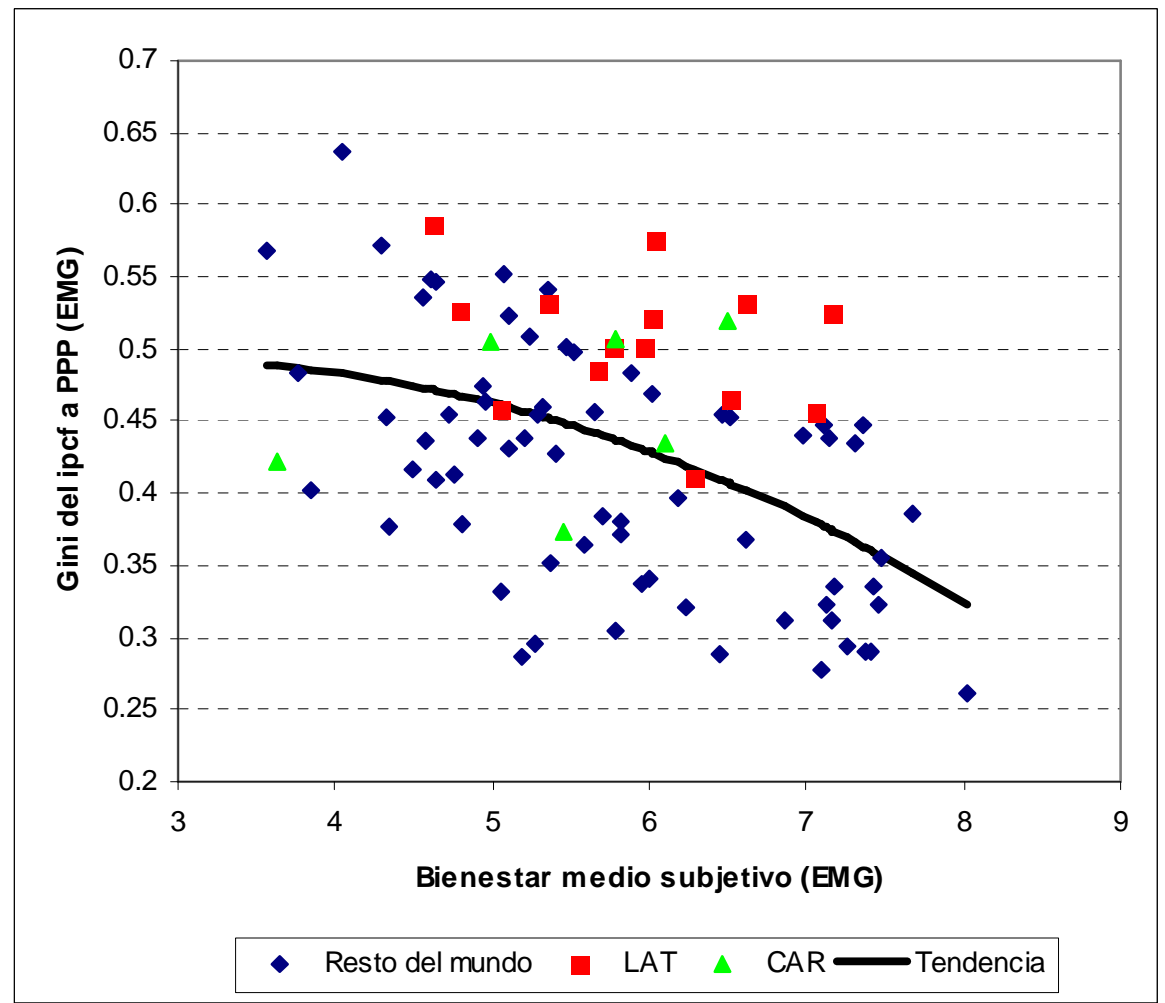

Fuente: elaboración propia basada en microdatos de la EMG 2006.

\section{Figura 6.8}

Efecto Aversión a la desigualdad del bienestar subjetivo Comparación del ratio entre bienestar y producto

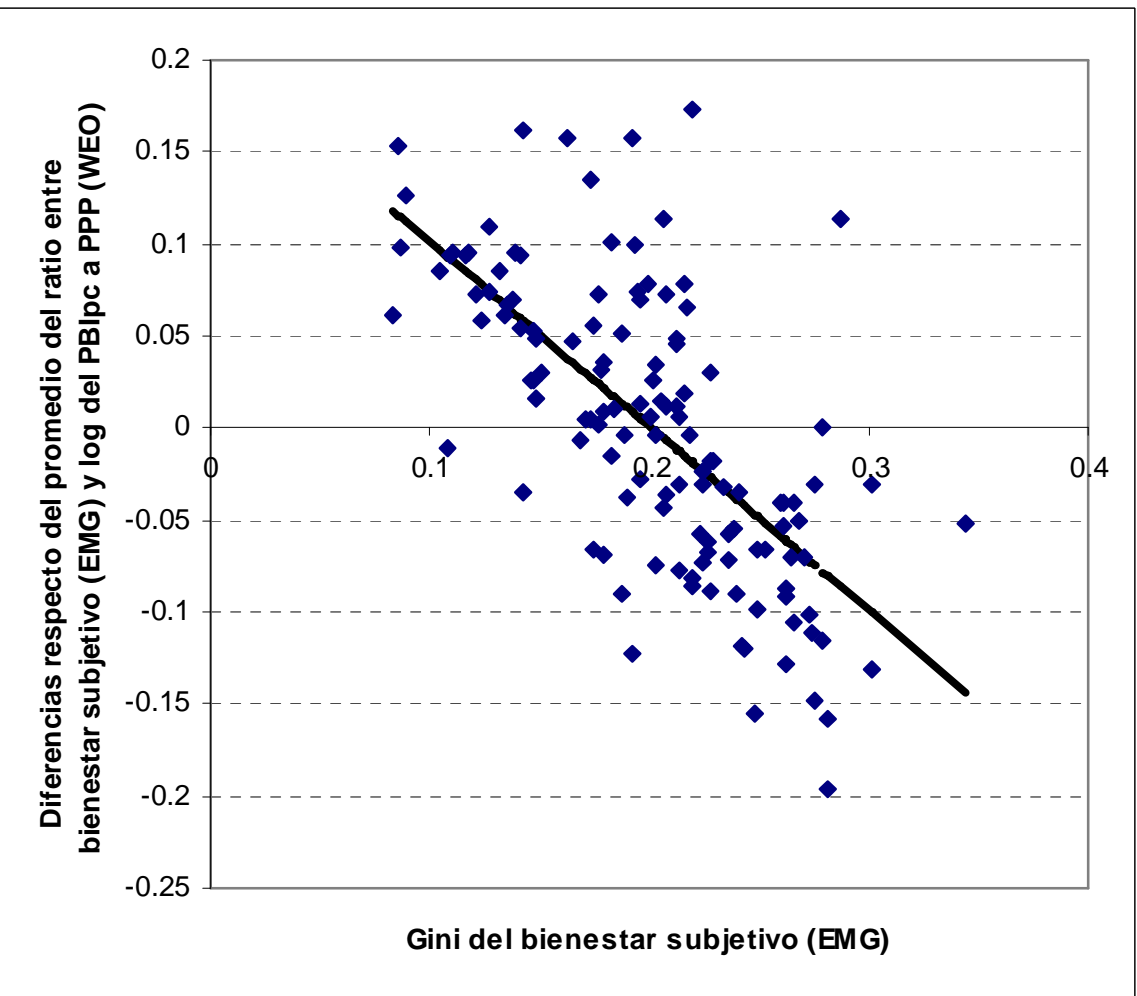

Fuente: elaboración propia basada en microdatos de la EMG 2006. 


\section{Figura 6.9}

Efecto Aversión a la desigualdad del bienestar subjetivo Comparación de rankings en términos bienestar y producto

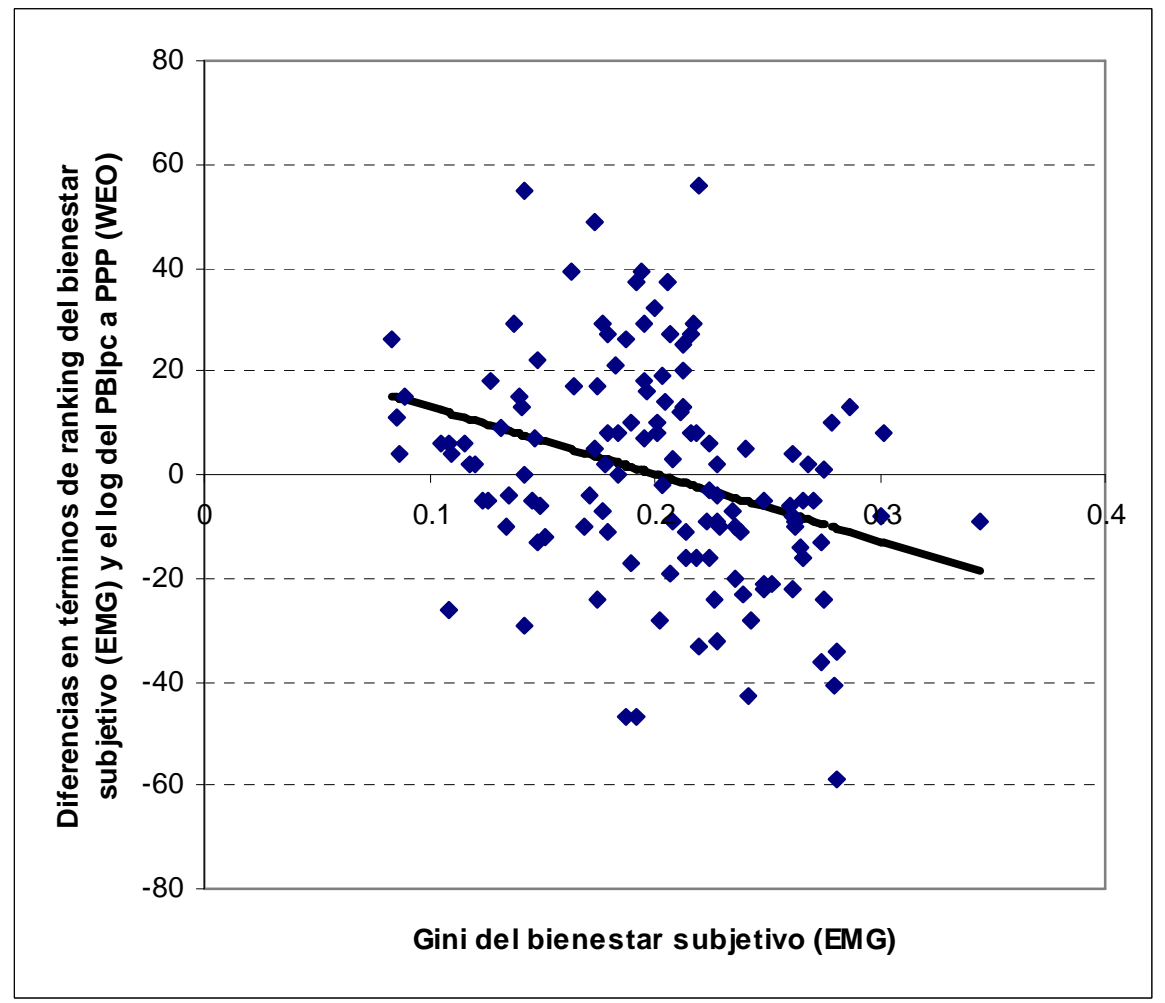

Fuente: elaboración propia basada en microdatos de la EMG 2006.

\section{Figura 6.10}

Efecto Aversión a la desigualdad del ingreso Comparación del ratio entre bienestar y producto

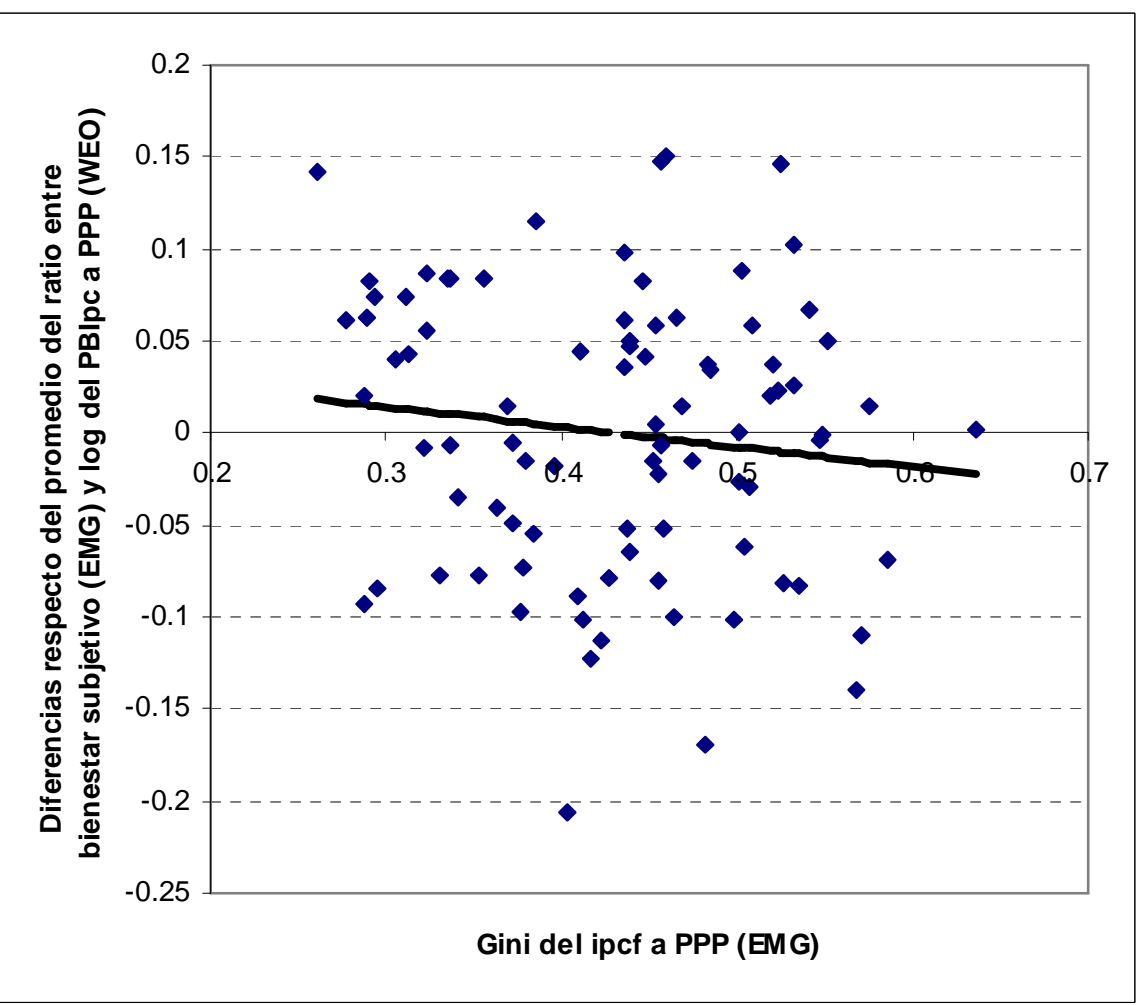

Fuente: elaboración propia basada en microdatos de la EMG 2006. 


\section{Figura 6.11}

Efecto Aversión a la desigualdad del ingreso

Comparación de rankings en términos bienestar y producto

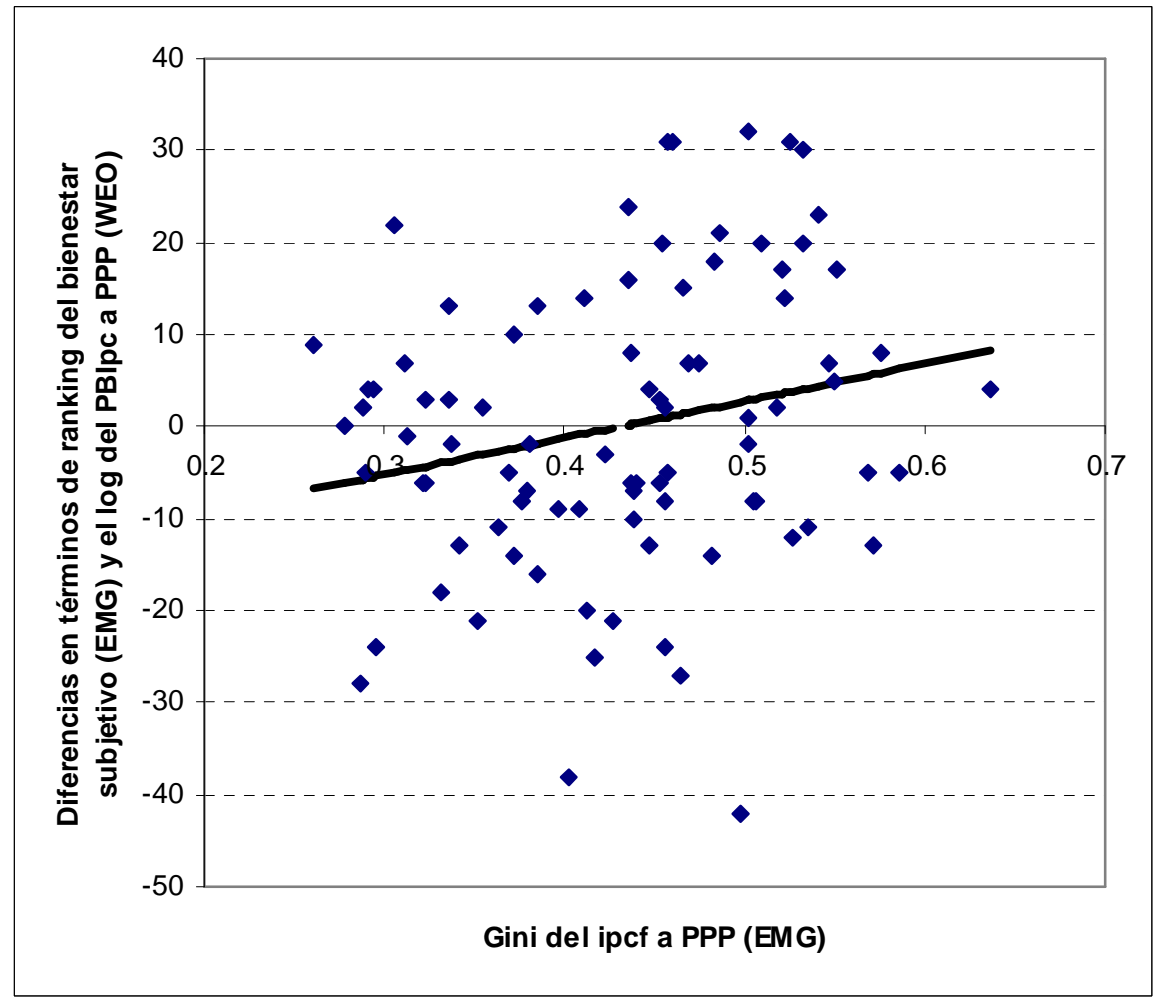

Fuente: elaboración propia basada en microdatos de la EMG 2006.

\section{Figura 6.12}

Desigualdad del bienestar subjetivo a nivel mundial Coeficientes de Gini globales y por países Regiones Geográficas

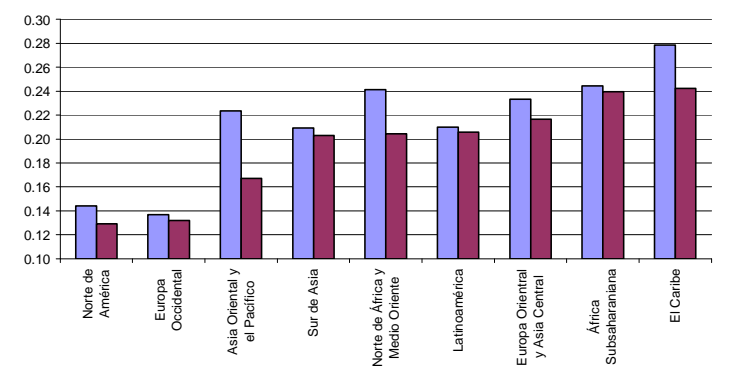

$\square$ Global $\square$ Promedio entre países

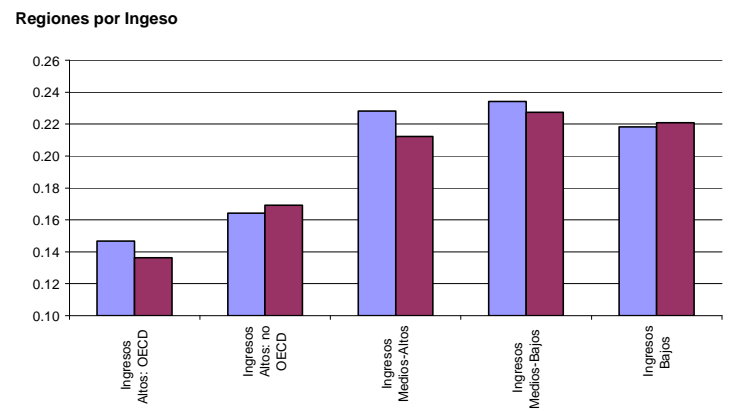

$\square$ Global $\square$ Promedio entre países

Fuente: elaboración propia basada en microdatos de la EMG 2006. 


\section{Figura 6.13}

Desigualdad del bienestar subjetivo a nivel mundial Descomposición del índice de Theil por regiones geográficas e ingreso

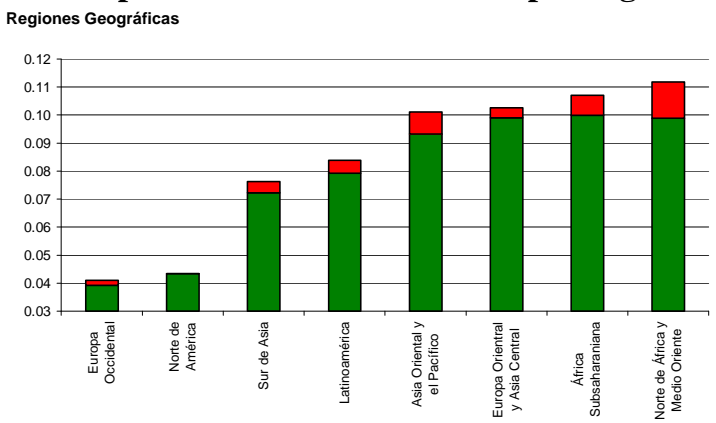

$\square$ Dentro de los países $\square$ Entre países
Regiones por Ingeso

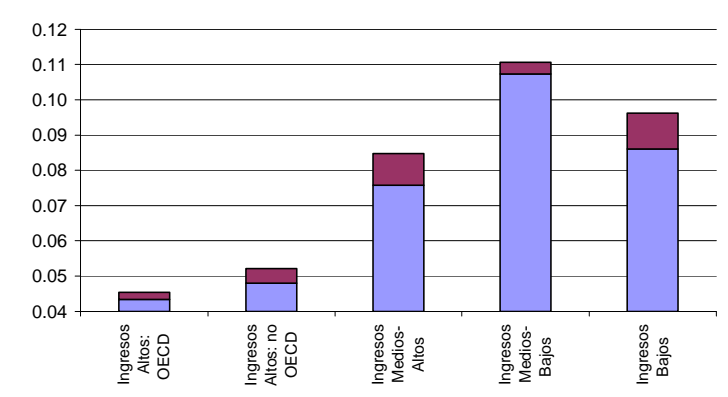

$\square$ Dentro de los países $\square$ Entre países

Fuente: elaboración propia basada en microdatos de la EMG 2006. 